\title{
Evidence-based Kernels: Fundamental Units of Behavioral Influence
}

\author{
Dennis D. Embry • Anthony Biglan
}

Published online: 20 August 2008

(C) The Author(s) 2008. This article is published with open access at Springerlink.com

\begin{abstract}
This paper describes evidence-based kernels, fundamental units of behavioral influence that appear to underlie effective prevention and treatment for children, adults, and families. A kernel is a behavior-influence procedure shown through experimental analysis to affect a specific behavior and that is indivisible in the sense that removing any of its components would render it inert. Existing evidence shows that a variety of kernels can influence behavior in context, and some evidence suggests that frequent use or sufficient use of some kernels may produce longer lasting behavioral shifts. The analysis of kernels could contribute to an empirically based theory of behavioral influence, augment existing prevention or treatment efforts, facilitate the dissemination of effective prevention and treatment practices, clarify the active ingredients in existing interventions, and contribute to efficiently developing interventions that are more effective. Kernels involve one or more of the following mechanisms of behavior influence: reinforcement, altering antecedents, changing verbal relational responding, or changing physiological states directly. The paper describes 52 of these kernels, and details practical, theoretical, and research implications, including calling for a national database of kernels that influence human behavior.
\end{abstract}

Keywords Evidence-based kernels .

Public-health benefits · Prevention · Treatment

D. D. Embry $(\bowtie)$

PAXIS Institute, P.O. 31205, Tucson, AZ 85751, USA

e-mail: dde@paxis.org

A. Biglan

Oregon Research Institute, Eugene, OR, USA

e-mail: tony@ori.org
This paper presents an analysis of fundamental units of behavioral influence that underlie effective prevention and treatment. We call these units kernels. They have two defining features. First, in experimental analysis, researchers have found them to have a reliable effect on one or more specific behaviors. Second, they are fundamental units of behavior influence in the sense that deleting any component of a kernel would render it inert. Understanding kernels could contribute to an empirically based theory of behavioral influence, facilitate dissemination of effective prevention and treatment practices, clarify the active ingredients in existing interventions, and contribute to developing interventions that are more efficient and effective. Subsequent sections of this paper expand on the two essential features of evidence-based kernels, as well as the origins of the idea and terminology.

The ultimate goals of treatment and prevention research are a reduction of the prevalence of the most common and costly problems of behavior and an increase in the prevalence of wellbeing. Current thinking about how to accomplish this assumes that we will identify empirically supported programs and, to a lesser extent, policies, and will disseminate them widely and effectively. Although substantial progress is occurring through this strategy, there are at least four limitations to it that point to the value of kernels as a complementary strategy.

First, it is difficult to implement a program's efficacy widely with fidelity or effectiveness. Ringwalt et al. (2003) surveyed a sample of 1,795 school staff members who were in charge of teaching substance-use prevention programs. Nearly two-thirds reported teaching content that metaanalyses showed was effective. However, only $17 \%$ used effective delivery and only $14 \%$ used both effective delivery and content. In a second study, Ringwalt et al. (2003) found that about one-fifth of teachers of substance- 
use prevention curricula did not use a curriculum guide at all and only $15 \%$ reported following one closely. Hallfors and Godette (2002) studied 104 school districts in 12 states. They found that many districts selected evidence-based programs, but only $19 \%$ of district coordinators indicated their schools implemented those programs with fidelity. They concluded there was inadequate funding and infrastructural support for implementation. More recently, prevention programs with long-standing efficacy data from more controlled conditions and settings, such as Project Alert or Reconnecting Youth (e.g., Bell et al. 1993; Ellickson et al. 1993), were tested for effectiveness in realworld contexts and conditions. Most often, the obtained effectiveness results do not replicate the efficacy trials (e.g., Hallfors et al. 2006; Sanchez et al. 2007; St. Pierre et al. 2005). Research on how to get programs widely adopted, effectively implemented, and appropriately adapted to different conditions is still in its infancy. However, initial evidence suggests that sole reliance on program dissemination to affect population outcomes will have a limited impact, even with restrictive policies (e.g., Hallfors et al. 2007).

Second, many problems - or behaviors-that affect wellbeing do not require lengthy or complex interventions involving consultations, workshops, training, or support. Consider a few examples. A teacher might improve classroom behavior just by using some non-verbal cues during transitions (Abbott et al. 1998; Krantz and Risley 1977; Rosenkoetter and Fowler 1986) or reduce aggression and bullying on the playground by cooperative games (Murphy et al. 1983). A parent might easily improve a teenager's cooperation with a mystery motivator (Madaus et al. 2003). A principal might reduce disturbing or disruptive behaviors and increase engaged learning with the principal's lottery (Thorpe et al. 1978). A college professor might increase participation of students with response cards instead of the expensive clicker systems (Shabani and Carr 2004). In other words, a simple method of behavior influence might well solve a specific problem, and that was all that was required. The simple solution might actually avoid larger, more unpleasant difficulties or have greater good over time. For example, the response cards used in a classroom increase academic achievement (Gardner et al. 1994) or the use of organized recess might not only reduce aggression on the playground, but also improve the academic performance of children in the classroom with ADHD (Jarrett et al. 1998). Thus, simple solutions might just be sufficient in many cases.

Third, program dissemination is unlikely to affect practices or problems that fall outside the scope of a program. Teachers, clinicians, parents, healthcare providers, coworkers, supervisors, and many others are constantly trying to have a beneficial influence on others' behavior.
Existing formal programs address only a small range of situations and behaviors they seek to influence. For example, parents may complain to a teacher, principal, nurse, or doctor how hard it is to get their young child moving in the morning. Alone, such a complaint does not merit implementing parenting skills training. However, a simple behavior change strategy, such as the Beat the Timer game (Adams and Drabman 1995), in which the child receives a reward for completing a behavior before the timer goes off, could solve the problem, and prevent parent-child conflict. Even in situations where an effective program exists, the program dissemination strategy will fail to affect any practices of those who choose not to adopt the program. A related issue is that that many problems have no evidence-based programs on published approved lists. For example, bipolar disorder is increasingly common among younger children, yet there are no listed programs for teachers with such children. Thus, given current evidence, it is likely that for now most daily practices that influence human development will fall outside the scope of existing programs. Failing to improve those practices is a missed opportunity.

Cost is a fourth limitation of depending solely on program dissemination to affect public health. The National Registry of Effective Programs and Practices provides cost information (see http://modelprograms.samhsa.gov/ template.cfm?page $=$ nrepbutton). Direct costs for program developers include material production, training, licensing, ongoing consultation of adopters, results monitoring, and program improvement. There are also hidden costs, such as venues, staff training, temporary staff replacement to cover duties, and administrative costs. For example, a model universal program that reduced observed aggression on the playground by about $10 \%$ (Grossman et al. 1997) requires $17.5 \mathrm{~h}$ of direct instruction per pupil, plus indirect costs for material and training of teachers. Thus, a school with 25 teachers may spend $\$ 12,000-15,000$ for materials, training, staff timing, and (possibly) substitute teachers. A cost of $\$ 500$ per teacher per universal program is unexceptional for listed programs. Therapeutic model programs (e.g., Ogden and Halliday-Boykins 2004; Szapocznik and Williams 2000) can cost between $\$ 80,000$ and 200,000 depending on the nature of licensing needs, training, materials, supervision, monitoring, and staffing. If multiple evidence-based programs are required, costs per problem (e.g., tobacco, alcohol, violence, bullying, or mental illness) can bring the total to hundreds of thousands of dollars in direct and indirect costs per setting. These funds are not typically available to schools, human service agencies, groups, and others charged with prevention and treatment. There is no reason to expect a surge in such funds at a local, state, or federal level anytime soon. Clearly, if program adoption is the only avenue to large population 
effects, progress will be slow and costly. It would be very useful from a public health and safety perspective if there were low-cost prevention, intervention, and treatment strategies to deploy easily-reducing the need for more expensive strategies that might not be possible to field where money and resources are scarce.

A fifth concern is that existing programs have limited effectiveness, modest effect sizes, scalability concerns, weak generalization, difficulty with maintenance or sustainability, and even iatrogenic effects (e.g., Hallfors et al. 2006; St. Pierre et al. 2005; Sanchez et al. 2007). This is not to diminish the enormous progress of prevention science in the past 30 years (Biglan 2004). However, inspection of recent meta-analyses of interventions (e.g., Bledsoe 2003; Derzon et al. 2005, 2006; Ennett et al. 2003; Lösel and Beelmann 2003; Lipsey et al. 2006; Scheckner et al. 2004; Tobler et al. 2000) finds plenty of room for improving the effectiveness of our programs.

A sixth concern is that current evidence-based programs do not easily meet the diffusion criteria (Rogers 1995). For instance, individuals who might be early adopters of proven and tested prevention strategies can often gain access to these strategies only through institutions such as schools or state agencies. If a school or agency lags, thousands of individuals or families in geographic areas cannot avail themselves of strategies that might prevent school failure, substance abuse, mental illness, delinquency, or other ills. Individual teachers also cannot adopt science-based strategies, as almost all evidence-based prevention programs require school or district adoptions. For example, it is easier for a parent or teacher to gain access to a prescription drug to treat ADHD or depression than to obtain evidence-based strategies that might similarly affect behavior (e.g., Ridgway et al. 2003; Schilling et al. 2003; Larun et al. 2006).

Each limitation points to the value of identifying and making available kernels of behavior influence. We do not suggest that kernels replace tested, proven programs; we propose that kernels supplement or strengthen programs, help to create new programs more efficiently, or make effective behavior-influence techniques available in situations where programs are unavailable, impractical, or just unnecessary based on the simplicity of the problem addressed.

\section{Kernel Definition, Derivation, and Examples}

We designate as evidence-based kernels any indivisible procedure shown through experimental evaluation to produce reliable effects on behavior (Embry 2004). The derivation of the term "kernels" arose in Embry's (2004) paper describing the active ingredients in evidenced-based prevention or treatment behavior-change programs, distinct from the earlier nebulous concepts of "principles of effectiveness." The perceived need for a taxonomy and nomenclature for these active ingredients emerged from a yearlong series of meetings organized by the second author, involving some 20 leading prevention, scientific, and policy leaders. Some of the scientists at the meetings were Richard Catalano, Harold Holder, Brian Flay, and the authors of this paper. These scientists had created and tested many prevention and treatment programs and had used some common ingredients to make those programs work. The scientists, however, had never denominated those ingredients or active components in ways that each other understood or that others might easily perceive for new invention or systematic replications.

Other disciplines do have such taxonomies and nomenclature. For example, medications contain lists of known "active ingredients," which have proven effectiveness separate from effects of the compounded product. For example, aspirin is clearly effective in its own right, and so are enteric coatings. Joined, they result in a product such as "buffered aspirin," composed of two separate active ingredients. One can look up medications' active ingredients in publications like the Physician's Desk Reference and look up how to use them in the Merck Manual. Nothing similar exists in applied behavioral science.

We chose the term "evidence-based kernel" for several reasons. First, it had the metaphorical resonance of something organic that influenced life or behavior. Second, the metaphor was about something very compact, although obviously in quantity or through blending, it could become something bigger or more productive. Third, the term was novel, which would confer the ability to track its use and make its meaning clear and crisp compared to words or phrases in past use such as "principles of effectiveness."

The unit of a kernel is indivisible in the sense that it would be ineffective if one eliminated any of its components. Experimental evaluations of kernels may involve randomized controlled trials (RCTs) or interrupted timeseries experiments (Flay et al. 2004). Examples of kernels include timeout, written praise notes, self-monitoring, framing relations among stimuli to affect the value of a given stimulus, and physiological strategies such as nasal breathing when upset or increasing omega- 3 fatty acids in the diet in order to influence behavior. The description of a kernel as an indivisible procedure merits discussion by metaphor and example.

First, a kernel is like a seed that contains central information for growth or change. Second, a kernel also evokes the idea of an implicit human technology to effect change from the earliest use of agriculture to the use of core routines in modern computers. A broken seed will not grow, and a broken core computer routine ("kernel panic") will 
cause the machine to be inoperative. One of the oldest prepared foods by humans, dating to the Neolithic erabread, further illustrates the point of indivisibility. Bread consists of flour and water. Bread may be leavened or unleavened. Even unleavened, bread can be quite varied: lavashes, tortilla, chapatis, rotis, naans, etc. Bread is simple and irreductable: remove the flour or liquid, there is no bread. The example of bread also illustrates the nearly infinite ways additions to it can make it sweet, spicy, bitter, fattening, medicinal, or celebratory. Of course other preparations of meat, legumes, fruits, or vegetables can be served with bread to form daily meals or diet-a culinary equivalent of a program.

Second, an evidence-based kernel has core components that cannot be removed and be effective. Consider some examples: (1) Timeout must be a brief removal from whatever is reinforcing the undesirable behavior, followed by intensive reinforcement for engaging in the desired behavior upon return; (2) a Home-Note from school must cue high rates of positive reinforcement from home adults, not emphasize the bad behavior at school; (3) beat the timer requires some kind of mechanical device to keep track of time, set for a brief time, and with a signal that cues reinforcement for the target behavior when the time elapses; and (4) nasal breathing must involve breathing through the nose and not the through the mouth, when upset, for the physiological and behavior benefits to happen.

Programs, however, are rarely irreductable. Programs contain many components or kernels, and the loss of a single one enables the program still to have some effect in most cases. For example, evidence-based reading programs like Direct Instruction or Success for All have kernels such as choral responding or peer-assisted learning among many other active ingredients. The loss or omission of a single program component may reduce results but will not obliterate results typically.

Naturally, some may ask about the cultural competence of evidence-based kernels. Anthropologists or evolutionary theorists (e.g., Wilson and Wilson 2007) posit human evolution and advancement are significantly based on our ability to influence each other for group benefit. We suggest that the idea of evidence-based kernels has deep roots in anthropology. Humans have a long history of creating ways to influence each other, and noticing the effects of their inventions to do so. While we hold fast to the notion that an evidence-based kernel must have peer-reviewed publication showing experimentally proven results, we are not blind to the fact that many kernels listed in this publication have more than chance analogue in the wisdom traditions of cultures to influence the behavior of relatives, mates, and neighbors. Many of the kernels herein are not just found in evidence-based programs or scientific journals; they can be found, too, in old culturally selected practices. For example, choral responding is a scientifically proven practice described herein (e.g., Godfrey et al. 2003), yet it can be found as a cultural practice from cultures as environmentally diverse as Polynesians to Arctic peoples; scientists funded by the National Institute of Health have recently experimentally demonstrated the efficacy of the omega-3 fatty acid on influencing many types of human behavior (e.g., Freeman et al. 2006a, b), while grandmothers several hundred years ago made sure that everybody had their daily dose of cod liver oil; and while legions of behavioral scientists since the 1960s may have demonstrated the effects of praise (e.g., Leblanc et al. 2005), the Yup'ik peoples of Alaska apparently applied the principle a long time before European contact.

Humans-be they parents, teachers, leaders, business people, or even scientists-attempt to influence behavior, which begs the question of what influence might mean. Thus, a kernel may increase the frequency or duration of a behavior or may make a behavior less likely. The change in frequency or duration of behavior is observable in real time. The mechanism of influence might be a function of an antecedent to channel behavior, a consequence following the behavior, a set of words about the behavior, or direct manipulation of physiology. These possible mechanisms or pathways of how kernels can influence the acquisition, rate, or duration of behavior will be discussed subsequently. Some examples of kernels now merit attention.

\section{The Example of Timeout}

Timeout was one of the first kernels of behavior-influence technology (Wolf et al. 1964). Dicky was a 3-year-old boy with autism who had undergone surgery for cataracts. He lived in a psychiatric hospital and had frequent tantrums resulting in self-injury. In tribute to the late Montrose Wolf, Risley described this landmark study (Risley 2005):

After having just discovered the power of adult attention for young children, and realizing that the staff could not simply ignore temper tantrums, especially violent ones with mild self-abuse, Wolf decided to prescribe a response to tantrums that would minimize any social reinforcing effect of the necessary attention and counterbalance that reinforcement with a period of social isolation. The prescription for tantrums was to place Dicky, calmly and without comment, in his room until the tantrum ceased and at least 10 minutes had passed. When tantrums were under control and after wearing glasses had been hand shaped, Dicky began to throw his 
glasses occasionally. When the social isolation prescription was applied, glasses throwing decreased from about twice per day to zero. But the hospital staff doubted that it was due to the procedure, because Dicky didn't seem to mind being taken to his room; he just rocked in his rocking chair and hummed to himself. Because throwing glasses was both less serious and more reliably measured than tantrums, Wolf agreed to discontinue the procedureand glasses throwing soon increased to the previous level. The social isolation procedure was reinstated, and glasses throwing decreased again to zero. (pp. 281-282)

Thus was born timeout, shown since in hundreds of studies to reduce the frequency of a vast range of behaviors. It is a staple of nearly every evidence-based prevention program for parenting (e.g., Incredible Years [Webster-Stratton and Reid 2007]; Triple P [Sanders and Markie-Dadds 1996]; Parent Management Training [Forgatch et al. 2005a, b]). It is also part of popular culture. Shows like Nanny 911 display its use; websites with advice to parents describe it (e.g., http://www.thelaboroflove.com/ forum/quality/timeout.html). Although there is no population-based data on the prevalence of families and schools using timeout, it seems that in many areas, timeout is the normative replacement for harsh methods of discipline.

\section{The Example of Nasal Breathing or "Doing Turtle"}

Humans are amazing at noticing the effects of small physiological interventions that influence human behavior. Grandmothers and experienced teachers, for example, often tell children who are emotionally overwrought and hyperventilating to close their mouths and breathe through the nose while exhaling through the mouth. This strategy is taught formally in such evidence-based prevention programs as the Incredible Years and PATHS (Positive Alternative Thinking Skills), and even has a child-friendly name and story of "doing turtle" (Robin et al. 1976). The strategy is based in empirical observations of the relationship among breathing patterns, physiological measures, behavior, and children's emotional states (McDonnell and Bowden 1989; Naveen et al. 1997; Perna et al. 2002; Pine et al. 1998; Telles et al. 1997; Zaichkowsky et al. 1986). This kernel also illustrates how a simple strategy might be independently discovered and tested from very different theoretical perspectives (e.g., pediatric medical practice, basic research, child psychology, prevention, parenting, and even alternative bodywork such as yoga). Like most kernels, it can be used and proven on its own, or incorporated in programmatic efforts.
Theoretical Taxonomy of Kernels

Although simple enumeration of kernels may support effective practice, their contribution may be more substantial if we organize them within a theoretical framework to delineate the key influences on behavior. Such a framework would facilitate generating new kernels and could point to overlooked procedures for influencing behavior.

Kernels are understandable in terms of the operant behavior of biological organisms, viewed within a developmental and evolutionary perspective. Human behavior-including verbal, cognitive, and emotional functioning-has developed over time as a function of the biological capacities of the organism and the consequences to behavior. Human behavioral tendencies are adaptive functions of current situations and a history of consequences for behaving in similar situations (e.g., Biglan 1995).

Kernels involve one of four primary processes. Many involve consequation of behavior-the presentation or removal of reinforcing or aversive consequences (Biglan 1995, Chap. 3). Others involve an antecedent stimulus affecting motivation to behave due to a history of consequences for responding to that stimulus (e.g., teachers' use of standard signals to prompt students to sit down; Jason, Neal, and Marinakis 1985; Wasserman 1977). A third type primarily involves altering the relations that people derive among verbal stimuli in ways that affect motivation. For example, to elicit a public commitment to engage in a behavior (Chassin et al. 1990), a person feels prompted to associate a network of consequences (such as others' approval) with engaging in the behavior and other consequences with not engaging in the behavior (e.g., disapproval). Each of these three types of kernels involves ways in which a person's social environment affects his or her behavior. In a sense, kernels provide prescriptions for how the social environment can show more support of human development.

A fourth type of kernel alters a biological function of the organisms in ways that affect behavior. An example is supplementation of diets with omega-3 fatty acid (Haag 2003). Indeed, any pharmacological agent that affects behavior would fall into this category, although we stress the importance of distinguishing prescription medications from nonprescription, scientifically proven kernels that individuals or organizations might choose to use without a prescription.

Table 1 presents a list of kernels organized according to this theoretical framework. We categorize each kernel in terms of the primary mechanism by which it affects behavior, although clearly many kernels involve more than one process. Space precludes a complete review of the empirical evidence for each kernel, but we cite all experimental evaluations done for each kernel along with the types of experimental evaluations that have occurred. In 


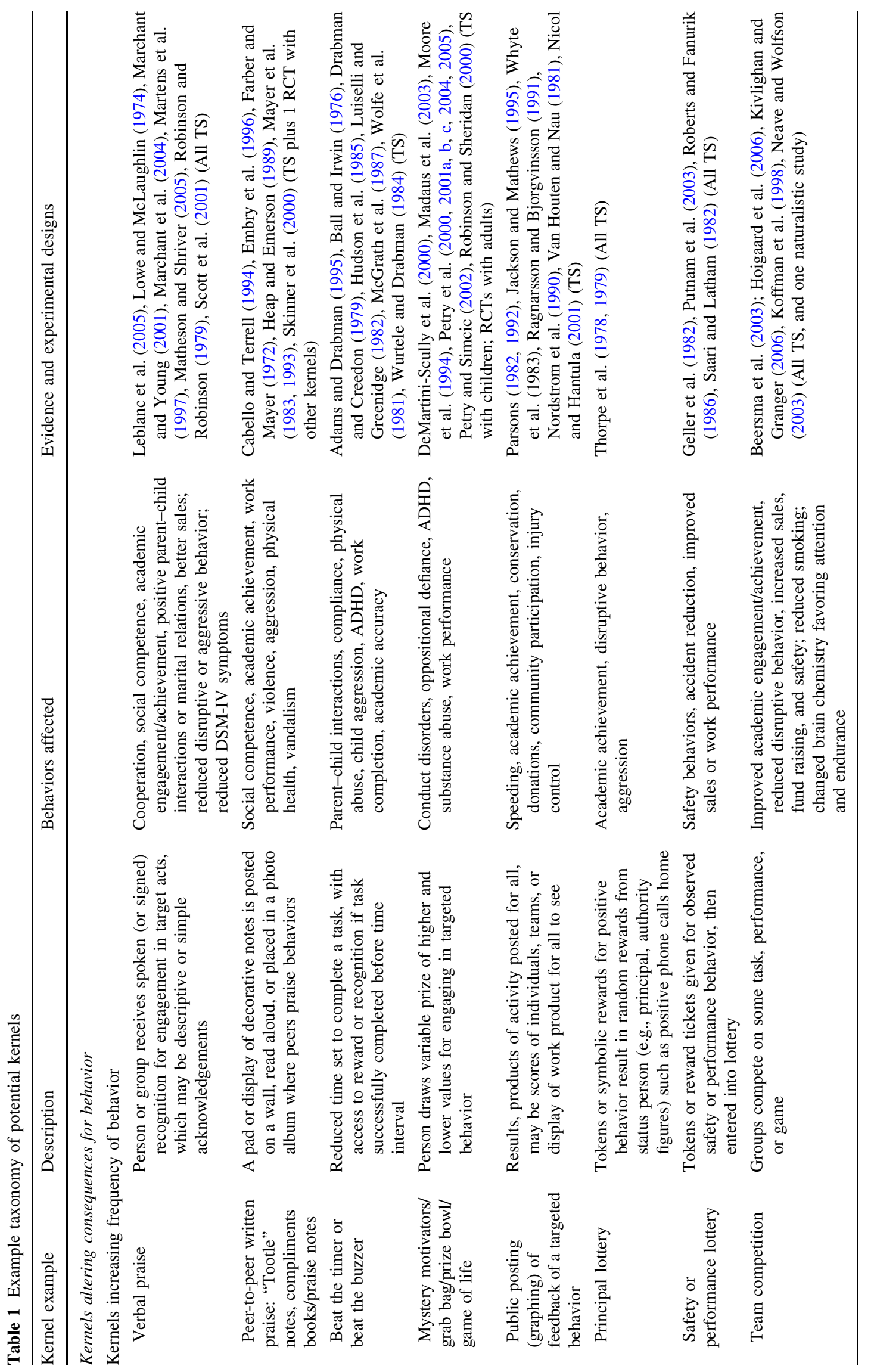




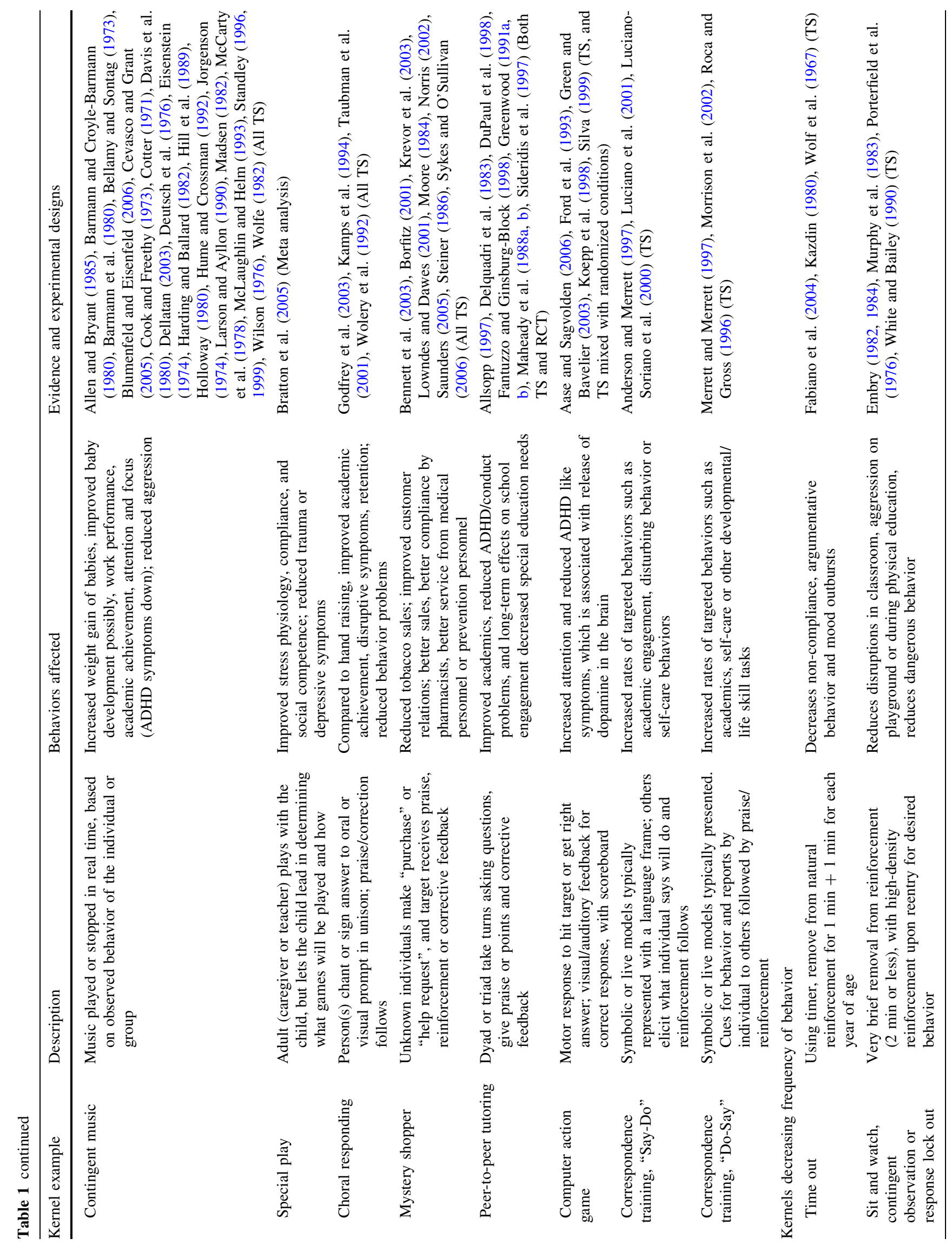




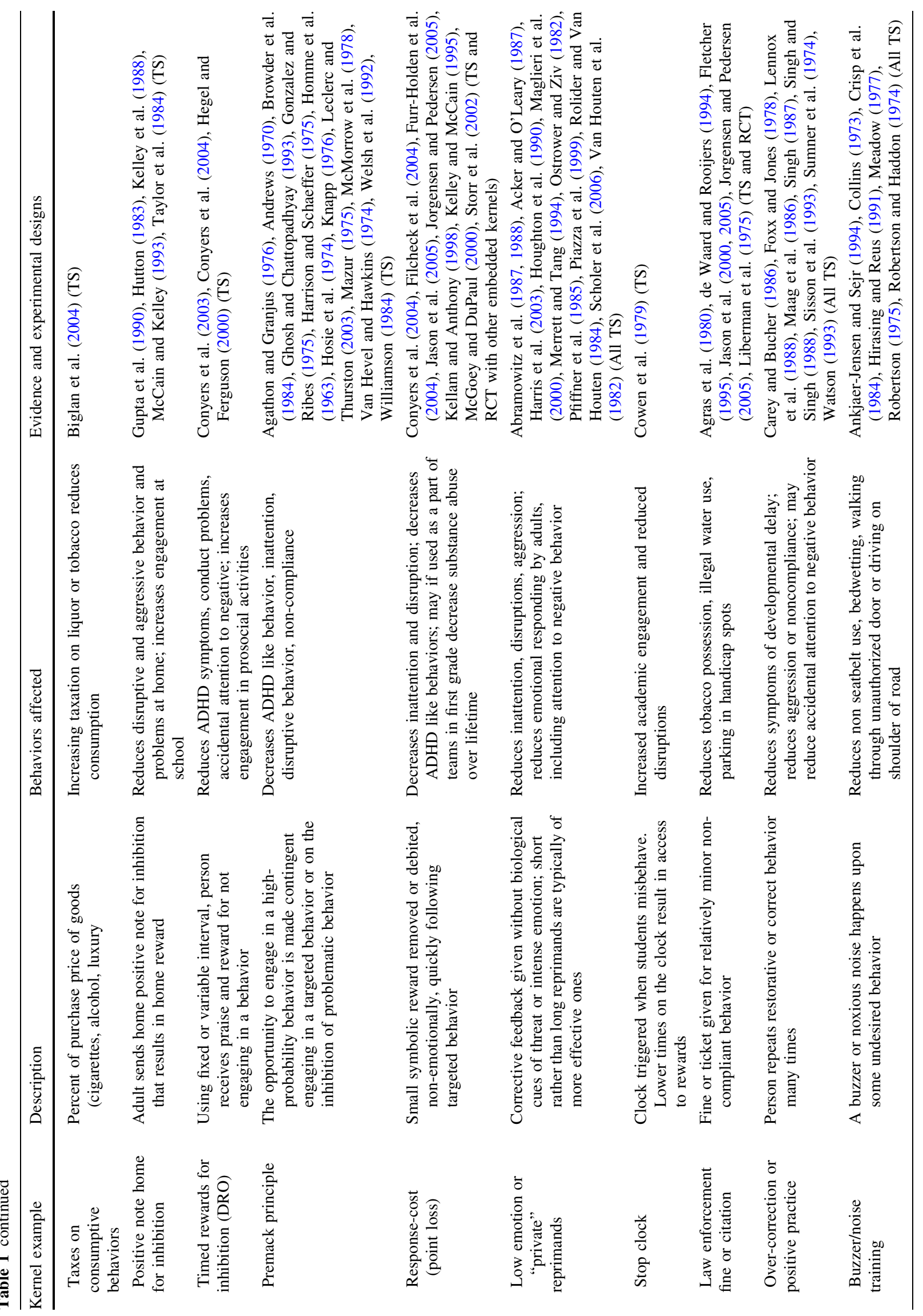




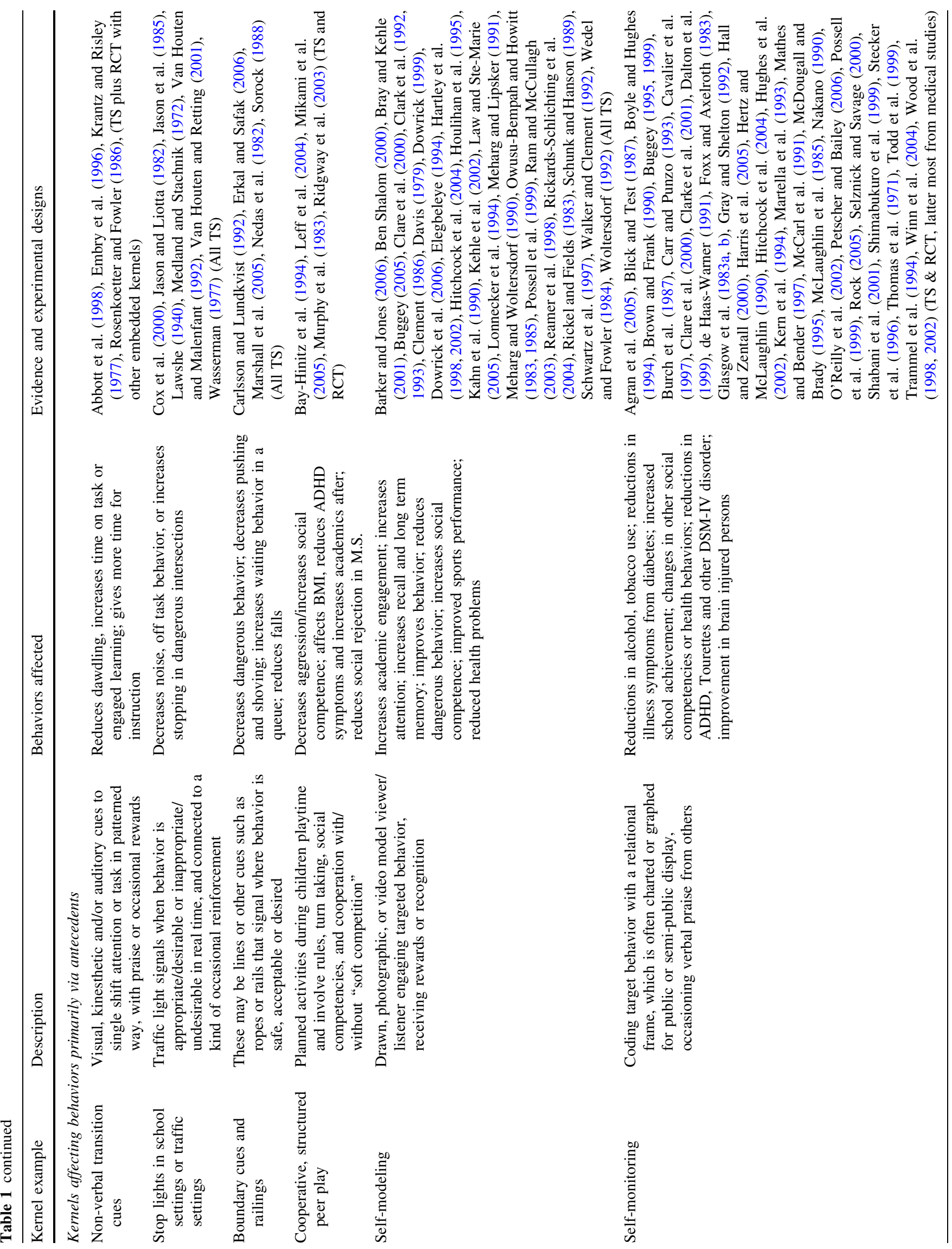




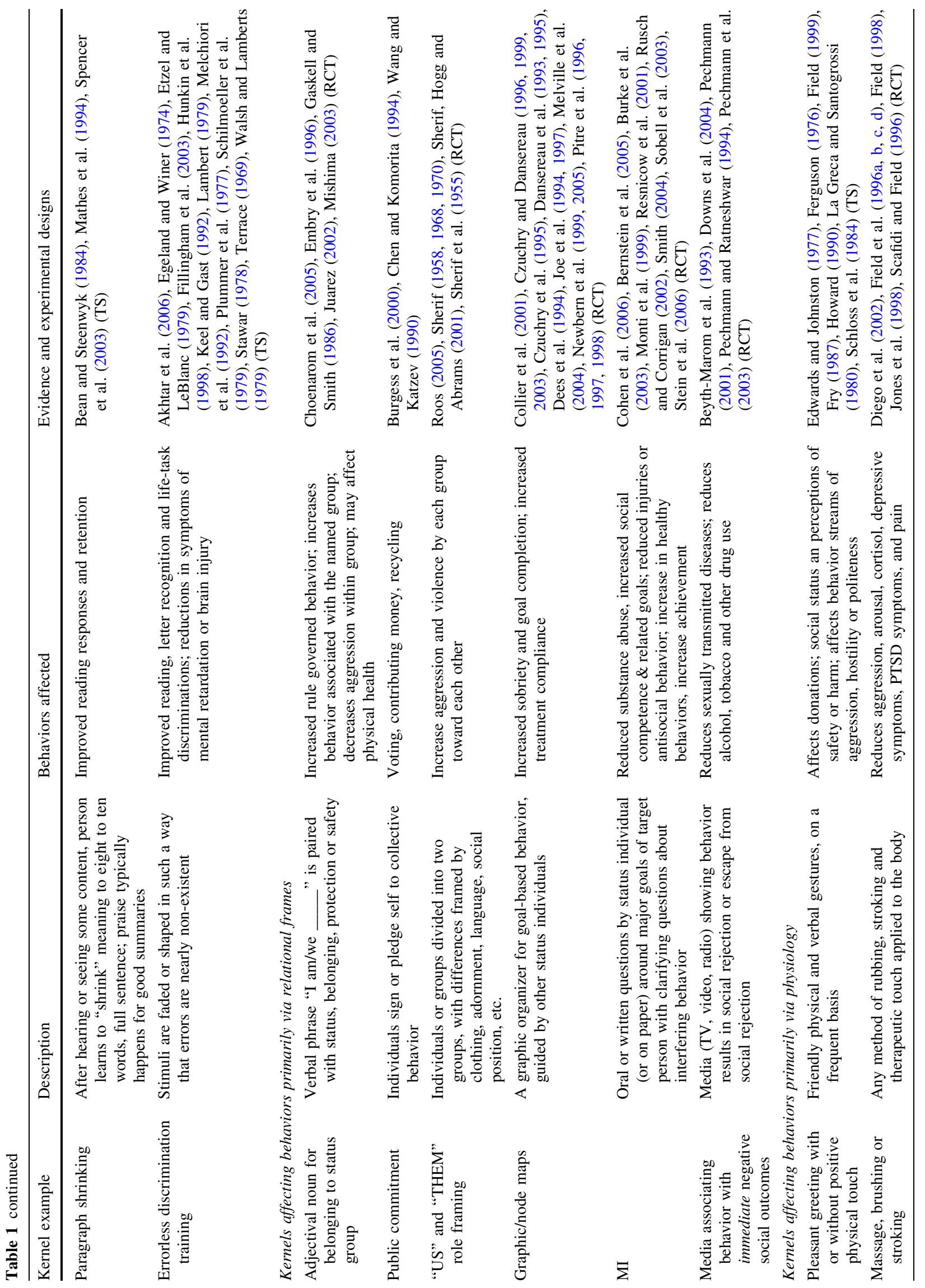




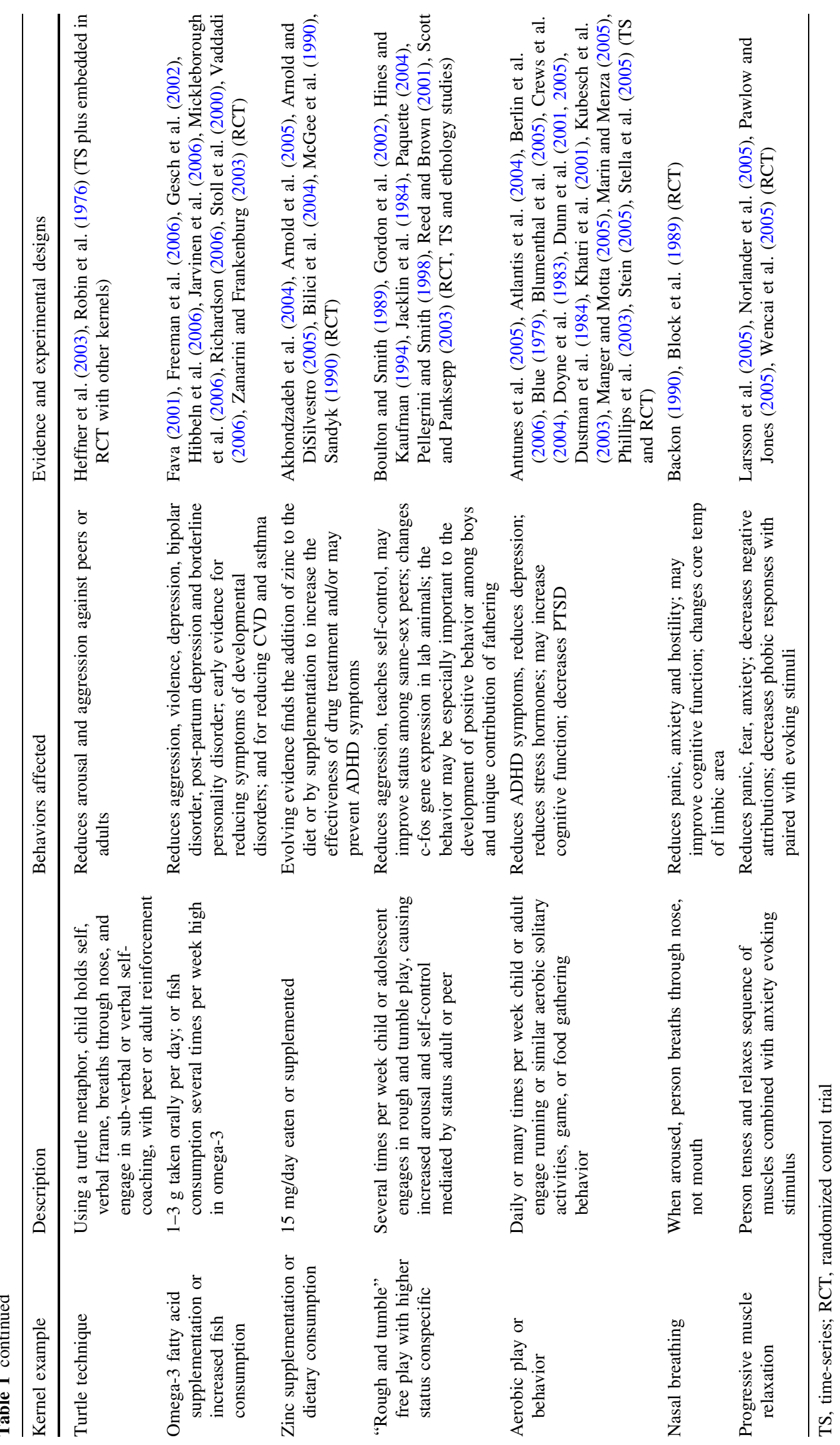


each of the following, we describe the empirical evidence in detail for one kernel.

\section{Designating Example Kernels for This Paper}

The 52 kernels presented in Table 1 are not exhaustive; they are simply examples that meet the definition of a kernel from the four types. That is, the kernel has one or more peerreviewed experimental studies showing behavior change. We are aware of many more kernels; the more kernels we identified, the more we found others. Because of the yearlong process that gave rise to the need for and idea denominating the active ingredients of evidence-based prevention and a book about the science of preventing problems of adolescence (Biglan et al. 2004), many of the 52 kernels were evident to us at first blush because of our own published studies and that of our colleagues on parenting, violence prevention, substance abuse prevention, etc.; others we chose deliberately to illustrate the potential theoretical diversity of kernels - an interesting point in itself, exemplified by reactions to early drafts of the paper. Some early readers were delighted to see the inclusion of examples from behavior analysis, yet chaffed at the physiological kernels such as omega-3 and massage-despite the scientific evidence available for each. Others objected to behavioral procedures, arguing that behavioral procedures were proven to be ineffective-despite studies showing otherwise. We are aware that any given professional community might disagree with the theoretical approach of another professional group, yet a taxonomy of kernels begins to elucidate how, where, when, for whom, and for what scientifically proven strategies might be more or less beneficial in influencing human behavior. We imagine that a database of kernels will emerge, much like the human genome project (i.e., http://genomics.energy.gov/) wherein the breadth, depth, magnitude, and replications of the effects of any given kernel might be reported by the international research community in order to build an opensource molecular technology of behavioral influence. The arbitrary selection of the 52 kernels in this paper illustrates the possibility of a rich "behaviornome" type project for fundamental units of behavioral influence. Subsequent paragraphs detail examples of four types of kernels for influencing behavior from Table 1, as a proof of concept from 52 experimentally demonstrated kernels.

\section{Kernels Altering Consequences for Behavior}

\section{Increasing Rate or Probability of Behavior}

Many kernels increase behavior by mobilizing reinforcement for the targeted behavior. These include vocal praise, written praise notes, prize bowls, and public posting of feedback about the rate of a targeted behavior. Each delivers positive consequences contingent on a behavior. In the case of public posting of feedback, it is necessary that the recipients of the post in some sense want to increase the behavior recorded in the postings. An example of a powerful yet simple reinforcement kernel involves writing positive notes to increase behavior. Written praise notes from a supervisor increase work performance (Nordstrom et al. 1988), notes written by a teacher to students increase academic success (Hickey et al. 1979), and notes from students to each other increase social competence (Skinner et al. 2000).

We also put special play with parents in this category. It involves adults letting the child lead in free play activities (Webster-Stratton and Reid 2007). Its purpose is to facilitate interactions in which parents do not command, criticize, or unduly restrict activities of the child and allow the child to engage in fantasy play with the parent. Such interactions presumably are reinforcing for parent and child; the child receives the undivided attention of the parent contingent on cooperative play, and the parent experiences cooperative and pleasant interactions with the child contingent on listening to the child and following the child's lead.

\section{Decrease Behavior by Altering Consequences}

Other procedures alter consequences in order to decrease the frequency or probability of a behavior. Some involve ensuring an undesirable behavior does not elicit reinforcement. Timeout is one such procedure. Rewarding behavior incompatible with the undesirable behavior is another.

A third set (ostensibly designed to decelerate behavior rates) involves delivering aversive consequences for a certain behavior-traditionally termed punishment. However, many so-called punishments (e.g., lengthy grounding, mandatory minimum sentences) have no beneficial effect and, in fact, cause harm (Sampson and Laub 1994). Indeed, a major challenge for many parenting programs is getting parents to be less punitive. Thus, in developing procedures to make aversive consequences contingent upon behavior, we must evaluate them carefully to ensure they are effective and have few side effects.

Fining is an example of a negative consequence affecting behavior. Agras et al. (1980) found that receiving a fine reduced individual, but not business, water wastage. Fletcher (1995) found that fines for parking in disabledreserved spaces notably decreased the behavior.

Kernels Altering Behavior Through Antecedents

Many kernels work by establishing the functions of antecedents to behavior. A common example in schools is 
teachers establishing signals to guide transitions (Marion and Muza 1998; Rosenkoetter and Fowler 1986; West et al. 1995). For example, many teachers turn lights off and on to signal students to return to their seats and become quiet and attentive. Of course, positive consequences (e.g., praise) are involved in establishing effectiveness of the stimulus, but once established, the salient feature is the influence of the light on the behavior.

Assigning students meaningful roles (Rutter 1981), such as setting up equipment for an assembly, taking roll, or taking photographs for communicating desirable school functions, are activities that organize useful behavior. Antecedents may also include organized playground activities to reduce aggressive behavior and occasion various social competencies (Murphy et al. 1983). Reinforcement follows naturally from the enactment of the role.

It would be arbitrary to classify antecedent interventions based upon whether they increase or decrease behavior. This is because antecedents that prompt a desired behavior simultaneously make troublesome behavior less likely.

\section{Kernels Altering Behavior by Influencing Relational Responding}

Tradition within psychology suggests it is unfeasible to deal with cognitive and emotional influences on behavior within a basic behavioral framework of antecedents and consequences. However, recent work on relational frame theory (Hayes et al. 2001) has shown that human cognitive and verbal behavior can be understood in terms of basic operant processes, while honoring that humans do appear to have unique evolutionarily selected brain structures supporting language. To the extent this is true, it provides a parsimonious account of complex human functioning within a contextualist framework focusing on manipulable influences on behavior (Biglan and Hayes 1996).

\section{Research on Relational Responding}

There is growing evidence that a fundamental feature of human cognitive or verbal processes is the relating of stimuli (Barnes et al. 2000). Because this analysis is a recent development and likely to be unfamiliar to most readers, we will elaborate on it here. Barnes et al. (2000) present a theoretical analysis of relational responding. According to them, relating stimuli is the core feature of verbal behavior. Perhaps the most rudimentary relational responding involves naming. At the beginning of learning language, young children learn to say names for objects and separately learn to orient to objects when they hear their names. Each response is operant behavior reinforced by consequences such as attention, praise, and gaining of an object. After multiple experiences of this sort, however, a child also learns that if an object has a name, the name also goes with the object. In other words, they become able to derive the mutual entailment of name to object and object to name. Further experiences like this enable children to derive relations that are more complex. For example, learning that a puppy is a kind of dog and that Buddy is a puppy, a child is able to derive that Buddy is a dog. We call this ability to derive relations between two stimuli based on their relations with a third stimulus combinatorial entailment.

The third defining feature of relational responding is the transformation of function. Humans' derivation of relations among stimuli can transform the functions of stimuli that participate in the relation. For example, discovering that one coin is worth more than another makes the coin more reinforcing. Learning that water has bacilli in it may have no impact on a child, but upon learning that bacilli are germs, and that germs can you make you sick, a child's reaction to the water changes.

A fourth defining feature of relational responding is arbitrary applicability. Many of the relations we learn arise from physical relations among stimuli. For example, smaller than and larger than are terms based on the relative size of objects. However, humans become able to relate stimuli in these terms even though the stimuli do not have physical features involving relative size. If you hear that one person has a bigger heart than another person does, you may expect that person to be kinder, even though you understand that his heart is not literally larger.

For theorists accustomed to the panoply of existing cognitive constructs, which admittedly do a good job of predicting much human behavior, the value of this analysis may be obscure. Its value lies in providing a direct analysis of the specific procedures that influence relational responding and thereby transform the functions of stimuli.

\section{Increasing Behavior by Altering Relational Responding}

Perhaps the simplest and most important procedures of this type are those that augment the value of stimuli by influencing people to relate them to stimuli they already value. If we tell children they can stay up a half hour more if they get five stickers, we change their valuing of the stickers. In essence, any procedures influencing people to relate a stimulus with stimuli they already value make that stimulus more reinforcing. Prevention and treatment scientists, unlike marketing professionals, are often unfamiliar with relational responding.

One example of relational responding involves branding to influence behavior (Fischer et al. 1991). A recent study shows that children preferred foods "branded" as McDonald's (logos, wrapping papers, etc.), even for 
carrots, which McDonald's does not sell (Robinson et al. 2007). Another example of branding is the introduction to the PeaceBuilders program (Embry et al. 1996). It used kernels like peer-to-peer praise/tootle notes and positive notes home to establish the word PeaceBuilder as a valued concept and to make being a PeaceBuilder-and all behaviors later related to this concept-more reinforcing. The program improved social competence and reduced aggression and injuries due to violence (Flannery et al. 2003; Krug et al. 1997). Biglan and colleagues recently completed a study showing that pairing fun social activities for middle-schoolers with a non-smoking brand ( $\mathrm{f} 2 \mathrm{~b}$-for Freedom to Breathe) reduced smoking among students even when the program had little overt antitobacco content (Gordon et al. 2008).

Another example of a kernel using relational responding involves public commitment. When people publicly commit to engage in a behavior, they are more likely to follow through on the behavior (e.g., Burn and Oskamp 1986). The public oath makes behavior inconsistent with that pledge aversive due to expected disapproval for failing to follow through with the promise.

In self-modeling, the professional helps to create a story about a person's behavior (Hosford 1980); the person typically participates in the process. The story embeds a person's self in a set of relations with desired behaviors and attributes (e.g., depicting a child as a hero at school or home for helping bring about peaceful behaviors; Embry et al. 1996). A child might learn a series of self-help skills through photographs or video (Hartley et al. 1998), making the child more apt to relate engaging in the behavior with valued ideas, such as being a "PeaceBuilder" (Embry et al. 1996).

Motivational interviewing (MI) is a powerful example of relational responding. MI may seem complex, yet we believe that subdividing it would destroy its effects. In MI, the interviewer prompts a person to discuss a topic he or she generally avoids (e.g., one's drinking patterns and difficulties associated with them; Bernstein et al. 2005; McCambridge and Strang 2004; Miller et al. 1988). The interviewer is warm and accepting as the person talks but asks questions designed to put the person in psychological contact with negative consequences of his/her behavior and the possible benefits of changing the behavior. It is clear this process has reinforcing and antecedent features, but the most salient aspect of the process seems to be that it alters the way people relate their problematic behavior to negative consequences and the possible alternatives to more reinforcing consequences. In other words, MI changes people's networks of relations in ways that make some behaviors more, and others less, desirable. Although most treatment professionals are familiar with complex forms of MI, very brief, scientifically validated forms do exist (McCambridge and Strang 2004)_including just 15 min (Cohen et al. 2006).

\section{Decreasing Behavior by Altering Relational Responding}

Some behavior-influence procedures discourage behavior by prompting a person to relate the behavior to aversive stimuli. In general, any procedure that prompts a person to relate undesirable behavior to negatively valenced stimuli would qualify as such a procedure-provided there was experimental evidence of its effect. For example, media associating drug use with negative outcomes have sometimes been shown to reduce drug use (Palmgreen et al. 1995). Messages suggesting that youth's peers will reject them for smoking affects their motivation to use tobacco (Pechmann and Knight 2002; Pechmann et al. 2003).

\section{Kernels Altering Behavior Through Physiological} Interventions

Finally, some procedures primarily affect physiological behavior. For centuries, humans have altered their health and mood by manipulating physiological states. Anthropological and archeological literatures are replete with examples (Lalramnghinglova 1999; Rajan et al. 2002; Rodrigues 2006; Spindler 1995). Hunters and gatherers often consume plants with stimulant properties, apparently since they confer an advantage during tasks such as hunting, which requires sustained effort and attention. Modern humans have similar reasons for using caffeine.

The impact of omega-3 fatty acid is a particularly important example of a physiological kernel (Olafsdottir et al. 2005). We use this example because of its exemplary laboratory, epidemiological, and randomized control studies across many domains of prevention, intervention, and treatment. Aside from epidemiological research on the relationships of omega-3 fatty acid (n-3) to a wide variety of causes of morbidity and mortality (Hibbeln 2001), experimental and quasi-experimental studies find supplementation of omega-3 reduces violent aggression among men (Gesch et al. 2002). Its use also reduces depression or bipolar disorder (Mischoulon and Fava 2000; Stoll et al. 1999; Sund et al. 2003) and other health or public health concerns, such as low birth weight and offspring IQ (Helland et al. 2003). Although not yet proven, omega-3 may even alleviate some of the problems associated with poverty, since poorer people have diets lower in omega-3 (Egeland et al. 2001; Liu et al. 2004).

Another intervention affecting behavior through direct impact on physiology is deep breathing, shown to reduce anxiety, arousal, and aggression among all ages (Appels et al. 1997; DiFilippo and Overholser 1999; Peck et al. 2005; Sharma et al. 2005; Suzuki et al. 2000). Zinc supplementation may reduce or moderate ADHD symptoms (Arnold et al. 2005; Bilici et al. 2004). We include a variety of strategies that enhance self-regulation in aroused 
states such as "rough and tumble" play and related martial arts training for children, as studies have shown it to reduce children's aggressive behavior (Bjorklund and Brown 1998; Paquette 2004; Pellegrini 1992; Shannon et al. 2002) and the mechanism appears to involve alteration of brain chemistry (Panksepp et al. 2003; Siviy et al. 1996; Taylor et al. 1986). The martial arts studies with children show improved self-regulation, less aggression, and positive mood along with decreased impulsiveness (Lakes and Hoyt 2004; Palermo et al. 2006; Twemlow and Sacco 1998; Zivin et al. 2001), though student self-report may show less change than classroom teacher reports (McDiarmid 2008).

The distinction between biological and environmental interventions is not certain. Of course, any environmental manipulation may influence biological functioning. Below we discuss interventions that directly manipulate biological processes instead of changing psychological or behavioral functioning.

Although many pharmacological agents alter behavior and meet our definition of a kernel, the substantial literature on these influences is beyond the scope of this paper. Moreover, unlike nutritional supplements and nasal breathing, FDA-approved pharmacological agents require prescriptions; thus, they would not be available to most prevention practitioners or consumers directly.

Prevention scientists, oriented toward the implementation of programs, may overlook physiological interventions. Publications about these kernels are not in journals devoted to behavioral science but more likely to appear in medical, public health, or specialty journals. However, the evidence for them suggests that treatment and prevention scientists should pay greater attention to the reciprocal relationships between physiology and behaviors.

\section{Types of Experimental Evidence Supporting Kernels}

We define kernels as procedures shown empirically to affect a behavior. In keeping with the Society for Prevention Research Standards of Evidence (Flay et al. 2004), our criteria for empirical support include RCTs and interrupted time-series designs in which a procedure's impact is evaluated on a repeated measure of target behavior. Most evaluations of kernels have been via interrupted time-series designs, while some, such as omega-3 impact, have been in randomized trials. Some have undergone evaluation both ways. Some studies measured generalizability of results across time, behaviors, people, or places; others measured only proximal or immediate effects.

Many kernels result from interplay between basic and applied research. Variable interval or ratio contingency management kernels (e.g., Mystery Motivator, Prize Bowl) have roots in animal (Ferster and Skinner 1957) then human (Majovski and Clement 1977) research. Researchers next conducted clinical studies using interrupted time series (Henderson et al. 1986; Leibowitz 1975; Libb et al. 1973; Madaus et al. 2003; Moore et al. 1994; Robinson and Sheridan 2000; Snell and Cole 1976) and formal RCTs (Petry et al. 2004, 2005).

Physiological kernels have a similar scientific trajectory. For example, the understanding of omega-3 (n-3) has roots in early epidemiological or forensic inquiries showing differences among individuals with diseases or disorders (Anderson and Connor 1989; Gudbjarnason et al. 1991; Lieber et al. 1969; Rudin 1981). Initial epidemiological findings (Hibbeln 1998, 2001, 2002) prompted precisionoriented laboratory studies (Hibbeln et al. 1998; Hibbeln and Salem 1995) and larger epidemiological inquiries. All this work led to clinical trials evaluating omega-3 supplementation (Nemets et al. 2002; Sund et al. 2003; Zanarini and Frankenburg 2003).

The frequent use of interrupted time-series designs in developing kernels deserves further comment. It reflects not simply an arbitrary methodological preference but an incremental, inductive, bottom-up strategy to build effective behavior-influence practices. Kernels are of necessity simple steps targeting a behavior one can easily measure repeatedly; it is thus easy to implement interrupted timeseries designs. Single-subject studies are quite robust in terms of reducing threats to validity (Sidman 1960) and in answering questions of whether a particular medication, procedure, or process is efficacious in changing the behavior of a person or small group of persons (e.g., families, classrooms, and organizations; Dadds et al. 1984; Greenwood and Matyas 1990; Mayer et al. 1983; McGrath et al. 1987; Reagles and O'Neill 1977). Such interrupted time-series designs are not limited to evaluating individuals but are often the choice for evaluating policy impact on large, important social issues (Briscoe et al. 1975; Hayes and Cone 1977; Wagenaar et al. 1988). One may summarize interrupted time-series designs effectively via effect sizes and metaanalyses (Campbell 2004; Stage and Quiroz 1997).

An important limitation on current understanding of kernels is that we have relatively little information about situations in which they will be effective and those in which they will not be effective. Further research should explore the range of situations in which given kernels work and seek to develop a theory of the relationship between situations and the efficacy of kernels.

\section{The Utility of Kernels}

Disseminating Effective Behavior-influence Practices

If our ultimate public health goal is to minimize the prevalence of behavioral and psychological problems and 
improve wellbeing, then increasing the prevalence of effective behavior-influence practices is essential. Disseminating kernels could be an important supplement to current reliance on program dissemination for achieving this outcome. Kernels have most features that Rogers (1995) identified as important in fostering dissemination. $\mathrm{He}$ observed that people are more likely to adopt and implement a practice if it is simple and easily tested, its effects are readily observable, it appears to offer an advantage over existing practices, it addresses an important problem, and it is compatible with existing practices.

Most kernels are quite simple and consist of an easily tested, low-cost activity. Moreover, it is usually possible to observe their immediate impact on a person's behavior; it does not require statistical analysis of groups of individuals. As a result, the person who tries a kernel is likely to observe immediate benefit, which will likely reinforce its use. Finally, as the list of kernels in Table 1 shows, most kernels affect behaviors important to change agents.

As noted above, even if empirically supported programs were widely disseminated, numerous behavior-influence interactions in society would fall outside the scope of existing programs. For example, programs may teach social competencies to avoid aggressive behavior (Taylor et al. 1999) but teachers and youth leaders need ways to structure interactions among youth so that prompts for aggressive behavior decrease. Cooperative games (Murphy et al. 1983); peer-to-peer tootle/praise notes (Embry et al. 1996; Mayer et al. 1983, 1993; Skinner et al. 2000); the principal's lottery or preferrals (Thorpe et al. 1978, 1979); and non-verbal transition cues (Abbott et al. 1998; Embry et al. 1996; Krantz and Risley 1977; Rosenkoetter and Fowler 1986) are easy to build into daily school or afterschool routines. They can also structure student interactions to minimize prompts to engage in aggression. If we widely disseminated kernels to behavior-influence agents (e.g., teachers, therapists, youth leaders, human service workers, and parents), it could result in effective behavior support practices being more widely used than if we waited for these agents to generalize good practices from programs that they were trained to use in specific situations.

Glasgow et al. (1999) proposed the RE-AIM framework for thinking about the long-term public health effects of interventions. They argue that the benefit of a practice is a function of its Reach times its Efficacy. However, even an efficacious intervention that reaches many people will have limited impact over time, unless it is Adopted, Implemented, and Maintained. From this standpoint, kernels supplement program dissemination strategies because their readily observed benefits (efficacy) make them prone for adoption and maintenance and because they will increase the reach of beneficial behavior-influence practices since there are kernels relevant to so many situations.
A recent RCT of a media version of Triple $\mathrm{P}$ (Positive Parenting Program(s); Sanders et al. 2000) illustrates this point. Behavioral parenting skills programs consist largely of kernels (e.g., timeout, praise, and special play). Parents who go through such programs learn several important behavior-influence strategies. However, the reach of these programs is limited, due to administration costs and costs in time and money to participants. Triple P's media version reflects the recognition that a population-based impact may be greater if specific kernels of effective parenting practice can reach large numbers of parents. Preliminary data from this 18-county RCT showed that the promotion of "kernellike" parenting practices through media, tip sheets, and brief, structured interactions reached about $25 \%$ of the population in intervention counties. Multiweek parenting courses were available for parents who needed support that was more intensive. The combination of kernels and programs, where needed, significantly reduced child-abuse reports, medical injuries, and out-of-home foster placement (Prinz et al. accepted).

In sum, in addition to empirically supported programs coming into wider use, we foresee the spread of kernels into the repertoires of many change agents for situations without designed programs and those where the problem does not require a multicomponent program.

\section{Reducing the Cost of Beneficially Influencing Behavior}

Making kernels widely available to behavior-influence agents may reduce the cost of bringing about widespread use of effective practices. Most of the kernels we identify are in the public domain, easy to adopt, and useful across many situations. Their dissemination requires no expensive materials. Training in their use can be accomplished much more cheaply (often simply by modeling or defining) than training in complex programs.

Since kernels are in the public domain, it discourages certain types of profit-motivated dissemination. For example, despite strong evidence of its efficacy for diverse problems, omega-3 (fish oil) offers little incentive to pharmaceutical companies to market it for treatment of bipolar disorder, post-partum depression, depression, developmental disabilities, or aggression.

Nevertheless, viable business models exist that would motivate dissemination of kernels. It is possible to make access to information about kernels a commodity sold on the Internet at low cost. Indeed, video modeling of - and supporting materials for-kernels could be available through iTunes, amazon.com, or e-bay. Alternatively, some kernels could be available at drug stores, supermarkets, or video rental stores. Workplaces, local governments, and other potential beneficiaries of kernels might well become bulk purchasers or distributors of kernels that they 
calculate will affect health, safety, competitiveness, or other important outcomes.

\section{Using Kernels Across Developmental Stages}

The example kernels in this paper have utility with particular ages or developmental periods. Table 2 includes kernels with experimental evidence across multiple developmental stages, those predicted to be useful for ages for which they have not undergone testing, and those without data or clear hypotheses about their utility for developmental stages except the ones on which they have been tested. We will show kernels that are effective across multiple age ranges.

\section{Implications of Kernels for Policy}

The evidence on kernels points to the possibility that policies requiring or promoting the use of some kernels may be appropriate. For example, peer-to-peer tutoring of Title 1 students in first grade increases long-term academic success into middle school (Greenwood 1991a, b). Creating a federal, state, or district policy to use peer-to-peer tutoring in Title 1 schools or at-risk areas theoretically could raise academic performance and reduce historical racial, ethnic, and cultural disparities (Greenwood 1991a, b) -without adopting a new curriculum. Communities or school districts with high rates of dropping out in ninth grade might consider making a policy around using the 15min motivational process in seventh grade that improves grades in ninth grade (Cohen et al. 2006). Another kernel, taking omega-3 (cod liver oil) during pregnancy increases the child IQ at age 4 (Helland et al. 2003). The evidence justifies a policy for providing free omega-3 to pregnant and post-partum mothers via Women, Infants, and Children (e.g., Helland et al. 2003; Hibbeln et al. 2006; Richardson 2006). The American Psychiatric Association recently created a policy recommending at least $1 \mathrm{~g} /$ day of omega- 3 for all psychiatric patients (Freeman et al. 2006b), which is an example of a professional organization adopting a kernel.

\section{Some Concerns About Kernels}

Some argue that kernels are useful only if their effects are lasting. Numerous kernels do have such effects. For example, the errorless-compliance training kernel has at least a 6-month maintenance of effects for parent-child pairs coming from violent homes (Ducharme et al. 2000) and for children diagnosed with autism (Ducharme and Drain 2004). The safe playing kernel (Embry 1984) has reduced dangerous behavior 9 months after parents
Table 2 Kernel utility across age groups

\begin{tabular}{|c|c|c|c|c|}
\hline & Infants & Children & Teens & Adults \\
\hline Verbal praise & * & $*$ & $*$ & $*$ \\
\hline $\begin{array}{l}\text { Peer-to-peer written praise- } \\
\text { "tootle" notes, compliments } \\
\text { books/praise notes }\end{array}$ & NA & $*$ & $*$ & $*$ \\
\hline Beat the timer or beat the buzzer & $*$ & $*$ & $*$ & $*$ \\
\hline $\begin{array}{l}\text { Mystery motivators/grab bag/prize } \\
\text { bowl/game of life }\end{array}$ & $\mathrm{P}$ & $*$ & $*$ & $*$ \\
\hline $\begin{array}{l}\text { Public posting (graphing) of } \\
\text { feedback of a targeted behavior }\end{array}$ & NA & $*$ & $*$ & $*$ \\
\hline Principal lottery & NA & $*$ & $*$ & \\
\hline Safety or performance lottery & NA & $*$ & $*$ & $*$ \\
\hline Contingent music & * & $*$ & $*$ & $*$ \\
\hline Team competition & NA & $*$ & $*$ & $*$ \\
\hline Special play & $*$ & $*$ & & \\
\hline Choral responding & $*$ & $*$ & $\mathrm{P}$ & $\mathrm{P}$ \\
\hline Mystery shopper & NA & & $\mathrm{P}$ & $\mathrm{P}$ \\
\hline Peer-to-peer tutoring & NA & $*$ & $*$ & $*$ \\
\hline Computer action game & $\mathrm{P}$ & $*$ & $*$ & $*$ \\
\hline $\begin{array}{l}\text { Correspondence training, "Say- } \\
\text { Do" }\end{array}$ & NA & $*$ & $*$ & $\mathrm{P}$ \\
\hline $\begin{array}{l}\text { Correspondence training, "Do- } \\
\text { Say" }\end{array}$ & NA & $*$ & $*$ & $\mathrm{P}$ \\
\hline Time out & $*$ & $*$ & & \\
\hline $\begin{array}{l}\text { Sit and watch, contingent } \\
\text { observation, or response lock } \\
\text { out }\end{array}$ & * & $*$ & $*$ & $*$ \\
\hline $\begin{array}{l}\text { Taxation on consumptive } \\
\text { behaviors }\end{array}$ & NA & NA & $*$ & $*$ \\
\hline Positive note home for inhibition & NA & $*$ & $*$ & \\
\hline $\begin{array}{l}\text { Timed rewards for inhibition } \\
\text { (DRO) }\end{array}$ & $*$ & $*$ & $*$ & $*$ \\
\hline Premack principle & * & $*$ & $*$ & $*$ \\
\hline Response-cost (point loss) & $\mathrm{P}$ & $*$ & $*$ & $*$ \\
\hline $\begin{array}{l}\text { Low emotion or "private" } \\
\text { reprimands }\end{array}$ & $*$ & $*$ & $*$ & $*$ \\
\hline Stop clock & NA & $*$ & $*$ & $*$ \\
\hline Law enforcement fine or citation & NA & NA & $*$ & $*$ \\
\hline $\begin{array}{l}\text { Over-correction or positive } \\
\text { practice }\end{array}$ & $*$ & $*$ & $*$ & $*$ \\
\hline "Buzzer/noise training" & $\mathrm{P}$ & $*$ & $*$ & \\
\hline Non-verbal transition cues & $*$ & $*$ & $*$ & $*$ \\
\hline $\begin{array}{l}\text { Stop lights in school settings or } \\
\text { traffic settings }\end{array}$ & NA & $*$ & $*$ & $*$ \\
\hline Boundary cues and railings & $*$ & $*$ & $*$ & $*$ \\
\hline Cooperative, structured peer play & $\mathrm{P}$ & $*$ & $*$ & \\
\hline Self-modeling & $\mathrm{P}$ & $*$ & $*$ & $*$ \\
\hline Self-monitoring & NA & $*$ & $*$ & $*$ \\
\hline Paragraph shrinking & NA & $*$ & $*$ & $\mathrm{P}$ \\
\hline Errorless discrimination training & * & $*$ & $*$ & $*$ \\
\hline $\begin{array}{l}\text { Adjectival noun for belonging to } \\
\text { status group }\end{array}$ & $\mathrm{P}$ & $*$ & $*$ & $*$ \\
\hline
\end{tabular}


Table 2 continued

\begin{tabular}{|c|c|c|c|c|}
\hline & Infants & Children & Teens & Adults \\
\hline Public commitment & NA & $*$ & * & * \\
\hline "US" and "THEM" role framing & $\mathrm{P}$ & $*$ & $*$ & $*$ \\
\hline Graphic/node maps & NA & $*$ & $*$ & $*$ \\
\hline MI & NA & $\mathrm{P}$ & $*$ & $*$ \\
\hline $\begin{array}{l}\text { Media associating behavior with } \\
\text { "immediate" negative social } \\
\text { outcomes }\end{array}$ & NA & $\mathrm{P}$ & $*$ & $*$ \\
\hline $\begin{array}{l}\text { Pleasant greeting with or without } \\
\text { positive physical touch }\end{array}$ & $*$ & $*$ & $*$ & $*$ \\
\hline Massage, brushing or stroking & $*$ & $*$ & $*$ & $*$ \\
\hline Turtle technique & $\mathrm{P}$ & $*$ & NA & NA \\
\hline $\begin{array}{l}\text { Omega- } 3 \text { fatty acid } \\
\text { supplementation or increased } \\
\text { fish consumption }\end{array}$ & $*$ & $*$ & $*$ & $*$ \\
\hline $\begin{array}{l}\text { Zinc supplementation or dietary } \\
\text { consumption }\end{array}$ & $\mathrm{P}$ & $*$ & $*$ & $*$ \\
\hline $\begin{array}{l}\text { "Rough and tumble" free play/ } \\
\text { martial arts with higher status } \\
\text { conspecific }\end{array}$ & NA & $*$ & $*$ & $*$ \\
\hline Aerobic play or behavior & $\mathrm{P}$ & $*$ & $*$ & $*$ \\
\hline Nasal breathing & $\mathrm{P}$ & $*$ & * & $*$ \\
\hline Progressive muscle relaxation & NA & $*$ & $*$ & * \\
\hline
\end{tabular}

NA, not applicable; *, experimental evidence; $\mathrm{P}$, predicted utility

implemented the strategy at home. Peer-to-peer tutoring has effects that last from first-grade intervention through middle school (Greenwood 1991a, b). Omega-3 supplementation of cod liver oil during pregnancy has effects on children's cognitive development at least through age 4 . Emotional writing reduces or prevents medication use, healthcare visits, or continued unemployments months later (Richards et al. 2000; Smyth et al. 1999; Spera et al. 1994). Response slates-as opposed to having students raise their hands-improve performance on academic measures of retention, recall, and end-of-term tests for that content (Christle and Schuster 2003; Kellum et al. 2001). Finally, a 15-min motivational interview on paper has an 18-month lasting effect on the improvement of grades of high-risk African American students from seventh grade to ninth grade (Cohen et al. 2006).

Yet even if a kernel does not seem to have a lasting impact, we should not overlook its value. In numerous situations, parents, teachers, youth workers, and others need to influence a behavior. For example, if the only evidence for response slates was that they increased classroom participation (Christle and Schuster 2003; Kellum et al. 2001), they would be valuable to teachers who want to raise classroom participation. In general, providing people with simple and reliable ways of influencing behavior is an important benefit for them, even with no current evidence that the impact is long lasting. Put another way, if we wish to create a society with high levels of caring and effective guidance in all areas, the widespread dissemination of kernels could help in this quest.

Another concern might be that kernels needed daily or weekly are futile. Yet to exclude from the approved armamentarium of prevention any strategies that do not permanently change behavior seems odd both scientifically and practically. Such a stance would exclude taking a daily aspirin to prevent strokes and heart attacks; using UV lotion to prevent skin cancer before going outside; conducting daily physical activity to prevent obesity, health problems, and depression; using a car seat each trip to protect an infant, etc. From a contextual standpoint, behavior is always, to some extent, a function of the immediate environment (e.g., Biglan 1995). In order to ensure that the environment promotes prosocial behavior through kernels is a useful way to improve human wellbeing.

\section{Population-level Prevention}

The literature reports two tracks of parenting interventions: brief solution focused and general parent training, each with experimental evidence supporting its efficacy. Solution-focused parenting involves brief interventions that may be kernels like safe playing or good shopper; others may be to-the-point recipes for going to restaurants, bedwetting, cleaning up, doing homework, getting ready for bed, etc., showing experimentally controlled results (e.g., Dadds et al. 1984; Sanders et al. 1984). The more general strategies-8-to-12 week courses focusing on general parenting skills with high-risk populations-also have positive results (e.g., Hoath and Sanders 2002).

Recently, the U.S. Centers for Disease Control supported an RCT of a combined solution-focused and general-parenting skill model to prevent child abuse in 18 South Carolina counties (Prinz et al. accepted). In counties receiving the multilevel parenting model (e.g., Sanders et al. 2003), most of the utilization of services was for the solution-focused kernels or recipes and not for the intensive services, yet the intervention produced significant reductions in substantiated child maltreatment reports, child maltreatment-related medical injuries, and out-ofhome placements (Prinz et al. accepted). It may seem counterintuitive that these simple and narrowly focused strategies could produce such effects, but many acts of child maltreatment happen precisely during the types of activities addressed by the solution-focused interventions-getting ready, mealtimes, homework, chores, bedtimes, etc. The defusion of the brief kernel-like recipes to solve these problems for thousands of parents in these communities makes further sense when one understands that official reports of child physical maltreatment 
underestimate its prevalence by 40 times (Theodore et al. 2007), making logistics and staffing for intensive parenting courses clearly impractical and improbable for thousands of families at any given time in a community or county.

The South Carolina experiment suggests that providing individuals access to self-selected simple preventative strategies could have large implications for public health and safety. The study hints that science-based prevention of behavioral issues could be an individual consumer product. Currently, individuals cannot access best practice prevention programs, as they can consume products for child safety, such as car seats, bike helmets, or safety guards for electric sockets or kitchen cabinets.

Improving the Effectiveness of Prevention and Treatment

Eddy (2006) has noted that intervention research does not contribute to the extent it could to improve our understanding of basic psychological and social processes that interventions must target. In most cases, we have no models of preventive interventions to show which social or psychological processes they target, the effects of the intervention on those targets, and the effects of changes in these targets on outcomes. As a result, we have not developed a robust and generalizable theory of the key aspects of human functioning and the ways in which to affect them. We can therefore say little about how to construct new interventions in new problem areas and cannot easily communicate to nonscientists what they might do for novel problems. All we can say is "apply this program." However, often there are no evidence-based programs to apply.

A theoretical analysis that pinpoints specific procedures to influence behavior and psychological processes would stimulate research to refine and improve these component strategies and encourage creation of new, more effective programs, and practices. Specifying fundamental units of behavioral influence could point to components to add to the existing programs and provide building blocks for creating new and more powerful programs. We propose that kernels are candidate building blocks for a generalizable science of intervention and prevention. The next few paragraphs, therefore, loop back to the conditions that gave rise to the need for a taxonomy of active ingredients of science-based prevention and treatment (Embry 2004) and discussed early in this paper, showing how existing evidence-based programs can be analyzed or strengthened by kernels.

In order to illustrate how we created one evidencedbased program using kernels, we briefly outline the active ingredients of PeaceBuilders (Embry et al. 1996), constructed by using previously validated kernels (Embry et al. 1996; Embry 1997). Note we did not have the language for kernels then, but quite consciously used the principle of kernels in the program design. There were five core kernels in PeaceBuilders. First, the children and adults received a framing language repertoire via a self-modeling story kernel, which we had tested for its impact on behavior. Second, children and adults created a vision of peaceful behavior using a goal/node map kernel. Third, adults and children adopted an adjectival identity noun kernel, "I am a PeaceBuilder." Fourth, adults and children learned to use praise notes or "caught-you-being good" notes for reinforcing behaviors defined earlier in the selfmodeling stories. At the same time, adults learned to use the positive-home note kernel to support the reinforcement of these same peacebuilding behaviors. Fifth, classrooms and schools received public recognition and posting for engaging in peacebuilding behaviors or creating peacebuilding "inventions" each week. Weekly walk-throughs of the school allowed monitoring of these active kernels. This combination of kernels was tested in a randomized control design over several years, and showed reductions in actual violent injuries (Krug et al. 1997), increased social competence and resiliency measures, as well as reduced aggression and inattention (Flannery et al. 2003). It affected the high-risk students the most (Vazsonyi et al. 2004). The selection and use of kernels in PeaceBuilders is an example of how kernels can both construct an intervention and clearly specify the putative ingredients.

In order to illustrate how kernels can clarify why programs work, we examine the Good Behavior Game (GBG), not created with kernels in mind. The GBG has already increased cooperative on-task behavior in school significantly (Barrish et al. 1969; Medland and Stachnik 1972) and reduced antisocial behavior and smoking in adolescence and adulthood (Kellam et al. 2008, 1994; Kellam and Anthony 1998). Its core kernels include a response cost for negative behavior (e.g., Conyers et al. 2004); team competition (e.g., Beersma et al. 2003); public posting of results (e.g., Parsons 1982); and team rotations (deemed critical but with no supporting study). Additional kernels include a low emotional response to negative behaviors (e.g., Abramowitz et al. 1987), playing three games per day, and using beat the timer (e.g., Adams and Drabman 1995).

The GBG also provides an occasion to describe the utility of kernels in helping disseminate programs. Until 2003, when the first author started collaborating with Johns Hopkins, there was virtually no diffusion of the GBG based on Kellam's work or even earlier behavior analysis studies, beyond journal articles. Inspection, direct replication, and systematic replication in different settings of the GBG (Embry 2002) as implemented by Kellam and colleagues, pointed to several ways that planned dissemination and 
further testing underway at Johns Hopkins could strengthen it. First, it was necessary to stop edible reinforcers used by Kellam and colleagues, as social context and validity do not support this 20 years later. A switch to a kernel of prizes based on the Premack Principle (Andrews 1970; Homme et al. 1963; Hosie et al. 1974; Premack 1962; Van Hevel and Hawkins 1974) proved acceptable and reinforcing to children and adults alike.

Second, we added kernels to improve adoption, implementation, and maintenance of the GBG based on observations and consumer feedback. These included nonverbal cues (e.g., Cox et al. 2000; Rosenkoetter and Fowler 1986) to improve generalization and adoption of the Game and meaningful roles as differential reinforcement of other behaviors (e.g., Rutter 1981) to reduce accidental negative attention. Another includes setting generalization recipes for carrying over the GBG to hallways, restrooms, cafeteria, etc. (e.g., Fishbein and Wasik 1981) to improve generalization by students and acceptability by adults. Other kernels include symbolic self-modeling (e.g., Embry et al. 1996) to improve imitation of behavior and schoolhome notes (e.g., Kelley et al. 1988) for prompting family reinforcement and generalization of behavior to home. Others are peer-to-peer praise notes (e.g., Skinner et al. 2000) to improve social competence and reduce negative peer attention, and the good behavior lottery (e.g., Putnam et al. 2003) to increase generalization when not playing the Game. Inserting these kernels provided a more systematic approach to address the issues of diffusion of scientific innovation, raised by Rogers (1995), of relative advantage, compatibility, ease of use, trialability, and observability.

Kernels may also be useful in strengthening existing programs. Several investigations have noted problems replicating the results of Project Alert in community contexts (e.g., St. Pierre et al. 2005). In Houston, an agency requested assistance from the first author for improving implementation of Project Alert in the context of gym classes - they had never tested it scientifically but it was the only slot available in the school day. Attendance was poor and pre-post assessments did not show that the program affected the students. We recommended use of several kernels in order to make attendance more reinforcing and the lessons more participatory, and to create peer pressure for attendance: prize-bowl, random calling, peer-to-peer tutoring, tootle notes, response slates, pleasant greetings to students by program staff in the halls, and student jobs. In year-to-year comparisons, attendance doubled, increasing to $90 \%$ in most of the schools. Moreover, for the first time, students achieve the target scores for the post-tests proposed to measure dose and fidelity by the developers of Project Alert.

The analysis of kernels can also help construct new interventions by putting together a set of kernels that all appear relevant and useful for new problems. For example, methamphetamine addiction is a serious public-health problem and there is a dearth of evidence-based programs to reduce it (Embry et al. 2005). Table 3 outlines a potential community- or state-level response to methamphetamine use via evidenced-based kernels. The table tackles the huge public health problem that arises from meth-exposed infants or children who enter the medical, social service, and legal systems as well as intervention, prevention, and treatment issues associated with teens or adults using or at risk for using methamphetamine.

Of course, such a constructed program demands experimental evaluation via randomized trials or at least via quasiexperimental studies. At the same time, however, practitioners and policymakers desperate to deal with the methamphetamine problem must have a strategy, that, although not yet evaluated in an RCT, is composed of elements, each one shown in prior experimental work in RCT or interrupted time series to affect its target behaviors. The bundled kernels to address this public health and safety problem could face testing in an interrupted time-series design across neighborhoods, communities, or counties using naturally occurring archival data on meth-related crimes, arrests, emergency-room care use, or child removals.

The theoretical analysis of kernels also may help to develop new kernels. In essence, the framework suggests that, in any instance requiring altered behavior, it will pay to examine systematically whether it is possible to alter consequences or antecedents for the behavior, if it is possible to influence relational responding in ways that change the value of relevant behaviors, and finally, whether physiological interventions could alter the probability of behavior. A thorough understanding of existing kernels would contribute to the success of this effort.

Prevention science might also gain strength by mapping kernels onto risk and protective factors. For instance, much research points to early antisocial behavior, school bonding, and inadequate parental monitoring as predictors of various adverse outcomes (Arthur et al. 2002; Dekovic 1999; Duncan et al. 2000). Numerous kernels are relevant to affect these constructs. Examples include the percentage of students with meaningful roles in a day, the square footage of student work displayed on the walls, the number of peer-to-peer positive written notes, the caught-you-being good notes, or positive notes home (Rutter 1981). Articulating the kernels relevant to each risk or protective factor would provide practitioners with more precise guidance as to which kernels are most useful for altering key risk and protective factors.

Thinking in terms of kernels may also facilitate our identifying kernel-like practices that occur naturally in society, as has already happened in some cases. For example, epidemiological studies show that omega-3 
Table 3 Applying kernel to community-level methamphetamine addiction issues

\begin{tabular}{|c|c|c|c|}
\hline Kernel & Strategy and procedure & Sample citations & Quality of evidence \\
\hline $\begin{array}{l}\text { Prize bowl (contingency } \\
\text { management) for } \\
\text { sobriety and recovery }\end{array}$ & $\begin{array}{l}\text { Multiple contracts/grants to organizations } \\
\text { to recruit individuals at jails, ERs, } \\
\text { shelters plus thru existing courts, } \\
\text { clinics, faith-based organizations } \\
\text { w/monitoring of results across settings }\end{array}$ & $\begin{array}{l}\text { Petry and Martin (2002), Petry et al. } \\
\text { (2000, 2001a, b, c, 2004, 2005), } \\
\text { Rawson et al. (2006) }\end{array}$ & $\begin{array}{l}\text { Multiple RCT; } 1 \text { with } \\
\text { comparisons to proven } \\
\text { program }\end{array}$ \\
\hline Omega-3 supplements & $\begin{array}{l}2 \mathrm{~g} / \text { day to reduce comorbid depression, } \\
\text { bipolar disorder, aggression, plus CVD } \\
\text { symptoms, promoted at jails, clinics, } \\
\text { shelters, public health, and outreach } \\
\text { workers. Policy changed to support } \\
\text { addition to government formularies }\end{array}$ & $\begin{array}{l}\text { Freeman et al. (2006), Gesch et al. } \\
\text { (2002), Stoll et al. (2000) }\end{array}$ & $\begin{array}{l}\text { Cross-national epi; lab studies; } \\
\text { RCT with/without other meds }\end{array}$ \\
\hline $\begin{array}{l}\text { Kangaroo care for } \\
\text { infants }\end{array}$ & $\begin{array}{l}\text { Infants born to addicted moms or moved } \\
\text { to foster care (Conde-Agudelo et al. } \\
\text { 2003; Feldman and Eidelman 2003) } \\
\text { given to reduce developmental } \\
\text { problems; training of caseworkers, } \\
\text { nurses, doctors; added to program } \\
\text { policy standards }\end{array}$ & $\begin{array}{l}\text { Ferber and Makhoul (2004), } \\
\text { Ludington-Hoe et al. (2004), Priya } \\
\text { (2004) }\end{array}$ & $\begin{array}{l}\text { Lab studies for mechanisms; case } \\
\text { studies; randomized trials }\end{array}$ \\
\hline $\begin{array}{l}\text { Errorless compliance } \\
\text { training for exposed } \\
\text { children }\end{array}$ & $\begin{array}{l}\text { Toddlers/preschoolers neglected or abused } \\
\text { by drug-using parents receive errorless } \\
\text { compliance training by bio parent, } \\
\text { foster parent, and/or teacher; Policy } \\
\text { implemented via court order }\end{array}$ & $\begin{array}{l}\text { Ducharme (2003), Ducharme et al. } \\
\quad(2000,2001,2002,2003)\end{array}$ & $\begin{array}{l}\text { Empirical case studies; several } \\
\text { multiple baselines; randomized } \\
\text { control studies }\end{array}$ \\
\hline $\begin{array}{l}\text { Self-modeling for } \\
\text { exposed preschool } \\
\text { and elementary } \\
\text { children }\end{array}$ & $\begin{array}{l}\text { Exposed preschoolers and elementary } \\
\text { children under court petition or special } \\
\text { ed receive self-modeling videos or } \\
\text { digitally created storybooks for social } \\
\text { skills and behavior at home, foster care, } \\
\text { or care settings. Academic, social skills } \\
\text { and self-regulatory behaviors taught } \\
\text { related to developmental delays }\end{array}$ & $\begin{array}{l}\text { Clare et al. (2000), Hitchcock et al. } \\
\text { (2003), Kehle et al. (2002), } \\
\text { Lonnecker et al. (1994), Reamer } \\
\text { et al. (1998) }\end{array}$ & $\begin{array}{l}\text { Multiple single subject studies } \\
\text { using interrupted time-series } \\
\text { designs; meta analyses of } \\
\text { single subject studies }\end{array}$ \\
\hline $\begin{array}{l}\text { Community-wide adult } \\
\text { to child/youth } \\
\text { positive praise notes }\end{array}$ & $\begin{array}{l}\text { Local governments and school districts } \\
\text { promote community-wide praise notes } \\
\text { from adults to increased protective } \\
\text { factor of reinforcement of social } \\
\text { competence, which protect against } \\
\text { substance abuse and related antisocial } \\
\text { behaviors }\end{array}$ & $\begin{array}{l}\text { Gupta et al. (1990), Hutton (1983), } \\
\text { Kelley et al. (1988), McCain and } \\
\text { Kelley (1993), Taylor et al. (1984), } \\
\text { Embry et al. (1996) }\end{array}$ & $\begin{array}{l}\text { Multiple interrupted time-series } \\
\text { studies on individual level and } \\
\text { school level; a few RCT with } \\
\text { practice embedded }\end{array}$ \\
\hline $\begin{array}{l}\text { Red flag training for } \\
\text { exposed children or } \\
\text { teens with serious } \\
\text { emotional disturbance }\end{array}$ & $\begin{array}{l}\text { Dependency or delinquency court order or } \\
\text { special education plan includes Red } \\
\text { Flag procedure to reduce explosive } \\
\text { anger and aggression among children } \\
\text { exposed to drugs, neglect, or abuse }\end{array}$ & Ninness et al. (1995), Ninness (1991) & $\begin{array}{l}\text { Multiple interrupted time-series } \\
\text { designs }\end{array}$ \\
\hline MI for at-risk youth & $\begin{array}{l}\text { Juvenile justice, emergency room, and } \\
\text { school personnel conduct motivational } \\
\text { interviews for youth engaged in } \\
\text { problematic behaviors; supportive } \\
\text { policies and contracts issued }\end{array}$ & $\begin{array}{l}\text { Colby et al. (1998), Diamond et al. } \\
\text { (2002), Monti et al. (1999), Smith } \\
\text { (2004), Spirito et al. (2004), Stein } \\
\text { et al. (2006) }\end{array}$ & $\begin{array}{l}\text { Multiple randomized control } \\
\text { studies }\end{array}$ \\
\hline
\end{tabular}

consumption was associated with many important health and behavior outcomes, such as reduced CVD, depression, and homicide (Hibbeln 2001, 2002; Hibbeln et al. 2007; McGrath-Hanna et al. 2003; Tanskanen et al. 2001). Then intervention studies showed that changes in the consumption of omega- 3 reduced these types of adverse conditions (Freeman et al. 2006a; Gesch et al.
2002). In a similar vein, epidemiologists can use existing evidence about kernels to examine whether kernels occur naturally in social systems and benefit the population. Such research would strengthen the link between epidemiology and intervention research and practice, while strengthening empirically based theory about human development. 


\section{A Database Repository of Kernels}

In the interest of fostering the dissemination and further development of kernels, we propose a database repository of kernels, analogous to the human genome project, which might be called the behaviornome. Initially, it would contain the kernels that Table 1 lists and would enable people to describe additional kernels and empirical evidence regarding their effects. The database would allow a user to search for specific kernels or to identify a behavior and search for kernels relevant to influence the behavior. We are hopeful that this repository will provide detailed information about how kernels influence behavior, the circumstances in which they do or do not work, and any iatrogenic effects, potential positive or negative combinations of kernels not documented presently, variations of kernels related to cultures or other establishing conditions, and proximal and distal behavioral effects. In time, the database would have hyperlinks to PsychInfo or PubMed. We expect the repository to help reduce the cost of beneficially influencing behavior and improving the efficacy of prevention and treatment practice and theory.

\section{Summary}

Kernels are fundamental units of behavior-influence technology. They provide a wealth of resources for those trying to influence human behavior in beneficial ways. The four primary mechanisms of kernels are providing consequences for behavior, establishing antecedent stimuli for behavior, altering people's relational framing about targeted behaviors, and altering physiology that affects behavior. Understanding the range and effectiveness of kernels could contribute to the public-health goals of decreasing the prevalence of problems and increasing wellbeing. Kernels could provide behavior-influence agents with a wider array of effective practices. Denomination of kernels could clarify the active components of existing programs. It could also lead to the development of new programs composed entirely of effective kernels. Finally, it could contribute to the development of an empirically based theory of behavior influence consistent with current knowledge of risk and protective factors and that clarifies the mechanisms through which behavior influence occurs.

Acknowledgments The inspiration for this paper comes from conversations over 20 years ago with the late Dr. Donald M. Baer, one of the founders of applied behavior analysis, and from a presentation by Dr. Shep Kellam in 1998 who proved that a very simple behavior analysis protocol could have lifetime effects. The authors prepared this manuscript under the auspices of the Center on Early Adolescence in Eugene, Oregon, NIDA Grant Number P30 DA018760. Dr. Biglan is the Director and Principal Investigator and
Dr. Embry is a co-investigator of the Center. The authors express their appreciation to co-investigators, Drs. Shawn Boles and Brian Flay, for their suggestions and insights for improving the manuscript. We also wish to thank Christine Cody for editorial assistance and for help in preparing the very complex manuscript.

Open Access This article is distributed under the terms of the Creative Commons Attribution Noncommercial License which permits any noncommercial use, distribution, and reproduction in any medium, provided the original author(s) and source are credited.

\section{References}

Aase, H., \& Sagvolden, T. (2006). Infrequent, but not frequent, reinforcers produce more variable responding and deficient sustained attention in young children with attention-deficit/ hyperactivity disorder (ADHD). Journal of Child Psychology and Psychiatry, and Allied Disciplines, 47(5), 457-471. doi: 10.1111/j.1469-7610.2005.01468.x.

Abbott, R. D., O’Donnell, J., Hawkins, J. D., Hill, K. G., Kosterman, R., \& Catalano, R. F. (1998). Changing teaching practices to promote achievement and bonding to school. The American Journal of Orthopsychiatry, 68, 542-552. doi:10.1037/h0080363.

Abramowitz, A. J., O'Leary, S. G., \& Futtersak, M. W. (1988). The relative impact of long and short reprimands on children's offtask behavior in the classroom. Behavior Therapy, 19(2), 243247. doi:10.1016/S0005-7894(88)80046-7.

Abramowitz, A. J., O'Leary, S. G., \& Rosen, L. A. (1987). Reducing off-task behavior in the classroom: A comparison of encouragement and reprimands. Journal of Abnormal Child Psychology, 15(2), 153-163. doi:10.1007/BF00916345.

Acker, M. M., \& O'Leary, S. G. (1987). Effects of reprimands and praise on appropriate behavior in the classroom. Journal of Abnormal Child Psychology, 15(4), 549-557. doi:10.1007/ BF00917240.

Adams, C. D., \& Drabman, R. S. (1995). Improving morning interactions: Beat-the-Buzzer with a boy having multiple handicaps. Child and Family Behavior Therapy, 17(3), 13-26. doi: 10.1300/J019v17n03_02.

Agathon, M., \& Granjus, M. (1976). Behavior modification of a character disorder. Perspectives Psychiatriques, 27(58), 1-274.

Agran, M., Sinclair, T., Alper, S., Cavin, M., Wehmeyer, M., \& Hughes, C. (2005). Using self-monitoring to increase followingdirection skills of students with moderate to severe disabilities in general education. Education and Training in Developmental Disabilities, 40(1), 3-13.

Agras, W. S., Jacob, R. G., \& Lebedeck, M. (1980). The California drought: A quasi-experimental analysis of social policy. Journal of Applied Behavior Analysis, 13, 561-570. doi:10.1901/jaba. 1980.13-561.

Akhondzadeh, S., Mohammadi, M. R., \& Khademi, M. (2004). Zinc sulfate as an adjunct to methylphenidate for the treatment of attention deficit hyperactivity disorder in children: A double blind and randomized trial. BMC Psychiatry, 4, 9. doi: 10.1186/1471-244X-4-9.

Akhtar, S., Moulin, C. J. A., \& Bowie, P. C. W. (2006). Are people with mild cognitive impairment aware of the benefits of errorless learning? Neuropsychological Rehabilitation, 16(3), 329-346. doi:10.1080/09602010500176674.

Allen, L. D., \& Bryant, M. C. (1985). A multielement analysis of contingent versus contingent-interrupted music. Applied Research in Mental Retardation, 6(1), 87-97. doi:10.1016/S02703092(85)80024-2. 
Allsopp, D. H. (1997). Using classwide peer tutoring to teach beginning algebra problem-solving skills in heterogeneous classrooms. Remedial and Special Education, 18(6), 367-379.

Anderson, G. J., \& Connor, W. E. (1989). On the demonstration of omega-3 essential-fatty-acid deficiency in humans. The American Journal of Clinical Nutrition, 49(4), 585-587.

Anderson, V., \& Merrett, F. (1997). The use of correspondence training in improving the in-class behaviour of very troublesome secondary school children. Educational Psychology, 17(3), 313328. doi:10.1080/0144341970170306

Andrews, H. B. (1970). The systematic use of the Premack principle in modifying classroom behaviors. Child Study Journal, 1(2), 74-79.

Ankjaer-Jensen, A., \& Sejr, T. E. (1994). Costs of the treatment of enuresis nocturna. Health economic consequences of alternative methods in the treatment of enuresis nocturna. Ugeskrift for Laeger, 156(30), 4355-4360.

Antunes, H. K. M., Stella, S. R. G, Santos, R. F., Bueno, O. F. A., \& de Mello, M. T. 1. (2005). Depression, anxiety and quality of life scores in seniors after an endurance exercise program. Revista Brasileira de Psiquiatria, 27(4), 266-271. doi:10.1590/S151644462005000400003.

Appels, A., Bar, F., Lasker, J., Flamm, U., \& Kop, W. (1997). The effect of a psychological intervention program on the risk of a new coronary event after angioplasty: A feasibility study. Journal of Psychosomatic Research, 43(2), 209-217. doi: 10.1016/S0022-3999(97)00022-6.

Arnold, L. E., Bozzolo, H., Hollway, J., Cook, A., DiSilvestro, R. A., Bozzolo, D. R., et al. (2005). Serum zinc correlates with parentand teacher- rated inattention in children with attention-deficit/ hyperactivity disorder. Journal of Child and Adolescent Psychopharmacology, 15(4), 628-636. doi:10.1089/cap.2005.15.628.

Arnold, L. E., \& DiSilvestro, R. A. (2005). Zinc in attention-deficit/ hyperactivity disorder. Journal of Child and Adolescent Psychopharmacology, 15(4), 619-627. doi:10.1089/cap.2005.15.619.

Arthur, M. W., Hawkins, J. D., Pollard, J. A., Catalano, R. F., \& Baglioni, A. J. (2002). Measuring risk and protective factors for substance use, delinquency, and other adolescent problem behaviors: Communities that care youth survey. Evaluation Review, 26(6), 575-601. doi:10.1177/019384102237850.

Atlantis, E., Chow, C.-M., Kirby, A., \& Singh, M. F. (2004). An effective exercise-based intervention for improving mental health and quality of life measures: A randomized controlled trial. Preventive Medicine, 39(2), 424-434. doi:10.1016/j.ypmed. 2004.02.007.

Backon, J. (1990). Forced unilateral nostril breathing: A technique that affects brain hemisphericity and autonomic activity. Brain and Cognition, 12(1), 155-157. doi:10.1016/0278-2626(90)90011-C.

Ball, T. S., \& Irwin, A. E. (1976). A portable, automated device applied to training a hyperactive child. Journal of Behavior Therapy and Experimental Psychiatry, 7(2), 185-187. doi: 10.1016/0005-7916(76)90082-3.

Barker, J. B., \& Jones, M. V. (2006). Using hypnosis, technique refinement, and self-modeling to enhance self-efficacy: A case study in cricket. The Sport Psychologist, 20(1), 94-110.

Barmann, B. C., \& Croyle-Barmann, C. (1980). Use of contingentinterrupted music in the treatment of disruptive behavior while riding a bus. Psychological Reports, 47, 269-270.

Barmann, B. C., Croyle-Barmann, C., \& McLain, B. (1980). The use of contingent-interrupted music in the treatment of disruptive bus-riding behavior. Journal of Applied Behavior Analysis, 13(4), 693-698. doi:10.1901/jaba.1980.13-693.

Barnes, D., Healy, O., \& Hayes, S. C. (2000). Relational frame theory and the relational evaluation procedure: Approaching human language as derived relational responding. In J. C. Leslie \& D.
Blackman (Eds.), Experimental and applied analysis of human behavior (pp. 149-180). Reno, NV: Context Press.

Barrish, H. H., Saunders, M., \& Wolf, M. M. (1969). Good behavior game: Effects of individual contingencies for group consequences on disruptive behavior in a classroom. Journal of Applied Behavior Analysis, 2, 119-124. doi:10.1901/jaba. 1969.2-119.

Bay-Hinitz, A. K., Peterson, R. F., \& Quilitch, H. R. (1994). Cooperative games: a way to modify aggressive and cooperative behaviors in young children. Journal of Applied Behavior Analysis, 27(3), 435-446. doi:10.1901/jaba.1994.27-435.

Bean, T. W., \& Steenwyk, F. L. (1984). The effect of three forms of summarization instruction on sixth graders' summary writing and comprehension. Journal of Reading Behavior, 16(4), 297-306.

Beersma, B., Hollenbeck, J. R., Humphrey, S. E., Moon, H., Conlon, D. E., \& Ilgen, D. R. (2003). Cooperation, competition, and team performance: toward a contingency approach. Academy of Management Journal, 46(5), 572-590.

Bell, R. M., Ellickson, P. L., \& Harrison, E. R. (1993). Do drug prevention effects persist into high school? How project ALERT did with ninth graders. Preventive Medicine, 22, 463-483. doi: 10.1006/pmed.1993.1038.

Bellamy, T., \& Sontag, E. (1973). Use of group contingent music to increase assembly line production rates of retarded students in a simulated sheltered workshop. Journal of Music Therapy, 10(3), $125-136$

Ben Shalom, D. (2000). Developmental depersonalization: The prefrontal cortex and self-functions in autism. Consciousness and Cognition, 9(3), 457-460. doi:10.1006/ccog.2000.0453.

Bennett, W., Petraitis, C., D'Anella, A., \& Marcella, S. (2003). Pharmacists' knowledge and the difficulty of obtaining emergency contraception. Contraception, 68(4), 261-267. doi: 10.1016/S0010-7824(03)00180-X.

Berlin, A. A., Kop, W. J., \& Deuster, P. A. (2006). Depressive mood symptoms and fatigue after exercise withdrawal: The potential role of decreased fitness. Psychosomatic Medicine, 68(2), 224230. doi:10.1097/01.psy.0000204628.73273.23.

Bernstein, J., Bernstein, E., Tassiopoulos, K., Heeren, T., Levenson, S., \& Hingson, R. (2005). Brief motivational intervention at a clinic visit reduces cocaine and heroin use. Drug and Alcohol Dependence, 77(1), 49-59. doi:10.1016/j.drugalcdep.2004.07.006.

Beyth-Marom, R., Austin, L., Fischhoff, B., Palmgren, C., \& Quadrel, M. J. (1993). Perceived consequences of risky behaviors. Developmental Psychology, 29, 549-563. doi:10.1037/00121649.29.3.549.

Biglan, A. (1995). Changing cultural practices: A contextualist framework for intervention research. Reno, NV: Context Press.

Biglan, A. (2004). Contextualism and the development of effective prevention practices. Prevention Science, 5, 15-21. doi:10.1023/ B:PREV.0000013977.07261.5a.

Biglan, A., Brennan, P. A., Foster, S. L., Holder, H. D., Miller, T. L., Cunningham, P. B., et al. (2004). Helping adolescents at risk: Prevention of multiple problem behaviors. New York: Guilford.

Biglan, A., \& Hayes, S. C. (1996). Should the behavioral sciences become more pragmatic? The case for functional contextualism in research on human behavior. Applied and Preventive Psychology, 5, 47-57. doi:10.1016/S0962-1849(96)80026-6.

Bilici, M., Yildirim, F., Kandil, S., Bekaroglu, M., Yildirmis, S., Deger, O., et al. (2004). Double-blind, placebo-controlled study of zinc sulfate in the treatment of attention deficit hyperactivity disorder. Progress in Neuro-Psychopharmacology and Biological Psychiatry, 28, 181-190. doi:10.1016/j.pnpbp.2003.09.034.

Bjorklund, D. F., \& Brown, R. D. (1998). Physical play and cognitive development: Integrating activity, cognition, and education. Child Development, 69(3), 604-606. doi:10.2307/1132190. 
Bledsoe, K. L. (2003). Effectiveness of drug prevention programs designed for adolescents of color: A meta-analysis. US: ProQuest Information \& Learning.

Blick, D. W., \& Test, D. W. (1987). Effects of self-recording on highschool students' on-task behavior. Learning Disability Quarterly, 10(3), 203-213. doi:10.2307/1510493.

Block, R. A., Arnott, D. P., Quigley, B., \& Lynch, W. C. (1989). Unilateral nostril breathing influences lateralized cognitive performance. Brain and Cognition, 9(2), 181-190. doi: 10.1016/0278-2626(89)90028-6.

Blue, F. R. (1979). Aerobic running as a treatment for moderate depression. Perceptual and Motor Skills, 48(1), 228.

Blumenfeld, H., \& Eisenfeld, L. (2006). Does a mother singing to her premature baby affect feeding in the neonatal intensive care unit? Clinical Pediatrics, 45(1), 65-70. doi:10.1177/00099 2280604500110.

Blumenthal, J. A., Sherwood, A., Babyak, M. A., Watkins, L. L., Waugh, R., Georgiades, A., et al. (2005). Effects of exercise and stress management training on markers of cardiovascular risk in patients with ischemic heart disease: A randomized controlled trial. Journal of the American Medical Association, 293(13), 1626-1634. doi:10.1001/jama.293.13.1626.

Borfitz, D. (2001). Is a "mystery shopper" lurking in your waiting room? Medical Economics, 78(10), 63-64.

Boulton, M. J., \& Smith, P. K. (1989). Rough and tumble play in children: Research and theory. Infancia y Aprendizaje, 48, 79-91.

Boyle, J. R., \& Hughes, C. A. (1994). Effects of self-monitoring and subsequent fading of external prompts on the on-task behavior and task productivity of elementary students with moderate mental retardation. Journal of Behavioral Education, 4(4), 439-457. doi:10.1007/BF01539544.

Bratton, S. C., Ray, D., Rhine, T., \& Jones, L. (2005). The efficacy of play therapy with children: A meta-analytic review of treatment outcomes. Professional Psychology, Research and Practice, 36(4), 376-390. doi:10.1037/0735-7028.36.4.376.

Bray, M. A., \& Kehle, T. J. (2001). Long-term follow-up of selfmodeling as an intervention for stuttering. School Psychology Review, 30(1), 135-141.

Briscoe, R. V., Hoffman, D. B., \& Bailey, J. S. (1975). Behavioral community psychology: Training a community board to problem solve. Journal of Applied Behavior Analysis, 8(2), 157-168. doi: 10.1901/jaba.1975.8-157.

Browder, D. M., Hines, C., McCarthy, L. J., \& Fees, J. (1984). A treatment package for increasing sight word recognition for use in daily living skills. Education and Training of the Mentally Retarded, 19(3), 191-200.

Brown, D., \& Frank, A. R. (1990). "Let me do it": Self-monitoring in solving arithmetic problems. Education and Treatment of Children, 13(3), 239-248.

Buggey, T. (1995). An examination of the effectiveness of videotaped self-modeling in teaching specific linguistic structures to preschoolers. Topics in Early Childhood Special Education, 15(4), 434-458.

Buggey, T. (2005). Video self-modeling applications with students with autism spectrum disorder in a small private school setting. Focus on Autism and Other Developmental Disabilities, 20(1), 52-63. doi:10.1177/10883576050200010501.

Buggey, T., Toombs, K., Gardener, P., \& Cervetti, M. (1999). Training responding behaviors in students with autism: Using videotaped self-modeling. Journal of Positive Behavior Interventions, 1(4), 205-214. doi:10.1177/109830079900100403.

Burch, M. R., Clegg, J. C., \& Bailey, J. S. (1987). Automated contingent reinforcement of correct posture. Research in Developmental Disabilities, 8(1), 15-20. doi:10.1016/0891-4222(87) 90037-0.
Burgess, D., Haney, B., Snyder, M., Sullivan, J. L., \& Transue, J. E. (2000). Rocking the vote: Using personalized messages to motivate voting among young adults. Public Opinion Quarterly, 64(1), 29-52. doi:10.1086/316758.

Burke, B. L., Arkowitz, H., \& Menchola, M. (2003). The efficacy of motivational interviewing: A meta-analysis of controlled clinical trials. Journal of Consulting and Clinical Psychology, 71(5), 843-861. doi:10.1037/0022-006X.71.5.843.

Burn, S. M., \& Oskamp, S. (1986). Increasing community recycling with persuasive communication and public commitment. Journal of Applied Social Psychology, 16, 29-41. doi:10.1111/j.15591816.1986.tb02276.x.

Cabello, B., \& Terrell, R. (1994). Making students feel like family: How teachers create warm and caring classroom climates. Journal of Classroom Interaction, 29(1), 17.

Campbell, J. M. (2004). Statistical comparison of four effect sizes for single-subject designs. Behavior Modification, 28(2), 234-246. doi: $10.1177 / 0145445503259264$.

Carey, R. G., \& Bucher, B. D. (1986). Positive practice overcorrection. Effects of reinforcing correct performance. Behavior Modification, 10(1), 73-92. doi:10.1177/01454455860101005.

Carlsson, A., \& Lundkvist, S. O. (1992). Road user effects of alternative roadway painting on a major road. VTI Meddelande 687. Linkoping: VTI Swedish Road \& Transport Research Institute.

Carr, S. C., \& Punzo, R. P. (1993). The effects of self-monitoring of academic accuracy and productivity on the performance of students with behavioral disorders. Behavioral Disorders, 18(4), 241-250.

Cavalier, A. R., Ferretti, R. P., \& Hodges, A. E. (1997). Selfmanagement within a classroom token economy for students with learning disabilities. Research in Developmental Disabilities, 18(3), 167-178. doi:10.1016/S0891-4222(96)00045-5.

Cevasco, A. M., \& Grant, R. E. (2005). Effects of the pacifier activated lullaby on weight gain of premature infants. Journal of Music Therapy, 42(2), 123-139.

Chassin, L., Presson, C. C., \& Sherman, S. J. (1990). Social psychological contributions to the understanding and prevention of adolescent cigarette smoking. Personality and Social Psychology Bulletin, 16(1), 133-151. doi:10.1177/0146167290161010.

Chen, X. P., \& Komorita, S. S. (1994). The effects of communication and commitment in a public goods social dilemma. Organizational Behavior and Human Decision Processes, 60, 367-386. doi:10.1006/obhd.1994.1090.

Choenarom, C., Williams, R. A., \& Hagerty, B. M. (2005). The role of sense of belonging and social support on stress and depression in individuals with depression. Archives of Psychiatric Nursing, 19(1), 18-29. doi:10.1016/j.apnu.2004.11.003.

Christle, C. A., \& Schuster, J. W. (2003). The effects of using response cards on student participation, academic achievement, and on-task behavior during whole-class, math instruction. Journal of Behavioral Education, 12, 147-165. doi:10.1023/ A: 1025577410113.

Clare, S. K., Jenson, W. R., Kehle, T. J., \& Bray, M. A. (2000). Selfmodeling as a treatment for increasing on-task behavior. Psychology in the Schools, 37(6), 517-522. doi:10.1002/15206807(200011)37:6<517::AID-PITS4>3.0.CO;2-Y.

Clark, E., Beck, D., Sloane, H., Goldsmith, D., Jenson, W., Bowen, J., et al. (1993). Self-modeling with preschoolers: Is it different? School Psychology International, 14(1), 83-89. doi: 10.1177/0143034393141006.

Clark, E., Kehle, T. J., Jenson, W. R., \& Beck, D. E. (1992). Evaluation of the parameters of self-modeling interventions. School Psychology Review, 21(2), 246-254.

Clarke, M. A., Bray, M. A., Kehle, T. J., \& Truscott, S. D. (2001). A school-based intervention designed to reduce the frequency of 
tics in children with Tourette's syndrome. School Psychology Review, 30(1), 11-22.

Clement, P. W. (1986). Behavioral approaches to anger management training. Journal of Psychology and Christianity, 5(4), 41-49.

Cohen, G. L., Garcia, J., Apfel, N., \& Master, A. (2006). Reducing the racial achievement gap: A social-psychological intervention. Science, 313(5791), 1307-1310. doi:10.1126/science.1128317.

Colby, S. M., Monti, P. M., Barnett, N. P., Rohsenow, D. J., Weissman, K., Spirito, A., et al. (1998). Brief motivational interviewing in a hospital setting for adolescent smoking: A preliminary study. Journal of Consulting and Clinical Psychology, 66(3), 574-578. doi:10.1037/0022-006X.66.3.574.

Collier, C. R., Czuchry, M., Dansereau, D. F., \& Pitre, U. (2001). The use of node-link mapping in the chemical dependency treatment of adolescents. Journal of Drug Education, 31, 305. doi: 10.2190/GMC2-K3XX-XLHF-K2J0.

Collins, R. W. (1973). Importance of the bladder-cue buzzer contingency in the conditioning treatment for enuresis. Journal of Abnormal Psychology, 82(2), 299-308. doi:10.1037/h0035171.

Conde-Agudelo, A., Diaz-Rossello, J. L., Belizan, J. M. (2003). Kangaroo mother care to reduce morbidity and mortality in low birthweight infants. Cochrane Database of Systematic Reviews (Online : Update Software), (2), CD002771. Update of Cochrane Database Syst Rev. 2000; (4):CD002771; PMID: 11034759.

Conyers, C., Miltenberger, R. G., Maki, A., Barenz, R., Jurgens, M., Sailer, A., et al. (2004). A comparison of response cost and differential reinforcement of other behavior to reduce disruptive behavior in a preschool classroom. Journal of Applied Behavior Analysis, 37(3), 411-415. doi:10.1901/jaba.2004.37-411.

Conyers, C., Miltenberger, R., Romaniuk, C., Kopp, B., \& Himle, M. (2003). Evaluation of DRO schedules to reduce disruptive behavior in a preschool classroom. Child and Family Behavior Therapy, 25(3), 1-6. doi:10.1300/J019v25n03_01.

Cook, M., \& Freethy, M. (1973). The use of music as a positive reinforcer to eliminate complaining behavior. Journal of Music Therapy, 10(4), 213-216.

Cotter, V. W. (1971). Effects of music on performance of manual tasks with retarded adolescent females. American Journal of Mental Deficiency, 76(2), 242-248.

Cowen, R. J., Jones, F. H., \& Bellack, A. S. (1979). Grandma's rule with group contingencies: A cost-efficient means of classroom management. Behavior Modification, 3(3), 397-418. doi: 10.1177/014544557933006.

Cox, B. S., Cox, A. B., \& Cox, D. J. (2000). Motivating signage prompts safety belt use among drivers exiting senior communities. Journal of Applied Behavior Analysis, 33, 635-638. doi: 10.1901/jaba.2000.33-635.

Crews, D. J., Lochbaum, M. R., \& Landers, D. M. (2004). Aerobic physical activity effects on psychological well-being in lowincome Hispanic children. Perceptual and Motor Skills, 98(1), 319-324. doi:10.2466/PMS.98.1.319-324.

Crisp, A. H., Sireling, L. I., \& Faizey, J. (1984). Nocturnal activity and the enuresis alarm device. Postgraduate Medical Journal, 60(702), 280-281.

Czuchry, M., \& Dansereau, D. F. (1996). Node-link mapping as an alternative to traditional writing assignments in undergraduate psychology courses. Teaching of Psychology (Columbia, Mo.), 23(2), 91. doi:10.1207/s15328023top2302_4.

Czuchry, M., \& Dansereau, D. F. (1999). Node-link mapping and psychological problems: Perceptions of a residential drug abuse treatment program for probationers. Journal of Substance Abuse Treatment, 17(4), 321. doi:10.1016/S0740-5472(99)00013-6.

Czuchry, M., \& Dansereau, D. (2003). A model of the effects of nodelink mapping on drug abuse counseling. Addictive Behaviors, 28(3), 537. doi:10.1016/S0306-4603(01)00252-0.
Czuchry, M., Dansereau, D. F., Dees, S. M., \& Simpson, D. D. (1995). The use of node-link mapping in drug abuse counseling: The role of attentional factors. Journal of Psychoactive Drugs, 27(2), 161.

Dadds, M. R., Sanders, M. R., \& Bor, B. (1984). Training children to eat independently: Evaluation of mealtime management training for parents. Behavioural Psychotherapy, 12(4), 356-366.

Dalton, T., Martella, R. C., \& Marchand-Martella, N. E. (1999). The effects of a self-management program in reducing off-task behavior. Journal of Behavioral Education, 9, 157-176. doi: 10.1023/A:1022183430622.

Dansereau, D. F., Dees, S. M., Greener, J. M., \& Simpson, D. D. (1995). Node-link mapping and the evaluation of drug abuse counseling sessions. Psychology of Addictive Behaviors, 9, 195. doi:10.1037/0893-164X.9.3.195.

Dansereau, D. F., Joe, G. W., \& Simpson, D. D. (1993). Node-link mapping: A visual representation strategy for enhancing drug abuse counseling. Journal of Counseling Psychology, 40(4), 385. doi:10.1037/0022-0167.40.4.385.

Davis, R. A. (1979). The impact of self-modeling on problem behaviors in school-age children. School Psychology Review, $8(1), 128-132$.

Davis, W. B., Wieseler, N. A., \& Hanzel, T. E. (1980). Contingent music in management of rumination and out-of-seat behavior in a profoundly mentally retarded institutionalized male. Mental Retardation, 18(1), 43-45.

de Haas-Warner, S. J. (1991). Effects of self-monitoring on preschoolers' on-task behavior: A pilot study. Topics in Early Childhood Special Education, 11(2), 59-73.

de Waard, D., \& Rooijers, T. (1994). An experimental study to evaluate the effectiveness of different methods and intensities of law enforcement on driving speed on motorways. Accident Analysis and Prevention, 26(6), 751-765. doi: 10.1016/0001-4575(94)90052-3.

Dees, S. M., Dansereau, D. F., \& Simpson, D. D. (1994). A visual representation system for drug abuse counselors. Journal of Substance Abuse Treatment, 11(6), 517. doi:10.1016/07405472(94)90003-5.

Dekovic, M. (1999). Risk and protective factors in the development of problem behavior during adolescence. Journal of Youth and Adolescence, 28(6), 667-685. doi:10.1023/A:1021635516758.

Dellatan, A. K. (2003). The use of music with chronic food refusal: A case study. Music Therapy Perspectives, 21(2), 105-109.

Delquadri, J. C., Greenwood, C. R., Stretton, K., \& Hall, R. V. (1983). The peer tutoring spelling game: A classroom procedure for increasing opportunity to respond and spelling performance. Education and Treatment of Children, 6(3), 225-239.

DeMartini-Scully, D., Bray, M. A., \& Kehle, T. J. (2000). A packaged intervention to reduce disruptive behaviors in general education students. Psychology in the Schools, 37, 149-156. doi:10.1002/ (SICI)1520-6807(200003)37:2<149::AID-PITS6>3.0.CO;2-K.

Derzon, J., Jimerson, S. R., \& Furlong, M. (2006). How effective are school-based violence prevention programs in preventing and reducing violence and other antisocial behaviors? A metaanalysis. In Handbook of school violence and school safety: From research to practice (pp. 429-441). Mahwah, NJ: Erlbaum.

Derzon, J. H., Sale, E., Springer, J. F., \& Brounstein, P. (2005). Estimating intervention effectiveness: Synthetic projection of field evaluation results. The Journal of Primary Prevention, 26, 321-343. doi:10.1007/s10935-005-5391-5.

Deutsch, H., Parks, A. L., \& Aylesworth, J. (1976). The use of contingent music to increase on-task academic behavior in children with emotional problems. Behavioral Engineering, 3(3), 77-79. 
Diamond, G., Godley, S. H., Liddle, H. A., Sampl, S., Webb, C., Tims, F. M., et al. (2002). Five outpatient treatment models for adolescent marijuana use: A description of the cannabis youth treatment interventions. Addiction (Abingdon, England), 97(Suppl 1), 70-83. doi:10.1046/j.1360-0443.97.s01.3.x.

Diego, M. A., Field, T., Hernandez-Reif, M., Shaw, J. A., Rothe, E. M., Castellanos, D., et al. (2002). Aggressive adolescents benefit from massage therapy. Adolescence, 37, 597.

DiFilippo, J. M., \& Overholser, J. C. (1999). Cognitive-behavioral treatment of panic disorder: Confronting situational precipitants. Journal of Contemporary Psychotherapy, 29(2), 99-113. doi: 10.1023/A: 1021952614479

Downs, J. S., Murray, P. J., de Bruin, W.n. B., Penrose, J., Palmgren, C., \& Fischhoff, B. (2004). Interactive video behavioral intervention to reduce adolescent females' STD risk: A randomized controlled trial. Social Science and Medicine, 59(8), 1561-1572. doi:10.1016/j.socscimed.2004.01.032.

Dowrick, P. W. (1999). A review of self modeling and related interventions. Applied and Preventive Psychology, 8(1), 23-39. doi:10.1016/S0962-1849(99)80009-2.

Dowrick, P. W., Kim-Rupnow, W. S., \& Power, T. J. (2006). Video feed-forward for reading. The Journal of Special Education, 39(4), 194-207. doi:10.1177/00224669060390040101.

Doyne, E. J., Chambless, D. L., \& Beutler, L. E. (1983). Aerobic exercise as a treatment for depression in women. Behavior Therapy, 14(3), 434-440. doi:10.1016/S0005-7894(83)80106-3.

Drabman, R. S., \& Creedon, D. L. (1979). Beat the buzzer. Child Behavior Therapy, 1, 295-296.

Ducharme, J. M. (2003). "Errorless" rehabilitation: strategies of proactive intervention for individuals with brain injury and their children. The Journal of Head Trauma Rehabilitation, 18(1), 88. doi:10.1097/00001199-200301000-00009.

Ducharme, J. M., Atkinson, L., \& Poulton, L. (2000). Success-based, noncoercive treatment of oppositional behavior in children from violent homes. Journal of the American Academy of Child and Adolescent Psychiatry, 39(8), 995. doi:10.1097/00004583200008000-00014.

Ducharme, J. M., Atkinson, L., \& Poulton, L. (2001). Errorless complicance training with physically abusive mothers: A singlecase approach. Child Abuse and Neglect, 25(6), 855. doi: 10.1016/S0145-2134(01)00243-5.

Ducharme, J. M., Davidson, A., \& Rushford, N. (2002). Treatment of oppositional behavior in children of parents with brain injury and chronic pain. Journal of Emotional and Behavioral Disorders, 10(4), 241. doi:10.1177/10634266020100040601.

Ducharme, J. M., \& Drain, T. L. (2004). Errorless academic compliance training: Improving generalized cooperation with parental requests in children with autism. Journal of the American Academy of Child and Adolescent Psychiatry, 43, 163-171. doi:10.1097/00004583-200402000-00011.

Ducharme, J. M., Harris, K., Milligan, K., \& Pontes, E. (2003). Sequential evaluation of reinforced compliance and graduated request delivery for the treatment of noncompliance in children with developmental disabilities. Journal of Autism and Developmental Disorders, 33(5), 519. doi:10.1023/A:1025831528809.

Duncan, S. C., Duncan, T. E., \& Strycker, L. A. (2000). Risk and protective factors influencing adolescent problem behavior: A multivariate latent growth curve analysis. Annals of Behavioral Medicine, 22(2), 103-109. doi:10.1007/BF02895772.

Dunn, A. L., Trivedi, M. H., Kampert, J. B., Clark, C. G., \& Chambliss, H. O. (2005). Exercise treatment for depression: Efficacy and dose response. American Journal of Preventive Medicine, 28(1), 1-8. doi:10.1016/j.amepre.2004.09.003.

Dunn, A. L., Trivedi, M. H., \& O'Neal, H. A. (2001). Physical activity dose-response effects on outcomes of depression and anxiety. Medicine and Science in Sports and Exercise, 33, S587S597. doi:10.1097/00005768-200106001-00027.

DuPaul, G. J., Ervin, R. A., Hook, C. L., \& McGoey, K. E. (1998). Peer tutoring for children with attention deficit hyperactivity disorder: Effects on classroom behavior and academic performance. Journal of Applied Behavior Analysis, 31(4), 579-592. doi:10.1901/jaba.1998.31-579.

Dustman, R. E., Ruhling, R. O., Russell, E. M., Shearer, D. E., Bonekat, H. W., Shigeoka, J. W., et al. (1984). Aerobic exercise training and improved neuropsychological function of older adults. Neurobiology of Aging, 5(1), 35-42. doi:10.1016/01974580(84)90083-6.

Eddy, J. M. (2006). The need for a paradigm shift in preventive intervention research. Invited Address to the 14th Annual Meeting of the Society for Prevention Research. San Antonio, TX, May 2006.

Edwards, K. A., \& Johnston, R. (1977). Increasing greeting and farewell responses in high school students by a bus driver. Education \& Treatment of Children, 1(1), 9-18.

Egeland, G. M., Meyer, H. E., Selmer, R., Tverdal, A., \& Vollset, S. E. (2001). Cod liver oil consumption, smoking, and coronary heart disease mortality: three counties, Norway. International Journal of Circumpolar Health, 60(2), 143-149.

Egeland, B., \& Winer, K. (1974). Teaching children to discriminate letters of the alphabet through errorless discrimination training. Journal of Reading Behavior, 6(2), 143-150.

Eisenstein, S. R. (1974). Effect of contingent guitar lessons on reading behavior. Journal of Music Therapy, 11(3), 138-146.

Elegbeleye, O. S. (1994). Differential effects of two modeling strategies on social competence development in Nigerian adolescents. IFE Psychologia, 2(1), 85-102.

Ellickson, P. L., Bell, R. M., \& Harrison, E. R. (1993). Changing adolescent propensities to use drugs: Results from project ALERT. Health Education Quarterly, 20, 227-242.

Embry, D. D. (1982). Reducing the risk of pedestrian accidents to preschoolers by parent training and symbolic modeling for children: An experimental analysis in the natural environment. Ann Arbor, MI: University Microfilms International.

Embry, D. D. (1984). The safe-playing program: A case study of putting research into practice. In S. Paine \& B. Bellamy (Eds.), Human services that work: From innovation to standard practice (p. 624). Baltimore, MD: Brookes.

Embry, D. D. (1997). Does your school have a peaceful environment? Using an audit to create a climate for change and resiliency. Intervention in School and Clinic, 32, 217-222.

Embry, D. D. (2002). The good behavior game: A best practice candidate as a universal behavioral vaccine. Clinical Child and Family Psychology Review, 5(4), 273-297. doi:10.1023/A:102 0977107086.

Embry, D. D. (2004). Community-based prevention using simple, low-cost, evidence-based kernels and behavior vaccines. Journal of Community Psychology, 32(5), 575. doi:10.1002/jcop.20020.

Embry, D. D., Flannery, D. J., Vazsonyi, A. T., Powell, K. E., \& Atha, H. (1996). PeaceBuilders: A theoretically driven, school-based model for early violence prevention. American Journal of Preventive Medicine, 12, 91.

Embry, D. D., Lopez, D. C. W., \& Minugh, P. A. (2005). Stop the methamphetamine epidemic. Arizona Medicine, October, 30-34.

Ennett, S. T., Ringwalt, C. L., Thorne, J., Rohrbach, L. A., Vincus, A., Simons-Rudolph, A., et al. (2003). A comparison of current practice in school-based substance use prevention programs with meta-analysis findings. Prevention Science, 4, 1-14. doi: 10.1023/A:1021777109369.

Erkal, S., \& Safak, S. (2006). Determination of the risks of domestic accidents for the 0-6 age group in the Tuzlucayir Village 
Clinic neighborhood. The Turkish Journal of Pediatrics, 48(1), $56-62$.

Etzel, B. C., \& LeBlanc, J. M. (1979). The simplest treatment alternative: The law of parsimony applied to choosing appropriate instructional control and errorless-learning procedures for the difficult-to-teach child. Journal of Autism and Developmental Disorders, 9, 361-382. doi:10.1007/BF01531445.

Fabiano, G. A., Pelham, W. E., Manos, M. J., Gnagy, E. M., Chronis, A. M., Onyango, A. N., et al. (2004). An evaluation of three time-out procedures for children with attention deficit/hyperactivity disorder. Behavior Therapy, 35(3), 449-469. doi: 10.1016/S0005-7894(04)80027-3.

Fantuzzo, J., \& Ginsburg-Block, M. (1998). Reciprocal peer tutoring: Developing and testing effective peer collaborations for elementary school students. Peer-assisted learning (pp. 121-144). Mahwah, NJ: Erlbaum.

Farber, H., \& Mayer, G. R. (1972). Behavior consultation in a barrio high school. The Personnel and Guidance Journal, 51(4), 273.

Fava, M. (2001). Augmentation and combination strategies in treatment-resistant depression. The Journal of Clinical Psychiatry, 62(Suppl 18), 4-11.

Feldman, R., \& Eidelman, A. I. (2003). Skin-to-skin contact (Kangaroo Care) accelerates autonomic and neurobehavioural maturation in preterm infants. Developmental Medicine and Child Neurology, 45(4), 274-281. doi:10.1017/S0012162203 000525.

Ferber, S. G., \& Makhoul, I. R. (2004). The effect of skin-to-skin contact (kangaroo care) shortly after birth on the neurobehavioral responses of the term newborn: a randomized, controlled trial. Pediatrics, 113(4), 858-865. doi:10.1542/peds.113.4.858.

Ferguson, C. A. (1976). The structure and use of politeness formulas. Language in Society, 5(2), 137-151.

Ferster, C. B., \& Skinner, B. F. (1957). Schedules of reinforcement. East Norwalk, CT: Appleton-Century-Crofts.

Field, T. M. (1998). Touch therapy effects on development. International Journal of Behavioral Development, 22(4), 779. doi: 10.1080/016502598384162.

Field, T. (1999). American adolescents touch each other less and are more aggressive toward their peers as compared with French adolescents. Adolescence, 34(136), 753.

Field, T. M., Grizzle, N., Scafidi, F., \& Schanberg, S. (1996a). Massage and relaxation therapies' effects on depressed adolescent mothers. Adolescence, 31(124), 903.

Field, T., Grizzle, N., Scafidi, F., Abrams, S., Richardson, S., Kuhn, C., et al. (1996b). Massage therapy for infants of depressed mothers. Infant Behavior and Development, 19(1), 107. doi: 10.1016/S0163-6383(96)90048-X.

Field, T., Kilmer, T., Hernandez-Reif, M., \& Burman, I. (1996c). Preschool children's sleep and wake behavior: Effects of massage therapy. Early Child Development and Care, 120, 39. doi:10.1080/0300443961200104.

Field, T., Seligman, S., Scafidi, F., \& Schanberg, S. (1996d). Alleviating post-traumatic stress in children following Hurricane Andrew. Journal of Applied Developmental Psychology, 17(1), 37. doi:10.1016/S0193-3973(96)90004-0.

Filcheck, H. A., McNeil, C. B., Greco, L. A., \& Bernard, R. S. (2004). Using a whole-class token economy and coaching of teacher skills in a preschool classroom to manage disruptive behavior. Psychology in the Schools, 41(3), 351-361. doi:10.1002/pits.10168.

Fillingham, J. K., Hodgson, C., Sage, K., \& Ralph, M. A. L. (2003). The application of errorless learning to aphasic disorders: A review of theory and practice. Neuropsychological Rehabilitation, 13(3), 337-363. doi:10.1080/09602010343000020.

Fischer, P. M., Schwartz, M. P., Richards, J. W., Jr, Goldstein, A. O., \& Rojas, T. H. (1991). Brand logo recognition by children aged 3 to 6 years. Mickey mouse and old Joe the camel. Journal of the
American Medical Association, 266(22), 3145-3148. doi: 10.1001/jama.266.22.3145.

Fishbein, J. E., \& Wasik, B. H. (1981). Effect of the good behavior game on disruptive library behavior. Journal of Applied Behavior Analysis, 14, 89-93. doi:10.1901/jaba.1981.14-89.

Flannery, D. J., Vazsonyi, A. T., Liau, A. K., Guo, S., Powell, K. E., Atha, H., et al. (2003). Initial behavior outcomes for the peacebuilders universal school-based violence prevention program. Developmental Psychology, 39(2), 292-308. doi: 10.1037/0012-1649.39.2.292.

Flay, B. R., Biglan, A., Boruch, R. F., Castro, F. G., Gottfredson, D., Kellam, S., et al. (2004). Standards of evidence: Criteria for efficacy, effectiveness, and dissemination. Washington, DC: Society for Prevention Research.

Fletcher, D. (1995). A five-year study of effects of fines, gender, race, and age on illegal parking in spaces reserved for people with disabilities. Rehabilitation Psychology, 40, 203-210. doi: 10.1037/0090-5550.40.3.203.

Ford, M. J., Poe, V., \& Cox, J. (1993). Attending behaviors of ADHD children in math and reading using various types of software. Journal of Computing in Childhood Education, 4(2), 183-196.

Forgatch, M. S., DeGarmo, D. S., \& Beldvas, Z. G. (2005a). An efficacious theory-based intervention for stepfamilies. Behavior Therapy, 34, 357-365. doi:10.1016/S0005-7894(05)80117-0.

Forgatch, M. S., Patterson, G. R., \& DeGarmo, D. S. (2005b). Evaluating fidelity: Predictive validity for a measure of competent adherence to the Oregon model of parent management training. Behavior Therapy, 36, 3-13. doi:10.1016/S00057894(05)80049-8.

Foxx, R. M., \& Axelroth, E. (1983). Nicotine fading, self-monitoring, and cigarette fading to produce cigarette abstinence or controlled smoking. Behaviour Research and Therapy, 21(1), 17-27. doi: 10.1016/0005-7967(83)90122-5.

Foxx, R. M., \& Jones, J. R. (1978). A remediation program for increasing the spelling achievement of elementary and junior high school students. Behavior Modification, 2, 211-230. doi: 10.1177/014544557822004.

Freeman, M. P., Hibbeln, J. R., Wisner, K. L., Brumbach, B. H., Watchman, M., \& Gelenberg, A. J. (2006a). Randomized doseranging pilot trial of omega-3 fatty acids for postpartum depression. Acta Psychiatrica Scandinavica, 113(1), 31-35. doi: 10.1111/j.1600-0447.2005.00660.x.

Freeman, M. P., Hibbeln, J. R., Wisner, K. L., Davis, J. M., Mischoulon, D., Peet, M., et al. (2006b). Omega-3 fatty acids: evidence basis for treatment and future research in psychiatry. The Journal of Clinical Psychiatry, 67(12), 1954-1967.

Fry, D. P. (1987). Differences between playfighting and serious fighting among Zapotec children. Ethology and Sociobiology, 8(4), 285. doi:10.1016/0162-3095(87)90029-X.

Furr-Holden, C. D., Ialongo, N. S., Anthony, J. C., Petras, H., \& Kellam, S. G. (2004). Developmentally inspired drug prevention: middle school outcomes in a school-based randomized prevention trial. Drug and Alcohol Dependence, 73(2), 149-158. doi: 10.1016/j.drugalcdep.2003.10.002.

Gardner, R., Heward, W. L., \& Grossi, T. A. (1994). Effects of response cards on student participation and academic achievement: A systematic replication with inner-city students during whole-class science instruction. Journal of Applied Behavior Analysis, 27, 63-71. doi:10.1901/jaba.1994.27-63.

Gaskell, G., \& Smith, P. (1986). Group membership and social attitudes of youth: An investigation of some implications of social identity theory. Social Behaviour, 1, 67-77.

Geller, E. S., Johnson, R. P., \& Pelton, S. L. (1982). Communitybased interventions for encouraging safety belt use. American Journal of Community Psychology, 10(2), 183. doi:10.1007/ BF00896423. 
Gesch, C. B., Hammond, S. M., Hampson, S. E., Eves, A., \& Crowder, M. J. (2002). Influence of supplementary vitamins, minerals and essential fatty acids on the antisocial behaviour of young adult prisoners. Randomised, placebo-controlled trial. The British Journal of Psychiatry, 181, 22-28. doi:10.1192/bjp. 181.1.22.

Ghosh, S., \& Chattopadhyay, P. K. (1993). Application of behaviour modification techniques in treatment of attention deficit hyperactivity disorder: A case report. Indian Journal of Clinical Psychology, 20(2), 124-129.

Glasgow, R. E., Klesges, R. C., Godding, P. R., \& Gegelman, R. (1983a). Controlled smoking, with or without carbon monoxide feedback, as an alternative for chronic smokers. Behavior Therapy, 14(3), 386-397. doi:10.1016/S0005-7894(83)80101-4.

Glasgow, R. E., Klesges, R. C., \& Vasey, M. W. (1983b). Controlled smoking for chronic smokers: An extension and replication. Addictive Behaviors, 8(2), 143-150. doi:10.1016/0306-4603(83) 90008-4.

Glasgow, R. E., Vogt, T. M., \& Boles, S. M. (1999). Evaluating the public health impact of health promotion interventions: The REAIM framework. American Journal of Public Health, 89, 13221327.

Godfrey, S. A., Grisham-Brown, J., Schuster, J. W., \& Hemmeter, M. L. (2003). The effects of three techniques on student participation with preschool children with attending problems. Education and Treatment of Children, 26(3), 255-272.

Gonzalez, M., \& Ribes, E. (1975). Reversibility of the reinforcementpunishment function in children. Revista Mexicana de Análisis de la Conducta, 1(1), 55-67.

Gordon, J., Biglan, A., \& Smolkowski, K. (2008). The impact on tobacco use of branded youth antitobacco activities and family communications about tobacco. Prevention Science, 9(2), 73-87. doi:10.1007/s11121-008-0089-6.

Gordon, N. S., Kollack-Walker, S., Akil, H., \& Panksepp, J. (2002). Expression of c-fos gene activation during rough and tumble play in juvenile rats. Brain Research Bulletin, 57(5), 651-659. doi:10.1016/S0361-9230(01)00762-6.

Gray, S. I., \& Shelton, R. L. (1992). Self-monitoring effects on articulation carryover in school-age children. Language, Speech and Hearing Services in Schools, 23(4), 334-342.

Green, C. S., \& Bavelier, D. (2003). Action video game modifies visual selective attention. Nature, 423(6939), 534-537. doi: 10.1038/nature01647.

Greenwood, C. R. (1991a). Classwide peer tutoring: longitudinal effects on the reading, language, and mathematics achievement of at-risk students. Journal of Reading, Writing, and Learning Disabilities International, 7(2), 105-123.

Greenwood, C. R. (1991b). Longitudinal analysis of time, engagement, and achievement in at-risk versus non-risk students. Exceptional Children, 57(6), 521-535.

Greenwood, K. M., \& Matyas, T. A. (1990). Problems with the application of interrupted time series analysis for brief singlesubject data. Behavioral Assessment, 12(3), 355-370.

Grossman, D. C., Neckerman, H. J., Koepsell, T. D., Liu, P., Asher, K. N., Beland, K., et al. (1997). Effectiveness of a violence prevention curriculum among children in elementary school. A randomized controlled trial. Journal of the American Medical Association, 277, 1605-1611. doi:10.1001/jama.277.20.1605.

Gudbjarnason, S., Benediktsdottir, V. E., \& Gudmundsdottir, E. (1991). Balance between omega- 3 and omega- 6 fatty acids in heart muscle in relation to diet, stress, and aging. World Review of Nutrition and Dietetics, 66, 292-305.

Gupta, R., Stringer, B., \& Meakin, A. (1990). A study to access the effectiveness of home-based reinforcement in a secondary school: Some preliminary findings. Association of Educational Psychologists Journal, 5(4), 197.
Haag, M. (2003). Essential fatty acids and the brain. Canadian Journal of Psychiatry, 48(3), 195-203.

Hall, A. M., \& Zentall, S. S. (2000). The effects of a learning station on the completion and accuracy of math homework for middle school students. Journal of Behavioral Education, 10(2-3), 123137. doi:10.1023/A:1016636113459.

Hallfors, D., Cho, H., Sanchez, V., Khatapoush, S., Kim, H. M., \& Bauer, D. (2006). Efficacy vs effectiveness trial results of an indicated "model" substance abuse program: implications for public health. American Journal of Public Health, 96(12), 2254 2259. doi:10.2105/AJPH.2005.067462.

Hallfors, D., \& Godette, D. (2002). Will the 'principles of effectiveness' improve prevention practice? Early findings from a diffusion study. Health Education Research, 17, 461-470. doi: 10.1093/her/17.4.461.

Hallfors, D. D., Pankratz, M., \& Hartman, S. (2007). Does federal policy support the use of scientific evidence in school-based prevention programs? Prevention Science, 8(1), 75-81. doi: 10.1007/s11121-006-0058-x.

Harding, C., \& Ballard, K. D. (1982). The effectiveness of music as a stimulus and as a contingent reward in promoting the spontaneous speech of three physically handicapped preschoolers. Journal of Music Therapy, 19(2), 86-101.

Harris, C. L., Aycicegi, A., \& Gleason, J. B. (2003). Taboo words and reprimands elicit greater autonomic reactivity in a first language than in a second language. Applied Psycholinguistics, 24(4), 561-579. doi:10.1017/S0142716403000286.

Harris, K. R., Friedlander, B. D., Saddler, B., Frizzelle, R., \& Graham, S. (2005). Self-monitoring of attention versus selfmonitoring of academic performance: Effects among students with ADHD in the general education classroom. The Journal of Special Education, 39, 145-156. doi:10.1177/00224669050 390030201.

Harrison, R. G., \& Schaeffer, R. W. (1975). Another test of the Premack principle. Bulletin of the Psychonomic Society, 6(6), $565-568$.

Hartley, E. T., Bray, M. A., \& Kehle, T. J. (1998). Self-modeling as an intervention to increase student classroom participation. Psychology in the Schools, 35(4), 363-372. doi:10.1002/ (SICI)1520-6807(199810)35:4M<363::AID-PITS7>3.0.CO;2-1.

Hartley, E. T., Kehle, T. J., \& Bray, M. A. (2002). Increasing student classroom participation through self-modeling. Journal of Applied School Psychology, 19(1), 51-63.

Hayes, S. C., Barnes-Holmes, D., \& Roche, B. (2001). Relational frame theory: A post-Skinnerian account of human language and cognition. New York: Kluwer/Plenum.

Hayes, S. C., \& Cone, J. D. (1977). Reducing residential electrical energy use: Payments, information and feedback. Journal of Applied Behavior Analysis, 10(3), 425-435. doi:10.1901/jaba. 1977.10-425.

Heap, C., \& Emerson, E. (1989). A note on the use of peer assistance and praise to increase engagement and productivity on a vocational assembly task. Mental Handicap Research, 2(2), 186-196.

Heffner, M., Greco, L. A., \& Eifert, G. H. (2003). Pretend you are a turtle: Children's responses to metaphorical versus literal relaxation instructions. Child and Family Behavior Therapy, 25(1), 19-33. doi:10.1300/J019v25n01_02.

Hegel, M. T., \& Ferguson, R. J. (2000). Differential reinforcement of other behavior (DRO) to reduce aggressive behavior following traumatic brain injury. Behavior Modification, 24(1), 94-101. doi:10.1177/0145445500241005.

Helland, I. B., Smith, L., Saarem, K., Saugstad, O. D., \& Drevon, C. A. (2003). Maternal supplementation with very-long-chain $n-3$ fatty acids during pregnancy and lactation augments children's IQ at 4 years of age. Pediatrics, 111(1), e39-e44. doi: 10.1542/peds.111.1.e39. 
Henderson, H. S., Jenson, W. R., \& Erken, N. F. (1986). Using variable interval schedules to improve on-task behavior in the classroom. Education and Treatment of Children, 9(3), 250-263.

Hertz, V., \& McLaughlin, T. F. (1990). Self-recording: Effects for ontask behavior of mildly handicapped adolescents. Child and Family Behavior Therapy, 12(3), 1-11. doi:10.1300/J019 v12n03_01.

Hibbeln, J. R. (1998). Fish consumption and major depression. Lancet, 351(9110), 1213. doi:10.1016/S0140-6736(05)79168-6.

Hibbeln, J. R. (2001). Seafood consumption and homicide mortality. A cross-national ecological analysis. World Review of Nutrition and Dietetics, 88, 41-46. doi:10.1159/000059747.

Hibbeln, J. R. (2002). Seafood consumption, the DHA content of mothers' milk and prevalence rates of postpartum depression: A cross-national, ecological analysis. Journal of Affective Disorders, 69(1-3), 15-29. doi:10.1016/S0165-0327(01)00374-3.

Hibbeln, J. R., Davis, J. M., Steer, C., Emmett, P., Rogers, I., Williams, C., et al. (2007). Maternal seafood consumption in pregnancy and neurodevelopmental outcomes in childhood (ALSPAC study): An observational cohort study. Lancet, 369, 578-585. doi:10.1016/S0140-6736(07)60277-3.

Hibbeln, J. R., Ferguson, T. A., \& Blasbalg, T. L. (2006a). Omega-3 fatty acid deficiencies in neurodevelopment, aggression, and autonomic dysregulation: opportunities for intervention. International Review of Psychiatry (Abingdon, England), 18(2), 107118. doi:10.1080/09540260600582967.

Hibbeln, J. R., Linnoila, M., Umhau, J. C., Rawlings, R., George, D. T., \& Salem, N., Jr. (1998). Essential fatty acids predict metabolites of serotonin and dopamine in cerebrospinal fluid among healthy control subjects, and early- and late-onset alcoholics. Biological Psychiatry, 44(4), 235-242. doi:10.1016/ S0006-3223(98)00141-3.

Hibbeln, J. R., Nieminen, L. R., Blasbalg, T. L., Riggs, J. A., \& Lands, W. E. (2006b). Healthy intakes of n-3 and n-6 fatty acids: estimations considering worldwide diversity. The American Journal of Clinical Nutrition, 83(6 Suppl), 1483S-1493S.

Hibbeln, J. R., \& Salem, N., Jr. (1995). Dietary polyunsaturated fatty acids and depression: when cholesterol does not satisfy. The American Journal of Clinical Nutrition, 62(1), 1-9.

Hickey, K., Imber, S. C., \& Ruggiero, E. (1979). Modifying reading behavior of elementary special needs children: A cooperative resource-parent program. Journal of Learning Disabilities, 12: 444-449.

Hill, J., Brantner, J., \& Spreat, S. (1989). The effect of contingent music on the in-seat behavior of a blind young woman with profound mental retardation. Education and Treatment of Children, 12(2), 165-173.

Hines, M., \& Kaufman, F. R. (1994). Androgen and the development of human sex-typical behavior: rough-and-tumble play and sex of preferred playmates in children with congenital adrenal hyperplasia (CAH). Child Development, 65(4), 1042-1053. doi: $10.2307 / 1131303$

Hirasing, R. A., \& Reus, H. (1991). Dry bed training in nocturnal enuresis. Nederlands Tijdschrift voor Geneeskunde, 135(38), $1750-1753$.

Hitchcock, C. H., Dowrick, P. W., \& Prater, M. A. (2003). Video selfmodeling intervention in school-based settings: A review. Remedial and Special Education, 24(1), 36-46. doi:10.1177/074 193250302400104.

Hitchcock, C. H., Prater, M. A., \& Dowrick, P. W. (2004). Reading comprehension and fluency: Examining the effects of tutoring and video self-modeling on first-grade students with reading difficulties. Learning Disability Quarterly, 27(2), 89-103. doi: $10.2307 / 1593644$.

Hoath, F. E., \& Sanders, M. R. (2002). A feasibility study of enhanced group Triple $\mathrm{P}$-positive parenting program for parents of ahildren with attention-deficit/hyperactivity disorder. Behaviour Change, 19, 191-206.

Hoigaard, R., Safvenbom, R., \& Tonnessen, F. E. (2006). The relationship between group cohesion, group norms, and perceived social loafing in soccer teams. Small Group Research, 37(3), 217-232. doi:10.1177/1046496406287311.

Holloway, M. S. (1980). A comparison of passive and active music reinforcement to increase preacademic and motor skills in severely retarded children and adolescents. Journal of Music Therapy, 17(2), 58-69.

Homme, L. E., Debaca, P. C., Devine, J. V., Steinhorst, R., \& Rickert, E. J. (1963). Use of the Premack principle in controlling the behavior of nursery school children. Journal of the Experimental Analysis of Behavior, 6(4), 544. doi:10.1901/jeab.1963.6-544.

Hosford, R. E. (1980). Self-as-a-model: A cognitive social learning technique. The Counseling Psychologist, 9(1), 45-62. doi: 10.1177/001100008000900113.

Hosie, T. W., Gentile, J. R., \& Carroll, J. D. (1974). Pupil preferences and the Premack principle. American Educational Research Journal, 11(3), 241-247.

Houghton, S., Wheldall, K., Jukes, R., \& Sharpe, A. (1990). The effects of limited private reprimands and increased private praise on classroom behaviour in four British secondary school classes. The British Journal of Educational Psychology, 60(3), 255-265.

Houlihan, D., Miltenberger, R. G., Trench, B., Larson, M., Larson, S., \& Vincent, J. (1995). A video-tape peer/self modeling program to increase community involvement. Child and Family Behavior Therapy, 17(3), 1-11. doi:10.1300/J019v17n03_01.

Howard, D. J. (1990). The influence of verbal responses to common greetings on compliance behavior: The foot-in-the-mouth effect. Journal of Applied Social Psychology, 20(14 Pt 2), 1185-1196. doi:10.1111/j.1559-1816.1990.tb00399.x.

Hudson, A., Vincent, J., Wilks, R., \& Drabman, R. (1985). "Beat the buzzer" for early morning dawdling: Two case illustrations. Behaviour Change, 2(2), 136-142.

Hughes, C., Copeland, S. R., Agran, M., Wehmeyer, M. L., Rodi, M. S., \& Presley, J. A. (2002). Using self-monitoring to improve performance in general education high school classes. Education and Training in Mental Retardation and Developmental Disabilities, 37, 262-272.

Hume, K. M., \& Crossman, J. (1992). Musical reinforcement of practice behaviors among competitive swimmers. Journal of Applied Behavior Analysis, 25(3), 665-670. doi:10.1901/jaba. 1992.25-665.

Hunkin, N. M., Squires, E. J., Parkin, A. J., \& Tidy, J. A. (1998). Are the benefits of errorless learning dependent on implicit memory? Neuropsychologia, 36(1), 25-36. doi:10.1016/S0028-3932(97) 00106-1.

Hutton, J. B. (1983). How to decrease problem behavior at school by rewarding desirable behavior at home. Pointer, 27(4), 25.

Jacklin, C. N., DiPietro, J. A., \& Maccoby, E. E. (1984). Sex-typing behavior and sex-typing pressure in child/parent interaction. Archives of Sexual Behavior, 13(5), 413-425. doi:10.1007/ BF01541427.

Jackson, N. C., \& Mathews, R. M. (1995). Using public feedback to increase contributions to a multipurpose senior center. Journal of Applied Behavior Analysis, 28, 449-455. doi:10.1901/jaba. 1995.28-449.

Jarrett, O. S., Maxwell, D. M., Dickerson, C., Hoge, P., Davies, G., \& Yetley, A. (1998). Impact of recess on classroom behavior: Group effects and individual differences. The Journal of Educational Research, 92, 121-126.

Jarvinen, R., Knekt, P., Rissanen, H., \& Reunanen, A. (2006). Intake of fish and long-chain n-3 fatty acids and the risk of coronary heart mortality in men and women. The British Journal of Nutrition, 95(4), 824-829. doi:10.1079/BJN20051687. 
Jason, L. A., Katz, R., Pokorny, S. B., Engstrom, M., Tegart, G., \& Curie, C. (2000). The relationship between youth tobacco control enforcement and crime rates in a Midwestern county. American Journal of Health Promotion, 14(4), 229-231.

Jason, L. A., \& Liotta, R. F. (1982). Pedestrian jaywalking under facilitating and nonfacilitating conditions. Journal of Applied Behavior Analysis, 15(3), 469-473. doi:10.1901/jaba.1982. 15-469.

Jason, L. A., Neal, A. M., \& Marinakis, G. (1985). Altering contingencies to facilitate compliance with traffic light systems. Journal of Applied Behavior Analysis, 18(1), 95-100. doi: 10.1901/jaba.1985.18-95.

Jason, L. A., Pokorny, S. B., Turner, P. L., Freeland, M., Corbin, S., \& Driscoll, M. (2005). Decreasing public smoking among youth: A preliminary study. Education and Treatment of Children, 28(3), 299-307.

Joe, G. W., Dansereau, D. F., Pitre, U., \& Simpson, D. D. (1997). Effectiveness of node-link mapping enhanced counseling for opiate addicts: A 12-month post-treatment follow-up. The Journal of Nervous and Mental Disease, 185(5), 306. doi: 10.1097/00005053-199705000-00004.

Joe, G. W., Dansereau, D. F., \& Simpson, D. D. (1994). Node-link mapping for counseling cocaine users in methadone treatment. Journal of Substance Abuse, 6(4), 393. doi:10.1016/S0899-3289 (94)90320-4.

Jones, N. A., Field, T., \& Davalos, M. (1998). Massage therapy attenuates right frontal EEG asymmetry in one-month-old infants of depressed mothers. Infant Behavior and Development, 21(3), 527. doi:10.1016/S0163-6383(98)90025-X.

Jorgenson, H. (1974). The use of a contingent music activity to modify behaviors which interfere with learning. Journal of Music Therapy, 11(1), 41-46.

Jorgensen, F., \& Pedersen, H. (2005). Enforcement of speed limitsactual policy and drivers' knowledge. Accident; Analysis and Prevention, 37(1), 53-62. doi:10.1016/j.aap.2004.06.004.

Juarez, F. (2002). Tendency and relationships in violent behavior patterns in groups. Revista Argentina de Clínica Psicológica, 11(2), 155-170.

Kahn, J. S., Kehle, T. J., Jenson, W. R., \& Clark, E. (1990). Comparison of cognitive-behavioral, relaxation, and self-modeling interventions for depression among middle-school students. School Psychology Review, 19(2), 196-211.

Kamps, D. M., Dugan, E. P., Leonard, B. R., \& Daoust, P. M. (1994). Enhanced small group instruction using choral responding and student interaction for children with autism and developmental disabilities. American Journal of Mental Retardation, 99(1), 60 73.

Kazdin, A. E. (1980). Acceptability of alternative treatments for deviant child behavior. Journal of Applied Behavior Analysis, 13(2), 259-273. doi:10.1901/jaba.1980.13-259.

Keel, M. C., \& Gast, D. L. (1992). Small-group instruction for students with learning disabilities: Observational and incidental learning. Exceptional Children, 58(4), 357-368.

Kehle, T. J., Bray, M. A., Margiano, S. G., Theodore, L. A., \& Zhou, Z. (2002). Self-modeling as an effective intervention for students with serious emotional disturbance: Are we modifying children's memories? Psychology in the Schools, 39(2), 203-207. doi: 10.1002/pits.10031.

Kellam, S. G., \& Anthony, J. C. (1998). Targeting early antecedents to prevent tobacco smoking: Findings from an epidemiologically based randomized field trial. American Journal of Public Health, 88(10), 1490-1495.

Kellam, S., Brown, C. H., Poduska, J., Ialongo, N., Wang, W., Toyinbo, P., et al. (2008). Effects of a universal classroom behavior management program in first and second grades on young adult behavioral, psychiatric, and social outcomes. Drug \& Alcohol Dependence (Special Issue), 24.

Kellam, S. G., Rebok, G. W., Ialongo, N., \& Mayer, L. S. (1994). The course and malleability of aggressive behavior from early first grade into middle school: Results of a developmental epidemiology-based preventive trial. Journal of Child Psychology and Psychiatry, and Allied Disciplines, 35, 259-281. doi: 10.1111/j.1469-7610.1994.tb01161.x.

Kelley, M. L., Carper, L. B., Witt, J. C., \& Elliott, S. N.(1988). Homebased reinforcement procedures. Handbook of behavior therapy in education (p. 419). New York: Plenum.

Kelley, M. L., \& McCain, A. P. (1995). Promoting academic performance in inattentive children. The relative efficacy of school-home notes with and without response cost. Behavior Modification, 19(3), 357-375.

Kellum, K. K., Carr, J. E., \& Dozier, C. L. (2001). Response-card instruction and student learning in a college classroom. Teaching of Psychology (Columbia, Mo.), 28, 101-104. doi: 10.1207/S15328023TOP2802_06.

Kern, L., Dunlap, G., Childs, K. E., \& Clarke, S. (1994). Use of a classwide self-management program to improve the behavior of students with emotional and behavioral disorders. Education and Treatment of Children, 17(4), 445-458.

Khatri, P., Blumenthal, J. A., Babyak, M. A., Craighead, W. E., Herman, S., Baldewicz, T., et al. (2001). Effects of exercise training on cognitive functioning among depressed older men and women. Journal of Aging and Physical Activity, 9(1), 43-57.

Kivlighan, K. T., \& Granger, D. A. (2006). Salivary a-amylase response to competition: Relation to gender, previous experience, and attitudes. Psychoneuroendocrinology, 31, 703-714. doi:10.1016/j.psyneuen.2006.01.007.

Knapp, T. J. (1976). The Premack principle in human experimental and applied settings. Behaviour Research and Therapy, 14(2), 133-147. doi:10.1016/0005-7967(76)90067-X.

Koepp, M. J., Gunn, R. N., Lawrence, A. D., Cunningham, V. J., Dagher, A., Jones, T., et al. (1998). Evidence for striatal dopamine release during a video game. Nature, 393, 266-268. doi: $10.1038 / 30498$.

Koffman, D. M., Lee, J. W., Hopp, J. W., \& Emont, S. L. (1998). The impact of including incentives and competition in a workplace smoking cessation program on quit rates. American Journal of Health Promotion, 13(2), 105-111.

Krantz, P. J., \& Risley, T. R. (1977). Behavioral ecology in the classroom. In K. D. O’Leary \& S. G. O'Leary (Eds.), Classroom management: The successful use of behavior modification (2nd ed., pp. 349-367). New York: Pergamon.

Krevor, B., Capitman, J. A., Oblak, L., Cannon, J. B., \& Ruwe, M. (2003). Preventing illegal tobacco and alcohol sales to minors through electronic age-verification devices: A field effectiveness study. Journal of Public Health Policy, 24(3-4), 251-268. doi: $10.2307 / 3343372$

Krug, E. G., Brener, N. D., Dahlberg, L. L., Ryan, G. W., \& Powell, K. E. (1997). The impact of an elementary school-based violence prevention program on visits to the school nurse. American Journal of Preventive Medicine, 13(6), 459-463.

Kubesch, S., Bretschneider, V., Freudenmann, R., Weidenhammer, N., Lehmann, M., Spitzer, M., et al. (2003). Aerobic endurance exercise improves executive functions in depressed patients. The Journal of Clinical Psychiatry, 64(9), 1005-1012.

La Greca, A. M., \& Santogrossi, D. A. (1980). Social skills training with elementary school students: A behavioral group approach. Journal of Consulting and Clinical Psychology, 48(2), 220. doi: 10.1037/0022-006X.48.2.220.

Lakes, K. D., \& Hoyt, W. T. (2004). Promoting self-regulation through school-based martial arts training. Journal of Applied 
Developmental Psychology, 25(3), 283-302. doi:10.1016/j. appdev.2004.04.002.

Lalramnghinglova, H. (1999). Ethnobiology in Mizoram state: folklore medico-zoology. Bulletin of the Indian Institute of History of Medicine (Hyderabad), 29(2), 123-148.

Lambert, J. L. (1979). Experiments with errorless discrimination learning. Enfance, 2, 107-132.

Larson, K., \& Ayllon, T. (1990). The effects of contingent music and differential reinforcement on infantile colic. Behaviour Research and Therapy, 28(2), 119-125. doi:10.1016/0005-7967(90) 90024-D.

Larsson, B., Carlsson, J., Fichtel, S., \& Melin, L. (2005). Relaxation treatment of adolescent headache sufferers: Results from a school-based replication series. Headache: The Journal of Head and Face Pain, 45(6), 692-704. doi:10.1111/j.1526-4610. 2005.05138.x.

Larun, L., Nordheim, L. V., Ekeland, E., Hagen, K. B., \& Heian, F. (2006). Exercise in prevention and treatment of anxiety and depression among children and young people. Cochrane Database of Systematic Reviews, 3, article number: CD004691. doi: 10.1002/14651858.CD004691.pub2.

Law, B., \& Ste-Marie, D. M. (2005). Effects of self-modeling on figure skating jump performance and psychological variables. European Journal of Sport Science, 5, 143-152. doi:10.1080/ 17461390500159273.

Lawshe, C. H. (1940). Studies in automobile speed on the highway II. Approach speeds and changes in sign size and location on the highway. The Journal of Applied Psychology, 24, 308-317. doi: 10.1037/h0057756.

Leblanc, M.-P., Ricciardi, J. N., \& Luiselli, J. K. (2005). Improving discrete trial instruction by paraprofessional staff through an abbreviated performance feedback intervention. Education and Treatment of Children, 28(1), 76-82.

Leclerc, R., \& Thurston, C. (2003). Applications of the Premack principle by the parents of an autistic child. Revue Francophone de la Déficience Intellectuelle, 14(2), 139-150.

Leff, S. S., Costigan, T., \& Power, T. J. (2004). Using participatory research to develop a playground-based prevention program. Journal of School Psychology, 42(1), 3. doi:10.1016/j.jsp.2003. 08.005 .

Leibowitz, J. M. (1975). Differential reinforcement effectiveness as a function of schedule of reinforcement and reinforcement history. The Psychological Record, 25(3), 343-354.

Lennox, D. B., Miltenberger, R. G., Spengler, P., \& Erfanian, N. (1988). Decelerative treatment practices with persons who have mental retardation: a review of five years of the literature. American Journal of Mental Retardation, 92(6), 492-501.

Libb, J. W., Sachs, C., \& Boyd, W. (1973). Reinforcement strategies for token economies in a special classroom setting. Psychological Reports, 32(3 Pt 1), 831-834.

Liberman, R. P., Ferris, C., Salgado, P., \& Salgado, J. (1975). Replication of the achievement place model in California. Journal of Applied Behavior Analysis, 8(3), 287-299. doi: 10.1901/jaba.1975.8-287.

Lieber, C. S., Spritz, N., \& DeCarli, L. M. (1969). Fatty liver produced by dietary deficiencies: Its pathogenesis and potentiation by ethanol. Journal of Lipid Research, 10(3), 283-287.

Lipsey, M. W., Dodge, K. A., Dishion, T. J., \& Lansford, J. E. (2006). The effects of community-based group treatment for delinquency: A meta-analytic search for cross-study generalizations. Deviant peer influences in programs for youth: Problems and solutions (pp. 162-184). New York: Guilford.

Liu, J., Raine, A., Venables, P. H., \& Mednick, S. A. (2004). Malnutrition at age 3 years and externalizing behavior problems at ages 8, 11, and 17 years. The American Journal of Psychiatry, 161(11), 2005-2013. doi:10.1176/appi.ajp.161.11.2005.
Lonnecker, C., Brady, M. P., McPherson, R., \& Hawkins, J. (1994). Video self-modeling and cooperative classroom behavior in children with learning and behavior problems: Training and generalization effects. Behavioral Disorders, 20(1), 24-34.

Lősel, F., \& Beelmann, A. (2003). Effects of child skills training in preventing antisocial behavior: A systematic review of randomized evaluations. The Annals of the American Academy of Political and Social Science, 587, 84-109. doi:10.1177/ 0002716202250793.

Lowe, T. O., \& McLaughlin, E. C. (1974). The use of verbal reinforcement by paraprofessionals in the treatment of underachieving elementary school students. Journal of the Student Personnel Association for Teacher Education, 12(3), 95.

Lowndes, M., \& Dawes, J. (2001). Do distinct SERVQUAL dimensions emerge from mystery shopping data? A test of convergent validity. The Canadian Journal of Program Evaluation, 16(2), 41-53.

Luciano, M. C., Herruzo, J., \& Barnes-Holmes, D. (2001). Generalization of say-do correspondence. The Psychological Record, 51(1), 111-130.

Luciano-Soriano, M. C., Molina-Cobos, F. J., \& Gomez-Becerra, I. (2000). Say-do-report training to change chronic behaviors in mentally retarded subjects. Research in Developmental Disabilities, 21(5), 355-366. doi:10.1016/S0891-4222(00)00048-2.

Ludington-Hoe, S. M., Anderson, G. C., Swinth, J. Y., Thompson, C., \& Hadeed, A. J. (2004). Randomized controlled trial of kangaroo care: cardiorespiratory and thermal effects on healthy preterm infants. Neonatal Network-Journal of Neonatal Nursing, 23(3), $39-48$.

Luiselli, J. K., \& Greenidge, A. (1982). Behavioral treatment of highrate aggression in a rubella child. Journal of Behavior Therapy and Experimental Psychiatry, 13(2), 152-157. doi:10.1016/ 0005-7916(82)90059-3.

Maag, J. W., Rutherford, R. B., Wolchik, S. A., \& Parks, B. T. (1986). Comparison of two short overcorrection procedures on the stereotypic behavior of autistic children. Journal of Autism and Developmental Disorders, 16(1), 83-87. doi:10.1007/BF015 31581.

Madaus, M. M. R., Kehle, T. J., Madaus, J., \& Bray, M. A. (2003). Mystery motivator as an intervention to promote homework completion and accuracy. School Psychology International, 24(4), 369-377. doi:10.1177/01430343030244001.

Madsen, C. K. (1982). The effect of contingent teacher approval and withholding music performance on improving attentiveness. Psychology of Music, Special Issue, 76-81.

Maglieri, K. A., DeLeon, I. G., Rodriguez-Catter, V., \& Sevin, B. M. (2000). Treatment of covert food stealing in an individual with Prader-Willi syndrome. Journal of Applied Behavior Analysis, 33(4), 615-618. doi:10.1901/jaba.2000.33-615.

Maheady, L., Harper, G. F., \& Sacca, K. (1988a). A classwide peer tutoring system in a secondary, resource room program for the mildly handicapped. Journal of Research and Development in Education, 21(3), 76-83.

Maheady, L., Sacca, M. K., \& Harper, G. F. (1988b). Classwide peer tutoring with mildly handicapped high school students. Exceptional Children, 55(1), 52-59.

Majovski, L. V., \& Clement, P. W. (1977). Children's lever-pulling rates under variable-interval percentage schedules. Journal of Experimental Child Psychology, 23(2), 212-225. doi: 10.1016/0022-0965(77)90100-X.

Manger, T. A., \& Motta, R. W. (2005). The impact of an exercise program on posttraumatic stress disorder, anxiety, and depression. International Journal of Emergency Mental Health, 7(1), 49-57.

Marchant, M., \& Young, K. R. (2001). The effects of a parent coach on parents' acquisition and implementation of parenting skills. Education and Treatment of Children, 24(3), 351-373. 
Marchant, M., Young, K. R., \& West, R. P. (2004). The effects of parental teaching on compliance behavior of children. Psychology in the Schools, 41(3), 337-350. doi:10.1002/pits.10165.

Marin, H., \& Menza, M. A. (2005). The management of fatigue in depressed patients. Essential Psychopharmacology, 6(4), 185192

Marion, M., \& Muza, R. (1998). Positive discipline: Six strategies for guiding behavior. Texas Child Care, 22(2), 6-11.

Marshall, S. W., Runyan, C. W., Yang, J., Coyne-Beasley, T., Waller, A. E., Johnson, R. M., et al. (2005). Prevalence of selected risk and protective factors for falls in the home. American Journal of Preventive Medicine, 28(1), 95-101. doi:10.1016/j.amepre.2004. 09.015 .

Martella, R. C., Leonard, I. J., Marchand-Martella, N. E., \& Agran, M. (1993). Self-monitoring negative statements. Journal of Behavioral Education, 3(1), 77-86. doi:10.1007/BF00947146.

Martens, B. K., Hiralall, A. S., \& Bradley, T. A. (1997). A note to teacher: Improving student behavior through goal setting and feedback. School Psychology Quarterly, 12(1), 33-41. doi: 10.1037/h0088945.

Mathes, M. Y., \& Bender, W. N. (1997). The effects of selfmonitoring on children with attention deficit/hyperactivity disorder who are receiving pharmacological interventions. Remedial and Special Education, 18(2), 121-128.

Mathes, P. G., Fuchs, D., Fuchs, L. S., Henley, A. M., et al. (1994). Increasing strategic reading practice with peabody classwide peer tutoring. Learning Disabilities Research and Practice, 9(1), $44-48$.

Matheson, A. S., \& Shriver, M. D. (2005). Training teachers to give effective commands: effects on student compliance and academic behaviors. School Psychology Review, 34, 202-219.

Mayer, G. R., Butterworth, T., Nafpaktitis, M., \& Sulzer-Azaroff, B. (1983). Preventing school vandalism and improving discipline: A three-year study. Journal of Applied Behavior Analysis, 16(4), 355-369. doi:10.1901/jaba.1983.16-355.

Mayer, G. R., Mitchell, L. K., Clementi, T., Clement-Robertson, E., Myatt, R., \& Bullara, D. T. (1993). A dropout prevention program for at-risk high school students: Emphasizing consulting to promote positive classroom climates. Education and Treatment of Children, 16(2), 135.

Mazur, J. E. (1975). The matching law and quantifications related to Premack's principle. Journal of Experimental Psychology. Animal Behavior Processes, 1(4), 374-386. doi:10.1037/00977403.1.4.374.

McCain, A. P., \& Kelley, M. L. (1993). Managing the classroom behavior of an ADHD preschooler: The efficacy of a schoolhome note intervention. Child and Family Behavior Therapy, 15(3), 33. doi:10.1300/J019v15n03_03.

McCambridge, J., \& Strang, J. (2004). The efficacy of single-session motivational interviewing in reducing drug consumption and perceptions of drug-related risk and harm among young people: results from a multi-site cluster randomized trial. Addiction (Abingdon, England), 99(1), 39-52. doi:10.1111/j.1360-0443. 2004.00564.x.

McCarl, J. J., Svobodny, L., \& Beare, P. L. (1991). Self-recording in a classroom for students with mild to moderate mental handicaps: Effects on productivity and on-task behavior. Education and Training of the Mentally Retarded, 26(1), 79-88.

McCarty, B. C., McElfresh, C. T., Rice, S. V., \& Wilson, S. J. (1978). The effect of contingent background music on inappropriate bus behavior. Journal of Music Therapy, 15, 150-156.

McDiarmid, A. K. (2008). The impact of traditional Taekwondo on self-control for middle school students.Dissertation Abstracts International Section A: Humanities and Social Sciences, 68 (8-A), 3282
McDonnell, L., \& Bowden, M. L. (1989). Breathing management: A simple stress and pain reduction strategy for use on a pediatric service. Issues in Comprehensive Pediatric Nursing, 12(5), 339344. doi:10.3109/01460868909038042.

McDougall, D., \& Brady, M. P. (1995). Using audio-cued selfmonitoring for students with severe behavior disorders. The Journal of Educational Research, 88(5), 309-317.

McGee, R., Williams, S., Anderson, J., McKenzie-Parnell, J. M., \& Silva, P. A. (1990). Hyperactivity and serum and hair zinc levels in 11-year-old children from the general population. Biological Psychiatry, 28(2), 165-168. doi:10.1016/0006-3223(90)90634-E.

McGoey, K. E., \& DuPaul, G. J. (2000). Token reinforcement and response cost procedures: Reducing the disruptive behavior of preschool children with attention-deficit/hyperactivity disorder. School Psychology Quarterly, 15(3), 330-343. doi:10.1037/ h0088790.

McGrath, M. L., Dorsett, P. G., Calhoun, M. E., \& Drabman, R. S. (1987). "Beat-the-buzzer": A method for decreasing parentchild morning conflicts. Child and Family Behavior Therapy, 9(3-4), 35-48.

McGrath-Hanna, N. K., Greene, D. M., Tavernier, R. J., \& Bult-Ito, A. (2003). Diet and mental health in the Arctic: Is diet an important risk factor for mental health in circumpolar peoples? A review. International Journal of Circumpolar Health, 62(3), $228-241$.

McLaughlin, T. F., \& Helm, J. L. (1993). Use of contingent music to increase academic performance of middle-school students. Psychological Reports, 72(2), 658.

McLaughlin, T. F., Krappman, V. F., \& Welsh, J. M. (1985). The effects of self-recording for on-task behavior of behaviorally disordered special education students. RASE: Remedial and Special Education, 6(4), 42-45.

McMorrow, M. J., Cullinan, D., \& Epstein, M. H. (1978). The use of the Premack principle to motivate patient activity attendance. Perspectives in Psychiatric Care, 16(1), 14-18.

Meadow, R. (1977). How to use buzzer alarms to cure bed-wetting. British Medical Journal, 2(6094), 1073-1075.

Medland, M. B., \& Stachnik, T. J. (1972). Good-behavior game: A replication and systematic analysis. Journal of Applied Behavior Analysis, 5(1), 45-51. doi:10.1901/jaba.1972.5-45.

Meharg, S. S., \& Lipsker, L. E. (1991). Parent training using videotape self-modeling. Child and Family Behavior Therapy, 13(4), 1-27. doi:10.1300/J019v13n04_01.

Meharg, S. S., \& Woltersdorf, M. A. (1990). Therapeutic use of videotape self-modeling: A review. Advances in Behaviour Research and Therapy, 12(2), 85-99. doi:10.1016/0146-6402 (90)90008-E.

Melchiori, L. E., Souza, D. G., \& Rose, J. C. (1992). Reading acquisition through an errorless discrimination procedure (exclusion): A replication with preschoolers. Psicologia: Teoria $e$ Pesquisa (Brasilia), 8(1), 101-111.

Melville, C. L., Davis, C. S., Matzenbacher, D. L., \& Clayborne, J. (2004). Node-link-mapping-enhanced group treatment for pathological gambling. Addictive Behaviors, 29(1), 73. doi: 10.1016/S0306-4603(03)00091-1.

Merrett, J., \& Merrett, F. (1997). Correspondence training as a means of improving study skills. Educational Psychology, 17(4), 469482. doi:10.1080/0144341970170407.

Merrett, F., \& Tang, W. M. (1994). The attitudes of British primary school pupils to praise, reward, punishments and reprimands. The British Journal of Educational Psychology, 64, 91-103.

Mickleborough, T. D., Lindley, M. R., Ionescu, A. A., \& Fly, A. D. (2006). Protective effect of fish oil supplementation on exerciseinduced bronchoconstriction in asthma. Chest, 129(1), 39-49. doi:10.1378/chest.129.1.39. 
Mikami, A. Y., Boucher, M. A., \& Humphreys, K. (2005). Prevention of peer rejection through a classroom-level intervention in middle school. The Journal of Primary Prevention, 26, 5-23. doi:10.1007/s10935-004-0988-7.

Miller, W. R., Sovereign, R. G., \& Krege, B. (1988). Motivational interviewing with problem drinkers: II. The Drinker's check-up as a preventive intervention. Behavioural Psychotherapy, 16(4), 251-268.

Mischoulon, D., \& Fava, M. (2000). Docosahexanoic acid and omega-3 fatty acids in depression. The Psychiatric Clinics of North America, 23(4), 785-794. doi:10.1016/S0193-953X (05)70197-0.

Mishima, K. (2003). How children address each other in class and in peer relations: power balance and group membership. Japanese Journal of Educational Psychology, 51(2), 121-129.

Monti, P. M., Colby, S. M., Barnett, N. P., Spirito, A., Rohsenow, D. J., Myers, M., et al. (1999). Brief intervention for harm reduction with alcohol-positive older adolescents in a hospital emergency department. Journal of Consulting and Clinical Psychology, 67(6), 989-994. doi:10.1037/0022-006X.67.6.989.

Moore, S. (1984). Unleashing the mystery shopper. Contemporary Administrator for Long-Term Care, 7(9), 73-76.

Moore, L. A., Waguespack, A. M., Wickstrom, K. F., Witt, J. C., et al. (1994). Mystery motivator: An effective and time efficient intervention. School Psychology Review, 23(1), 106-118.

Morrison, R. S., Sainato, D. M., Benchaaban, D., \& Endo, S. (2002). Increasing play skills of children with autism using activity schedules and correspondence training. Journal of Early Intervention, 25(1), 58-72. doi:10.1177/105381510202500106.

Murphy, H. A., Hutchison, J. M., \& Bailey, J. S. (1983). Behavioral school psychology goes outdoors: The effect of organized games on playground aggression. Journal of Applied Behavior Analysis, 16(1), 29. doi:10.1901/jaba.1983.16-29.

Nakano, K. (1990). Operant self-control procedure in modifying type A behavior. Journal of Behavior Therapy and Experimental Psychiatry, 21(4), 249-255. doi:10.1016/0005-7916(90)90025-G.

Naveen, K. V., Nagarathna, R., Nagendra, H. R., \& Telles, S. (1997). Yoga breathing through a particular nostril increases spatial memory scores without lateralized effects. Psychological Reports, 81(2), 555-561.

Neave, N., \& Wolfson, S. (2003). Testosterone, territoriality, and the 'home advantage.' Physiology and Behavior, 78(2), 269-275. doi:10.1016/S0031-9384(02)00969-1.

Nedas, N. D., Balcar, G. P., \& Macy, P. R. (1982). Road markings as an alcohol countermeasure for highway safety: Field study of standard and wide edgelines. Abridged. http://pubsindex.trb.org/ document/view/default.asp?lbid=182183.

Nemets, B., Stahl, Z., \& Belmaker, R. H. (2002). Addition of omega3 fatty acid to maintenance medication treatment for recurrent unipolar depressive disorder. The American Journal of Psychiatry, 159(3), 477-479. doi:10.1176/appi.ajp.159.3.477.

Newbern, D., Dansereau, D. F., Czuchry, M., \& Simpson, D. (2005). Node-link mapping in individual counseling: Treatment impact on clients with ADHD-related behaviors. Journal of Psychoactive Drugs, 37(1), 93.

Newbern, D., Dansereau, D. F., \& Pitre, U. (1999). Positive effects on life skills motivation and self-efficacy: Node-link maps in a modified therapeutic community. The American Journal of Drug and Alcohol Abuse, 25(3), 407. doi:10.1081/ADA-10010 1869.

Nicol, N., \& Hantula, D. A. (2001). Decreasing delivery drivers' departure times. Journal of Organizational Behavior Management, 21, 105-116. doi:10.1300/J075v21n04_07.

Ninness, H. A. C., Fuerst, J., \& Rutherford, R. (1995). A descriptive analysis of disruptive behavior during pre- and post-unsupervised self-management by students with serious emotional disturbance: A within-study replication. Journal of Emotional and Behavioral Disorders, 3(4), 230-240.

Ninness, H. C., Fuerst, J., Rutherford, R. D., \& Glenn, S. S. (1991). Effects of self-management training and reinforcement on the transfer of improved conduct in the absence of supervision. Journal of Applied Behavior Analysis, 24(3), 499-508. doi: 10.1901/jaba.1991.24-499.

Nordstrom, R., Hall, R. V., Lorenzi, P., \& Delquadri, J. (1988). Organizational behavior management in the public sector: Three field experiments. Journal of Organizational Behavior Management, 9, 91-112.

Nordstrom, R., Lorenzi, P., \& Hall, V. (1990). A review of public posting of performance feedback in work settings. Journal of Organizational Behavior Management, 11, 101-121. doi: 10.1300/J075v11n02_07.

Norlander, T., Moas, L., \& Archer, T. (2005). Noise and stress in primary and secondary school children: noise reduction and increased concentration ability through a short but regular exercise and relaxation program. School Effectiveness and School Improvement, 16, 91-99. doi:10.1080/092434505000114173.

Norris, P. T. (2002). Purchasing restricted medicines in New Zealand pharmacies: Results from a "mystery shopper" study. Pharmacy World \& Science, 24(4), 149-153. doi:10.1023/A:10195 06120713

Ogden, T., \& Halliday-Boykins, C. A. (2004). Multisystemic treatment of antisocial adolescents in Norway: Replication of clinical outcomes outside of the US. Child and Adolescent Mental Health Care, 9, 77-83. doi:10.1111/j.1475-3588.2004. 00085.x.

Olafsdottir, A. S., Magnusardottir, A. R., Thorgeirsdottir, H., Hauksson, A., Skuladottir, G. V., \& Steingrimsdottir, L. (2005). Relationship between dietary intake of cod liver oil in early pregnancy and birthweight. BJOG: an International Journal of Obstetrics and Gynaecology, 112(4), 424-429. doi: 10.1111/j.1471-0528.2005.00477.x.

O’Reilly, M., Tiernan, R., Lancioni, G., Lacey, C., Hillery, J., \& Gardiner, M. (2002). Use of self-motivating and delayed feedback to increase on-task behavior in a post-institutionalized child within regular classroom settings. Education and Treatment of Children, 25(1), 91-102.

Ostrower, C., \& Ziv, A. (1982). Soft reprimands and self-control as ways of behavior modification in the classroom. Israeli Journal of Psychology and Counseling in Education, 15, 21-28.

Owusu-Bempah, J., \& Howitt, D. L. (1983). Self-modeling and weight control. The British Journal of Medical Psychology, 56(2), 157-165.

Owusu-Bempah, J., \& Howitt, D. (1985). The effects of self-modeling on cigarette smoking behavior. Current Psychological Research and Reviews, 4(2), 133-142. doi:10.1007/BF02686580.

Palermo, M. T., Di Luigi, M., Dal Forno, G., Dominici, C., Vicomandi, D., Sambucioni, A., et al. (2006). Externalizing and oppositional behaviors and Karate-do: The way of crime prevention: A pilot study. International Journal of Offender Therapy and Comparative Criminology, 50(6), 654-660. doi: 10.1177/0306624X06293522.

Palmgreen, P., Lorch, E. P., Donohew, L., \& Harrington, N. G. (1995). Reaching at-risk populations in a mass media drug abuse prevention campaign: Sensation seeking as a targeting variable. Drugs and Society, 8, 29-45. doi:10.1300/J023v08n03_04.

Panksepp, J., Burgdorf, J., Turner, C., \& Gordon, N. (2003). Modeling ADHD-type arousal with unilateral frontal cortex damage in rats and beneficial effects of play therapy. Brain and Cognition, 52(1), 97-105. doi:10.1016/S0278-2626(03)00013-7.

Paquette, D. (2004). Theorizing the father-child relationship: Mechanisms and developmental outcomes. Human Development, 47(4), 193-219. doi:10.1159/000078723. 
Parsons, H. M. (1982). More on the Hawthorne effect. The American Psychologist, 37, 856-857. doi:10.1037/0003-066X.37.7.856.b.

Parsons, H. M. (1992). Hawthorne: An early OBM experiment. Journal of Organizational Behavior Management, 12(1), 27. doi: 10.1300/J075v12n01_03.

Pawlow, L. A., \& Jones, G. E. (2005). The impact of abbreviated progressive muscle relaxation on salivary cortisol and salivary immunoglobulin a (sIgA). Applied Psychophysiology and Biofeedback, 30(4), 375-387. doi:10.1007/s10484-005-8423-2.

Pechmann, C. (2001). A comparison of health communication models: Risk learning versus stereotype priming. Media Psychology, 3(2), 189-210. doi:10.1207/S1532785XMEP0302_04.

Pechmann, C., \& Knight, S. J. (2002). An experimental investigation of the joint effects of advertising and peers on adolescents' beliefs and intentions about cigarette consumption. Journal of Consumer Research. Inc, 29, 5-19.

Pechmann, C., \& Ratneshwar, S. (1994). The effects of antismoking and cigarette advertising on young adolescents' perceptions of peers who smoke. The Journal of Consumer Research, 21(2), 236-251. doi:10.1086/209395.

Pechmann, C., Zhao, G., Goldberg, M. E., \& Reibling, E. T. (2003). What to convey in antismoking advertisements for adolescents: The use of protection motivation theory to identify effective message themes. Journal of Marketing, 67, 1-18. doi:10.1509/ jmkg.67.2.1.18607.

Peck, H. L., Kehle, T. J., Bray, M. A., \& Theodore, L. A. (2005). Yoga as an intervention for children with attention problems. School Psychology Review, 34(3), 415-424.

Pellegrini, A. D. (1992). Rough-and-tumble play and social problem solving flexibility. Creativity Research Journal, 5(1), 13-26.

Pellegrini, A. D., \& Smith, P. K. (1998). Physical activity play: Consensus and debate. Child Development, 69(3), 609-610. doi: $10.2307 / 1132192$.

Perna, G., Ieva, A., Caldirola, D., Bertani, A., \& Bellodi, L. (2002). Respiration in children at risk for panic disorder. Archives of General Psychiatry, 59(2), 185-186. doi:10.1001/archpsyc. 59.2.185.

Petry, N. M., \& Martin, B. (2002). Low-cost contingency management for treating cocaine- and opioid-abusing methadone patients. Journal of Consulting and Clinical Psychology, 70(2), 398-405. doi:10.1037/0022-006X.70.2.398.

Petry, N. M., Martin, B., Cooney, J. L., \& Kranzler, H. R. (2000). Give them prizes and they will come: Contingency management for treatment of alcohol dependence. Journal of Consulting and Clinical Psychology, 68(2), 250-257. doi:10.1037/0022-006X. 68.2 .250

Petry, N. M., Martin, B., \& Finocche, C. (2001a). Contingency management in group treatment: A demonstration project in an HIV drop-in center. Journal of Substance Abuse Treatment, 21(2), 89-96. doi:10.1016/S0740-5472(01)00184-2.

Petry, N. M., Petrakis, I., Trevisan, L., Wiredu, G., Boutros, N. N., Martin, B., et al. (2001b). Contingency management interventions: From research to practice. The American Journal of Psychiatry, 158(5), 694-702. doi:10.1176/appi.ajp.158.5.694.

Petry, N. M., Tedford, J., \& Martin, B. (2001c). Reinforcing compliance with non-drug-related activities. Journal of Substance Abuse Treatment, 20(1), 33-44. doi:10.1016/S07405472(00)00143-4.

Petry, N. M., Peirce, J. M., Stitzer, M. L., Blaine, J., Roll, J. M., Cohen, A., et al. (2005). Effect of prize-based incentives on outcomes in stimulant abusers in outpatient psychosocial treatment programs: A national drug abuse treatment clinical trials network study. Archives of General Psychiatry, 62(10), 11481156. doi:10.1001/archpsyc.62.10.1148.

Petry, N. M., \& Simcic, F., Jr. (2002). Recent advances in the dissemination of contingency management techniques: Clinical and research perspectives. Journal of Substance Abuse Treatment, 23(2), 81-86. doi:10.1016/S0740-5472(02)00251-9.

Petry, N. M., Tedford, J., Austin, M., Nich, C., Carroll, K. M., \& Rounsaville, B. J. (2004). Prize reinforcement contingency management for treating cocaine users: how low can we go, and with whom? Addiction (Abingdon, England), 99(3), 349-360. doi:10.1111/j.1360-0443.2003.00642.x.

Petscher, E. S., \& Bailey, J. S. (2006). Effects of training, prompting, and self-monitoring on staff behavior in a classroom for students with disabilities. Journal of Applied Behavior Analysis, 39(2), 215-226. doi:10.1901/jaba.2006.02-05.

Pfiffner, L. J., O'Leary, S. G., Rosen, L. A., \& Sanderson, W. C. (1985). A comparison of the effects of continuous and intermittent response cost and reprimands in the classroom. Journal of Clinical Child Psychology, 14(4), 348-352. doi:10.1207/ s15374424jccp1404_14.

Phillips, W. T., Kiernan, M., \& King, A. C. (2003). Physical activity as a nonpharmacological treatment for depression: A review. Complementary Health Practice Review, 8, 139-152. doi: 10.1177/1076167502250792.

Piazza, C. C., Bowman, L. G., Contrucci, S. A., Delia, M. D., Adelinis, J. D., \& Goh, H.-L. (1999). An evaluation of the properties of attention as reinforcement for destructive and appropriate behavior. Journal of Applied Behavior Analysis, 32(4), 437-449. doi:10.1901/jaba.1999.32-437.

Pine, D. S., Coplan, J. D., Papp, L. A., Klein, R. G., Martinez, J. M., Kovalenko, P., et al. (1998). Ventilatory physiology of children and adolescents with anxiety disorders. Archives of General Psychiatry, 55(2), 123-129. doi:10.1001/archpsyc.55.2.123.

Pitre, U., Dansereau, D. F., \& Joe, G. W. (1996). Client education levels and the effectiveness of node-link maps. Journal of Addictive Diseases, 15(3), 27. doi:10.1300/J069v15n03_02.

Pitre, U., Dansereau, D. F., Newbern, D., \& Simpson, D. D. (1998). Residential drug abuse treatment for probationers: Use of nodelink mapping to enhance participation and progress. Journal of Substance Abuse Treatment, 15(6), 535. doi:10.1016/S07405472(97)00313-9.

Pitre, U., Dansereau, D. F., \& Simpson, D. D. (1997). The role of node-link maps in enhancing counseling efficiency. Journal of Addictive Diseases, 16(3), 39.

Plummer, S., Baer, D. M., \& LeBlanc, J. M. (1977). Functional considerations in the use of procedural timeout and in effective alternative. Journal of Applied Behavior Analysis, 10(4), 689705. doi:10.1901/jaba.1977.10-689.

Porterfield, J. K., Herbert-Jackson, E., \& Risley, T. R. (1976). Contingent observation: an effective and acceptable procedure for reducing disruptive behavior of young children in a group setting. Journal of Applied Behavior Analysis, 9(1), 55-64. doi: 10.1901/jaba.1976.9-55.

Possell, L. E., Kehle, T. J., McLoughlin, C. S., \& Bray, M. A. (1999). Self-modeling as an intervention to reduce disruptive classroom behavior. Cognitive and Behavioral Practice, 6(2), 99-105. doi: 10.1016/S1077-7229(99)80017-0.

Premack, D. (1962). Reversibility of the reinforcement relation. Science, 136(3512), 255-257. doi:10.1126/science.136.3512.255.

Prinz, R. J., Sanders, M. R., Shapiro, C. J., Whitaker, D. J., \& Lutzker, J. R. (accepted). Population-based prevention of child maltreatment: The U.S. Triple P System Population Trial. Prevention Science.

Priya, J. J. (2004). Kangaroo care for low birth weight babies. Nursing Journal of India, 95(9), 209-212.

Putnam, R. F., Handler, M. W., Ramirez-Platt, C. M., \& Luiselli, J. K. (2003). Improving student bus-riding behavior through a wholeschool intervention. Journal of Applied Behavior Analysis, 36(4), 583. doi:10.1901/jaba.2003.36-583.

Ragnarsson, R. S., \& Bjorgvinsson, T. (1991). Effects of public posting on driving speed in Icelandic traffic. Journal of 
Applied Behavior Analysis, 24, 53-58. doi:10.1901/jaba.1991. 24-53.

Rajan, S., Sethuraman, M., \& Mukherjee, P. K. (2002). Ethnobiology of the Nilgiri Hills, India. Phytotherapy Research, 16(2), 98116. doi:10.1002/ptr.1098.

Ram, N., \& McCullagh, P. (2003). Self-modeling: Influence on psychological responses and physical performance. The Sport Psychologist, 17(2), 220-241.

Rawson, R. A., McCann, M. J., Flammino, F., Shoptaw, S., Miotto, K., Reiber, C., et al. (2006). A comparison of contingency management and cognitive-behavioral approaches for stimulantdependent individuals. Addiction (Abingdon, England), 101(2), 267-274. doi:10.1111/j.1360-0443.2006.01312.x.

Reagles, K. W., \& O'Neill, J. (1977). Single-subject design for client groups: Implications for program evaluation. Rehabilitation Counseling Bulletin, 21(1), 13-22.

Reamer, R. B., Brady, M. P., \& Hawkins, J. (1998). The effects of video self-modeling on parents' interactions with children with developmental disabilities. Education and Training in Mental Retardation and Developmental Disabilities, 33(2), 131-143.

Reed, T., \& Brown, M. (2001). The expression of care in the rough and tumble play of boys. Journal of Research in Childhood Education, 15(1), 104-116.

Resnicow, K., Jackson, A., Wang, T., De, A. K., McCarty, F., Dudley, W. N., et al. (2001). A motivational interviewing intervention to increase fruit and vegetable intake through black churches: Results of the Eat for Life trial. American Journal of Public Health, 91, 1686-1693.

Richards, J. M., Beal, W. E., Seagal, J. D., \& Pennebaker, J. W. (2000). Effects of disclosure of traumatic events on illness behavior among psychiatric prison inmates. Journal of Abnormal Psychology, 109, 156-160. doi:10.1037/0021-843X.109.1.156.

Richardson, A. J. (2006). Omega-3 fatty acids in ADHD and related neurodevelopmental disorders. International Review of Psychiatry (Abingdon, England), 18(2), 155-172. doi:10.1080/0954 0260600583031.

Rickards-Schlichting, K. A., Kehle, T. J., \& Bray, M. A. (2004). A self-modeling intervention for high school students with public speaking anxiety. Journal of Applied School Psychology, 20(2), 47-60.

Rickel, A. U., \& Fields, R. B. (1983). Storybook models and achievement behavior of preschool children. Psychology in the Schools, 20(1), 105. doi:10.1002/1520-6807(198301)20:1<105:: AID-PITS2310200121>3.0.CO;2-G

Ridgway, A., Northup, J., Pellegrin, A., LaRue, R., \& Hightsoe, A. (2003). Effects of recess on the classroom behavior of children with and without attention-deficit hyperactivity disorder. School Psychology Quarterly, 18(3), 253-268. doi:10.1521/scpq.18.3. 253.22578.

Ringwalt, C. L., Ennett, S., Johnson, R., Rohrbach, L. A., SimonsRudolph, A., Vincus, A., et al. (2003). Factors associated with fidelity to substance use prevention curriculum guides in the nation's middle schools. Health Education \& Behavior, 30, 375391. doi:10.1177/1090198103030003010.

Risley, T. (2005). Montrose M. Wolf (1935-2004). Journal of Applied Behavior Analysis, 38(2), 279-287. doi:10.1901/jaba. 2005.165-04

Roberts, M. C., \& Fanurik, D. (1986). Rewarding elementary schoolchildren for their use of safety belts. Health Psychology, 5(3), 185. doi:10.1037/0278-6133.5.3.185.

Robertson, L. S. (1975). Safety belt use in automobiles with starterinterlock and buzzer-light reminder systems. American Journal of Public Health, 65(12), 1319-1325.

Robertson, L. S., \& Haddon, W., Jr. (1974). The buzzer-light reminder system and safety belt use. American Journal of Public Health, 64(8), 814-815.
Robin, A., Schneider, M., \& Dolnick, M. (1976). The turtle technique: An extended case study of self-control in the classroom. Psychology in the Schools, 13(4), 449-453. doi:10.1002/15206807(197610)13:4<449::AID-PITS2310130420>3.0.CO;2-W.

Robinson, T. N., Borzekowski, D. L. G., Matheson, D. M., \& Kraemer, H. C. (2007). Effects of fast food branding on young children's taste preferences. Archives of Pediatrics and Adolescent Medicine, 161(8), 792-797. doi:10.1001/archpedi.161.8.792.

Robinson, C. M., \& Robinson, L. W. (1979). Involving parents in the treatment of behaviorally disordered children. Clinical Social Work Journal, 7(3), 182-193. doi:10.1007/BF00760495.

Robinson, K. E., \& Sheridan, S. M. (2000). Using the Mystery Motivator to improve child bedtime compliance. Child and Family Behavior Therapy, 22(1), 29-49.

Roca, J. V., \& Gross, A. M. (1996). Report-do-report: Promoting setting and setting-time generalization. Education and Treatment of Children, 19(4), 408-424.

Rock, M. L. (2005). Use of strategic self-monitoring to enhance academic engagement, productivity, and accuracy of students with and without exceptionalities. Journal of Positive Behavior Interventions, 7(1), 3-17. doi:10.1177/10983007050070010201.

Rodrigues, E. (2006). Plants and animals utilized as medicines in the Jau National Park (JNP), Brazilian Amazon. Phytotherapy Research, 20(5), 378-391. doi:10.1002/ptr.1866.

Rogers, E. M. (1995). Diffusion of innovations (4th ed.). New York: The Free Press.

Rolider, A., \& Van Houten, R. (1984). The effects of DRO alone and DRO plus reprimands on the undesirable behavior of three children in home settings. Education and Treatment of Children, 7(1), 17-31.

Roos, S. (2005). Blind trust: Large groups and their leaders in times of crisis and terror. Gestalt Review, 9(1), 129-135.

Rosenkoetter, S. E., \& Fowler, S. A. (1986). Teaching mainstreamed children to manage daily transitions. Teaching Exceptional Children, 19(1), 20-23.

Rudin, D. O. (1981). The major psychoses and neuroses as omega-3 essential fatty acid deficiency syndrome: Substrate pellagra. Biological Psychiatry, 16(9), 837-850.

Rusch, N., \& Corrigan, P. W. (2002). Motivational interviewing to improve insight and treatment adherence in schizophrenia. Psychiatric Rehabilitation Journal, 26(1), 23-32. doi: 10.2975/26.2002.23.32.

Rutter, M. (1981). School influences on children's behavior and development: The 1979 Kenneth Blackfan Lecture, Children's Hospital Medical Center, Boston. Annual Progress in Child Psychiatry and Child Development, 170, 197.

Saari, L. M., \& Latham, G. P. (1982). Employee reaction to continuous and variable ratio reinforcement schedules involving a monetary incentive. The Journal of Applied Psychology, 67, 506. doi:10.1037/0021-9010.67.4.506.

Sampson, R. J., \& Laub, J. H. (1994). Urban poverty and the family context of delinquency: A new look at structure and process in a classic study. Child Development, 65, 523-540. doi: 10.2307/1131400.

Sanchez, V., Steckler, A., Nitirat, P., Hallfors, D., Cho, H., \& Brodish, P. (2007). Fidelity of implementation in a treatment effectiveness trial of reconnecting youth. Health Education Research, 22(1), 95-107. doi:10.1093/her/cyl052.

Sanders, M. R., Bor, W., \& Dadds, M. R. (1984). Modifying bedtime disruptions in children using stimulus control and contingency management techniques. Behavioural Psychotherapy, 12, 130141.

Sanders, M. R., Cann, W., \& Markie-Dadds, C. (2003). Why a universal population-level approach to the prevention of child abuse is essential. Child Abuse Review, 12, 145-154. doi: 10.1002/car.797. 
Sanders, M. R., Markie-Dadds, C. (1996). Triple P: A multilevel family intervention program for children with disruptive behaviour disorders. Early intervention and prevention in mental health (7th ed., pp. 59-85). Carlton, South VIC: Australian Psychological Society.

Sanders, M. R., Montgomery, D. T., \& Brechman-Toussaint, M. L. (2000). The mass media and the prevention of child behavior problems: The evaluation of a television series to promote positive outcomes for parents and their children. Journal of Child Psychology and Psychiatry, and Allied Disciplines, 41, 939-948. doi:10.1017/S0021963099006198.

Sandyk, R. (1990). Zinc deficiency in attention-deficit hyperactivity disorder. The International Journal of Neuroscience, 52(3-4), 239-241.

Saunders, C. M. (2005). Effectiveness of the toll-free line for public insurance programs. Evaluation and the Health Professions, 28(1), 27-39. doi:10.1177/0163278704273082.

Scafidi, F., \& Field, T. (1996). Massage therapy improves behavior in neonates born to HIV-positive mothers. Journal of Pediatric Psychology, 21(6), 889. doi:10.1093/jpepsy/21.6.889.

Scheckner, S., Rollin, S. A., Kaiser-Ulrey, C., Wagner, R., \& Gerler, E. R., Jr. (2004). School violence in children and adolescents: A meta-analysis of the effectiveness of current interventions. Handbook of school violence (pp. 81-113). New York: Haworth Press.

Schilling, D. L., Washington, K., Billingsley, F. F., \& Deitz, J. (2003). Classroom seating for children with attention deficit hyperactivity disorder: Therapy balls versus chairs. The American Journal of Occupational Therapy., 57, 534-541.

Schilmoeller, G. L., Schilmoeller, K. J., Etzel, B. C., \& LeBlanc, J. M. (1979). Conditional discrimination after errorless and trialand-error training. Journal of the Experimental Analysis of Behavior, 31(3), 405-420. doi:10.1901/jeab.1979.31-405.

Schloss, P. J., Schloss, C. N., \& Harris, L. (1984). A multiple baseline analysis of an interpersonal skills training program for depressed youth. Behavioral Disorders, 9(3), 182-188.

Scholer, S. J., Nix, R. L., \& Patterson, B. (2006). Gaps in pediatricians' advice to parents regarding early childhood aggression. Clinical Pediatrics, 45(1), 23-28. doi:10.1177/ 000992280604500104.

Schunk, D. H., \& Hanson, A. R. (1989). Self-modeling and children's cognitive skill learning. Journal of Educational Psychology, 81(2), 155-163. doi:10.1037/0022-0663.81.2.155.

Schwartz, C., Houlihan, D., Krueger, K. F., \& Simon, D. A. (1997). The behavioral treatment of a young adult with post-traumatic stress disorder and a fear of children. Child and Family Behavior Therapy, 19(1), 37-49. doi:10.1300/J019v19n01_03.

Scott, E., \& Panksepp, J. (2003). Rough-and-tumble play in human children. Aggressive Behavior, 29(6), 539-551. doi:10.1002/ ab. 10062 .

Scott, S., Spender, Q., Doolan, M., Jacobs, B., \& Aspland, H. (2001). Multicentre controlled trial of parenting groups for childhood antisocial behaviour in clinical practice. British Medical Journal, 323, 194. doi:10.1136/bmj.323.7306.194.

Selznick, L., \& Savage, R. C. (2000). Using self-monitoring procedures to increase on-task behavior with three adolescent boys with brain injury. Behavioral Interventions, 15, 243-260. doi:10.1002/1099-078X(200007/09)15:3<243::AID-BIN59>3.0. $\mathrm{CO} ; 2-1$.

Shabani, D. B., \& Carr, J. E. (2004). An evaluation of response cards as an adjunct to standard instruction in university classrooms: A systematic replication and extension. North American Journal of Psychology, 6, 85-100.

Shabani, D. B., Wilder, D. A., \& Flood, W. A. (2001). Reducing stereotypic behavior through discrimination training, differential reinforcement of other behavior, and self monitoring. Behavioral Interventions, 16(4), 279-286. doi:10.1002/bin.96.

Shannon, J. D., Tamis-LeMonda, C. S., London, K., \& Cabrera, N. (2002). Beyond rough and tumble: Low-income fathers' interactions and children's cognitive development at 24 months. Parenting, Science and Practice, 2(2), 77-104. doi:10.1207/ S15327922PAR0202_01.

Sharma, N. R., Yadava, A., \& Hooda, D. (2005). Effect of yoga on psychophysical functions. Journal of Indian Psychology, 23(1), 37-42.

Sherif, M. (1958). Superordinate goals in the reduction of intergroup conflict. American Journal of Sociology, 63, 349. doi:10.1086/ 222258.

Sherif, M. (1968). If the social scientist is to be more than a mere technician. The Journal of Social Issues, 24(1), 41.

Sherif, M. (1970). On the relevance of social psychology. The American Psychologist, 25(2), 144. doi:10.1037/h0029429.

Sherif, M., Hogg, M. A., \& Abrams, D.(2001). Superordinate goals in the reduction of intergroup conflict. Intergroup relations: Essential readings (p. 64). New York: Psychology Press.

Sherif, M., White, B. J., \& Harvey, O. J. (1955). Status in experimentally produced groups. American Journal of Sociology, 60, 370. doi:10.1086/221569.

Shimabukuro, S. M., Prater, M. A., Jenkins, A., \& Edelen-Smith, P. (1999). The effects of self-monitoring of academic performance on students with learning disabilities and ADD/ADHD. Education and Treatment of Children, 22(4), 397-414.

Sideridis, G. D., Utley, C., Greenwood, C. R., Delquadri, J., Dawson, H., Palmer, P., et al. (1997). Classwide peer tutoring: Effects on the spelling performance and social interactions of students with mild disabilities and their typical peers in an integrated instructional setting. Journal of Behavioral Education, 7, 435462. doi:10.1023/A:1022855218347.

Sidman, M. (1960). Tactics of scientific research. Oxford, UK: Basic Books.

Silva, F. J. (1999). Beyond the "hot-and-cold" game": A demonstration of computer-controlled shaping. Behavior Research Methods, Instruments and Computers, 31(1), 63-73.

Singh, N. N. (1987). Overcorrection of oral reading errors. A comparison of individual- and group-training formats. Behavior Modification, 11(2), 165-181. doi:10.1177/01454455870112003.

Singh, N. N., \& Singh, J. (1988). Increasing oral reading proficiency through overcorrection and phonic analysis. American Journal of Mental Retardation, 93(3), 312-319.

Sisson, L. A., Van Hasselt, V. B., \& Hersen, M. (1993). Behavioral interventions to reduce maladaptive responding in youth with dual sensory impairment. An analysis of direct and concurrent effects. Behavior Modification, 17(2), 164-188. doi: 10.1177/01454455930172005.

Siviy, S. M., Fleischhauer, A. E., Kerrigan, L. A., \& Kuhlman, S. J. (1996). D-sub-2 dopamine receptor involvement in the roughand-tumble play behavior of juvenile rats. Behavioral Neuroscience, 110(5), 1168-1176. doi:10.1037/0735-7044.110.5.1168.

Skinner, C. H., Cashwell, T. H., \& Skinner, A. L. (2000). Increasing tootling: The effects of a peer-monitored group contingency program on students' reports of peers' prosocial behaviors. Psychology in the Schools, 37(3), 263-270. doi:10.1002/ (SICI) 1520-6807(200005)37:3<263::AID-PITS6>3.0.CO;2-C.

Smith, D. K. (2004). Risk, reinforcement, retention in treatment, and reoffending for boys and girls in multidimensional treatment Foster care. Journal of Emotional and Behavioral Disorders, 12(1), 38-48. doi:10.1177/10634266040120010501.

Smyth, J. M., Stone, A. A., Hurewitz, A., \& Kaell, A. (1999). Effects of writing about stressful experiences on symptom reduction in patients with asthma or rheumatoid arthritis: A randomized trial. 
JAMA: Journal of the American Medical Association, 281, 1304-1309. doi:10.1001/jama.281.14.1304.

Snell, R., \& Cole, M. (1976). The use of a VI schedule of token reinforcement to effect all-day control of thumbsucking in the classroom. SALT: School Applications of Learning Theory, 9(2), 14-21.

Sobell, L. C., Agrawal, S., Sobell, M. B., Leo, G. I., Young, L. J., Cunningham, J. A., et al. (2003). Comparison of a quick drinking screen with the timeline followback for individuals with alcohol problems. Journal of Studies on Alcohol, 64(6), 858-861.

Sorock, G. S. (1988). Falls among the elderly: Epidemiology and prevention. American Journal of Preventive Medicine, 4(5), 282-288.

Spencer, V. G., Scruggs, T. E., \& Mastropieri, M. A. (2003). Content area learning in middle school social studies classrooms and students with emotional or behavioral disorders: A comparison of strategies. Behavioral Disorders, 28(2), 77-93.

Spera, S. P., Buhrfeind, E. D., \& Pennebaker, J. W. (1994). Expressive writing and coping with job loss. Academy of Management Journal, 37, 722-733. doi:10.2307/256708.

Spindler, K. (1995). The man in the ice: The discovery of a 5,000year-old body reveals the secrets of the Stone Age. New York, NY: Three Rivers Press.

Spirito, A., Monti, P. M., Barnett, N. P., Colby, S. M., Sindelar, H., Rohsenow, D. J., et al. (2004). A randomized clinical trial of a brief motivational intervention for alcohol-positive adolescents treated in an emergency department. The Journal of Pediatrics, 145(3), 396-402 (see comment). doi:10.1016/j.jpeds.2004.04. 057.

St. Pierre, T. L., Osgood, D., Mincemoyer, C. C., Kaltreider, D. L., \& Kauh, T. J. (2005). Results of an independent evaluation of project ALERT delivered in schools by cooperative extension. Prevention Science, 6, 305-317. doi:10.1007/s11121-0050015-0.

Stage, S. A., \& Quiroz, D. R. (1997). A meta-analysis of interventions to decrease disruptive classroom behavior in public education settings. School Psychology Review, 26(3), 333-368.

Standley, J. M. (1996). A meta-analysis on the effects of music as reinforcement for education/therapy objectives. Journal of Research in Music Education, 44(2), 105-133. doi:10.2307/ 3345665

Standley, J. M. (1999). Music therapy in the NICU: Pacifieractivated-lullabies (PAL) for reinforcement of nonnutritive sucking. International Journal of Arts Medicine, 6, 17-21.

Stawar, T. L. (1978). The modification of coprophagic behavior in a 16-month-old boy using errorless discrimination learning. Journal of Behavior Therapy and Experimental Psychiatry, 9(4), 373-376. doi:10.1016/0005-7916(78)90017-4.

Stecker, P. M., Whinnery, K. W., \& Fuchs, L. S. (1996). Selfrecording during unsupervised academic activity: Effects on time spent out of class. Exceptionality, 6(3), 133-147. doi: $10.1207 / \mathrm{s} 15327035$ ex0603_1.

Stein, M. B. (2005). Sweating away the blues: Can exercise treat depression? American Journal of Preventive Medicine, 28(1), 140-141. doi:10.1016/j.amepre.2004.09.024.

Stein, L. A. R., Colby, S. M., Barnett, N. P., Monti, P. M., Golembeske, C., Lebeau-Craven, R., et al. (2006). Enhancing substance abuse treatment engagement in incarcerated adolescents. Psychological Services, 3(1), 25-34. doi:10.1037/15411559.3.1.0.

Steiner, K. (1986). The mystery shopper: An anonymous review of your services. Health Care Strategic Management, 4(6), 9-11.

Stella, S. G., Vilar, A. P., Lacroix, C., Fisberg, M., Santos, R. F., Mello, M. T., et al. (2005). Effects of type of physical exercise and leisure activities on the depression scores of obese Brazilian adolescent girls. Brazilian Journal of Medical and Biological
Research, 38(11), 1683-1689. doi:10.1590/S0100-879X200500 1100017.

Stoll, A. L., Damico, K. E., Marangell, L. B., \& Severus, W. E. (2000a). Omega 3 fatty acids in bipolar disorder: A preliminary double-blind, placebo-controlled trial. Archives of General Psychiatry, 57(7), 716-717 (Reply). doi:10.1001/archpsyc.57. 7.716.

Stoll, A. L., Marangell, L., \& Severus, W. E. (2000b). Omega 3 fatty acids in bipolar disorder: A preliminary double-blind, placebocontrolled trial. Archives of General Psychiatry, 57(7), 715 (Reply). doi:10.1001/archpsyc.57.7.715.

Stoll, A. L., Severus, E., Freeman, M. P., Rueter, S., Zboyan, H. A., Diamond, E., et al. (1999). Omega 3 fatty acids in bipolar disorder: A preliminary double-blind, placebo-controlled trial. Archives of General Psychiatry, 56(5), 407-412. doi:10.1001/ archpsyc.56.5.407.

Storr, C. L., Ialongo, N. S., Kellam, S. G., \& Anthony, J. C. (2002). A randomized controlled trial of two primary intervention strategies to prevent early onset tobacco smoking. Drug and Alcohol Dependence, 66(1), 51. doi:10.1016/S0376-8716(01)00184-3.

Sumner, J. H., Mueser, S. T., Hsu, L., \& Morales, R. G. (1974). Overcorrection treatment for radical reduction of aggressivedisruptive behavior in institutionalized mental patients. Psychological Reports, 35(1 Pt 2), 655-662.

Sund, K.-P., Huang, S.-Y., Chiu, C.-C., \& Shen, W. W. (2003). Omega-3 fatty acids in major depressive disorder. A preliminary double-blind, placebo-controlled trial. European Neuropsychopharmacology, 13(4), 267-271. doi:10.1016/S0924-977X(03) 00032-4.

Suzuki, T., Egami, S., \& Haruki, Y. (2000). Improvement in the state of the type A behavior pattern by breathing exercises. Japanese Journal of Health Psychology, 13(1), 1-12.

Sykes, S., \& O'Sullivan, K. (2006). A 'mystery shopper' project to evaluate sexual health and contraceptive services for young people in Croydon. The Journal of Family Planning and Reproductive Health Care, 32(1), 25-26. doi:10.1783/14711890 6775275334.

Szapocznik, J., \& Williams, R. A. (2000). Brief strategic family therapy: Twenty-five years of interplay among theory, research, and practice in adolescent behavior problems and drug abuse. Clinical Child and Family Psychology Review, 3, 117-134. doi: 10.1023/A:1009512719808.

Tanskanen, A., Hibbeln, J. R., Tuomilehto, J., Uutela, A., Haukkala, A., Viinamaki, H., et al. (2001). Fish consumption and depressive symptoms in the general population in Finland. Psychiatric Services (Washington, D.C.), 52(4), 529-531. doi:10.1176/appi. ps.52.4.529.

Taubman, M., Brierley, S., Wishner, J., Baker, D., McEachin, J., \& Leaf, R. B. (2001). The effectiveness of a group discrete trial instructional approach for preschoolers with developmental disabilities. Research in Developmental Disabilities, 22(3), 205-219. doi:10.1016/S0891-4222(01)00068-3.

Taylor, G. T., Frechmann, T., \& Royalty, J. (1986). Social behaviour and testicular activity of juvenile rats. The Journal of Endocrinology, 110(3), 533-537.

Taylor, T. K., Eddy, J. M., \& Biglan, A. (1999). Interpersonal skills training to reduce aggressive and delinquent behavior: Limited evidence and the need for an evidence-based system of care. Clinical Child and Family Psychology Review, 2, 169-182. doi: 10.1023/A:1021855022385.

Taylor, V. L., Cornwell, D. D., \& Riley, M. T. (1984). Home-based contingency management programs that teachers can use. Psychology in the Schools, 21(3), 368. doi:10.1002/15206807(198407)21:3<368::AID-PITS2310210316>3.0.CO;2-U.

Telles, S., Narendran, S., Raghuraj, P., Nagarathna, R., \& Nagendra, H. R. (1997). Comparison of changes in autonomic and 
respiratory parameters of girls after yoga and games at a community home. Perceptual and Motor Skills, 84(1), 251-257.

Terrace, H. S. (1969). Extinction of a discriminative operant following discrimination learning with and without errors. Journal of the Experimental Analysis of Behavior, 12, 571582. doi:10.1901/jeab.1969.12-571.

Theodore, A., Runyan, D., \& Chang, J. J. (2007). Measuring the risk of physical neglect in a population-based sample. Child Maltreatment, 12(1), 96-105. doi:10.1177/1077559506296904.

Thomas, E. J., Abrams, K. S., \& Johnson, J. B. (1971). Selfmonitoring and reciprocal inhibition in the modification of multiple tics of Gilles de la Torette's syndrome. Journal of Behavior Therapy and Experimental Psychiatry, 2(3), 159-171. doi:10.1016/0005-7916(71)90054-1.

Thorpe, H. W., Darch, C. B., \& Drecktrah, M. (1978). The principal lottery: A system utilizing contingent principal telephone calls to increase on-task behavior. Corrective and Social Psychiatry and Journal of Behavior Technology Methods and Therapy, 24(1), 20.

Thorpe, H. W., Drecktrah, M., \& Darch, C. B. (1979). The principal lottery revisited in a middle school classroom. Corrective and Social Psychiatry and Journal of Behavior Technology Methods and Therapy, 25(3), 86.

Tobler, N. S., Roona, M. R., Ochshorn, P., Marshall, D. G., Streke, A. V., \& Stackpole, K. M. (2000). School-based adolescent drug prevention programs: 1998 meta-analysis. The Journal of Primary Prevention, 20, 275-336. doi:10.1023/A:1021314704811.

Todd, A. W., Horner, R. H., \& Sugai, G. (1999). Self-monitoring and self-recruited praise: Effects on problem behavior, academic engagement, and work completion in a typical classroom. Journal of Positive Behavior Interventions, 1(2), 66-76. doi: 10.1177/109830079900100201.

Trammel, D. L., Schloss, P. J., \& Alper, S. (1994). Using selfrecording, evaluation, and graphing to increase completion of homework assignments. Journal of Learning Disabilities, 27, $75-81$.

Twemlow, S. W., \& Sacco, F. C. (1998). The application of traditional martial arts practice and theory to the treatment of violent adolescents. Adolescence, 33(131), 505-518.

Vaddadi, K. (2006). Essential fatty acids and mental illness. International Review of Psychiatry (Abingdon, England), 18(2), 81-84. doi:10.1080/09540260600581837.

Van Hevel, J., \& Hawkins, R. P. (1974). Modification of behavior in secondary school students using the Premack principle and response cost technique. SALT: School Applications of Learning Theory, 6(4), 31-41.

Van Houten, R., \& Malenfant, L. (1992). The influence of signs prompting motorists to yield before marked crosswalks on motor vehicle-pedestrian conflicts at crosswalks with flashing amber. Accident Analysis and Prevention, 24(3), 217-225. doi: 10.1016/0001-4575(92)90001-Y.

Van Houten, R., \& Nau, P. A. (1981). A comparison of the effects of posted feedback and increased police surveillance on highway speeding. Journal of Applied Behavior Analysis, 14, 261-271. doi:10.1901/jaba.1981.14-261.

Van Houten, R., Nau, P. A., MacKenzie-Keating, S. E., Sameoto, D., \& Colavecchia, B. (1982). An analysis of some variables influencing the effectiveness of reprimands. Journal of Applied Behavior Analysis, 15(1), 65-83. doi:10.1901/jaba.1982.15-65.

Van Houten, R., \& Retting, R. A. (2001). Increasing motorist compliance and caution at stop signs. Journal of Applied Behavior Analysis, 34(2), 185-193. doi:10.1901/jaba.2001. 34-185.

Vazsonyi, A. T., Belliston, L. M., \& Flannery, D. J. (2004). Evaluation of a school-based, universal violence prevention program: Low-, medium-, and high-risk children. Youth Violence and Juvenile Justice, 2, 185-206. doi:10.1177/15412040032 62224.

Wagenaar, A. C., Maybee, R. G., \& Sullivan, K. P. (1988). Mandatory seat belt laws in eight states: A time-series evaluation. Journal of Safety Research, 19(2), 51-70. doi:10.1016/0022-4375(88) 90044-8.

Walker, C. J., \& Clement, P. W. (1992). Treating inattentive, impulsive, hyperactive children with self-modeling and stress inoculation training. Child \& Family Behavior Therapy, 14(2), 75-85. doi:10.1300/J019v14n02_05.

Walsh, B. F., \& Lamberts, F. (1979). Errorless discrimination and picture fading as techniques for teaching sight words to TMR students. American Journal of Mental Deficiency, 83(5), 473479.

Wang, T. H., \& Katzev, R. D. (1990). Group commitment and resource conservation: two field experiments on promoting recycling. Journal of Applied Social Psychology, 20, 265-275. doi:10.1111/j.1559-1816.1990.tb00411.x.

Wasserman, T. H. (1977). The utilization of a clock-light cueing device to signal group progress towards reinforcement in a classroom setting. Psychology in the Schools, 14(4), 471-479. doi:10.1002/1520-6807(197710)14:4<471::AID-PITS23101404 $19>3.0 . \mathrm{CO} ; 2-\mathrm{K}$.

Watson, T. S. (1993). Effectiveness of arousal and arousal plus overcorrection to reduce nocturnal bruxism. Journal of Behavior Therapy and Experimental Psychiatry, 24, 181-185. doi: 10.1016/0005-7916(93)90047-Z.

Webster-Stratton, C., \& Reid, M. J. (2007). Incredible years parents and teachers training series: A head start partnership to promote social competence and prevent conduct problems. In P. H. Tolan, J. Szapocznik, \& S. Sambrano (Eds.), Preventing youth substance abuse: Science-based programs for children and adolescents (pp. 67-88). Washington, DC: American Psychological Association.

Wedel, J. W., \& Fowler, S. A. (1984). "Read me a story, Mom": A home-tutoring program to teach prereading skills to languagedelayed children. Behavior Modification, 8(2), 245. doi: 10.1177/01454455840082006.

Welsh, D. H., Bernstein, D. J., \& Luthans, F. (1992). Application of the Premack principle of reinforcement to the quality performance of service employees. Journal of Organizational Behavior Management, 13(1), 9-32. doi:10.1300/J075v13 n01_03.

Wencai, Z., Xinhu, L., Kele, Y., \& Yiyuan, T. (2005). The effect of relaxation training on heart rate, $\mathrm{T}$-wave amplitude and mental arithmetic achievement. Psychological Science (China), 28(3), 706-707.

West, R. P., Young, K. R., \& Callahan, K. (1995). The musical clocklight: Encouraging positive classroom behavior. Teaching Exceptional Children, 27(2), 46-52.

White, A. G., \& Bailey, J. S. (1990). Reducing disruptive behaviors of elementary physical education students with sit and watch. Journal of Applied Behavior Analysis, 23, 353-359. doi: 10.1901/jaba.1990.23-353.

Williamson, P. N. (1984). An intervention for hypochondriacal complaints. Clinical Gerontologist, 3(1), 64-68.

Wilson, C. V. (1976). The use of rock music as a reward in behavior therapy with children. Journal of Music Therapy, 13(1), 39-48.

Wilson, D. S., \& Wilson, E. O. (2007). Rethinking the theoretical foundation of sociobiology. The Quarterly Review of Biology, $82,327-348$.

Winn, B. D., Skinner, C. H., Allin, J. D., \& Hawkins, J. A. (2004). Practicing school consultants can empirically validate interventions: A description and demonstration of the non-concurrent multiple-baseline design. Journal of Applied School Psychology, 20, 109-128. 
Wolery, M., Ault, M. J., Doyle, P. M., Gast, D. L., et al. (1992). Choral and individual responding during small group instruction: Identification of interactional effects. Education and Treatment of Children, 15(4), 289-309.

Wolf, M. M., Risley, T., \& Mees, H. (1964). Application of operant conditioning procedures to the behavior problems of an autistic child. Behaviour Research and Therapy, 1, 305-312. doi: 10.1016/0005-7967(63)90045-7.

Wolf, M., Risley, T. R., Johnston, M., Harris, F. R., \& Allen, K. E. (1967). Application of operant conditioning procedures to the behavior problems of an autistic child: A follow-up and extension. Behaviour Research and Therapy, 5(2), 103-112. doi: 10.1016/0005-7967(67)90004-6.

Wolfe, D. E. (1982). The effect of interrupted and continuous music on bodily movement and task performance of third grade students. Journal of Music Therapy, 19(2), 74-85.

Wolfe, D. A., Kelly, J. A., \& Drabman, R. S. (1981). "Beat the buzzer": A method for training an abusive mother to decrease recurrent child conflicts. Journal of Clinical Child Psychology, 10(2), 114-116.

Woltersdorf, M. A. (1992). Videotape self-modeling in the treatment of attention-deficit hyperactivity disorder. Child and Family Behavior Therapy, 14(2), 53-73. doi:10.1300/J019v14n02_04.

Wood, S. J., Murdock, J. Y., \& Cronin, M. E. (2002). Self-monitoring and at-risk middle school students: Academic performance improves, maintains, and generalizes. Behavior Modification, 26(5), 605-626. doi:10.1177/014544502236653.

Wood, S. J., Murdock, J. Y., Cronin, M. E., Dawson, N. M., \& Kirby, P. C. (1998). Effects of self-monitoring on on-task behaviors of at-risk middle school students. Journal of Behavioral Education, 8, 263-279. doi:10.1023/A:1022891725732.

Wurtele, S. K., \& Drabman, R. S. (1984). "Beat the buzzer" for classroom dawdling: A one-year trial. Behavior Therapy, 15(4), 403-409. doi:10.1016/S0005-7894(84)80009-X.

Zaichkowsky, L. B., Zaichkowsky, L. D., \& Yeager, J. (1986). Biofeedback-assisted relaxation training in the elementary classroom. Elementary School Guidance and Counseling, 20(4), 261-267.

Zanarini, M. C., \& Frankenburg, F. R. (2003). Omega-3 fatty acid treatment of women with borderline personality disorder: A double-blind, placebo-controlled pilot study. The American Journal of Psychiatry, 160(1), 167-169. doi:10.1176/appi.ajp. 160.1.167.

Zivin, G., Hassan, N. R., DePaula, G. F., Monti, D. A., Harlan, C., Hossain, K. D., et al. (2001). An effective approach to violence prevention: Traditional martial arts in middle school. Adolescence, 36(143), 443-459. 